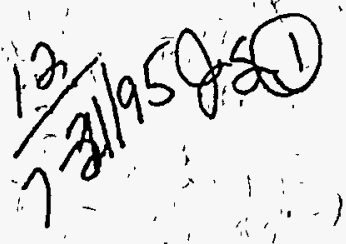

\title{
Hanford Radiological Protection Support Services Annual Report for 1994
}
M. Lyon
R. K. Piper
D. E. Bihl
T. J. Froelich
J.J. Fix
P. C. Olsến

June 1995

Prepared for the U.S. Department of Energy under Contract DE-AC06-76RLO-1830

Pacific Nórthwest Laboratory Operated for the U.S. Department of Energy

by Battelle Memorial Institute

\section{Battelle}




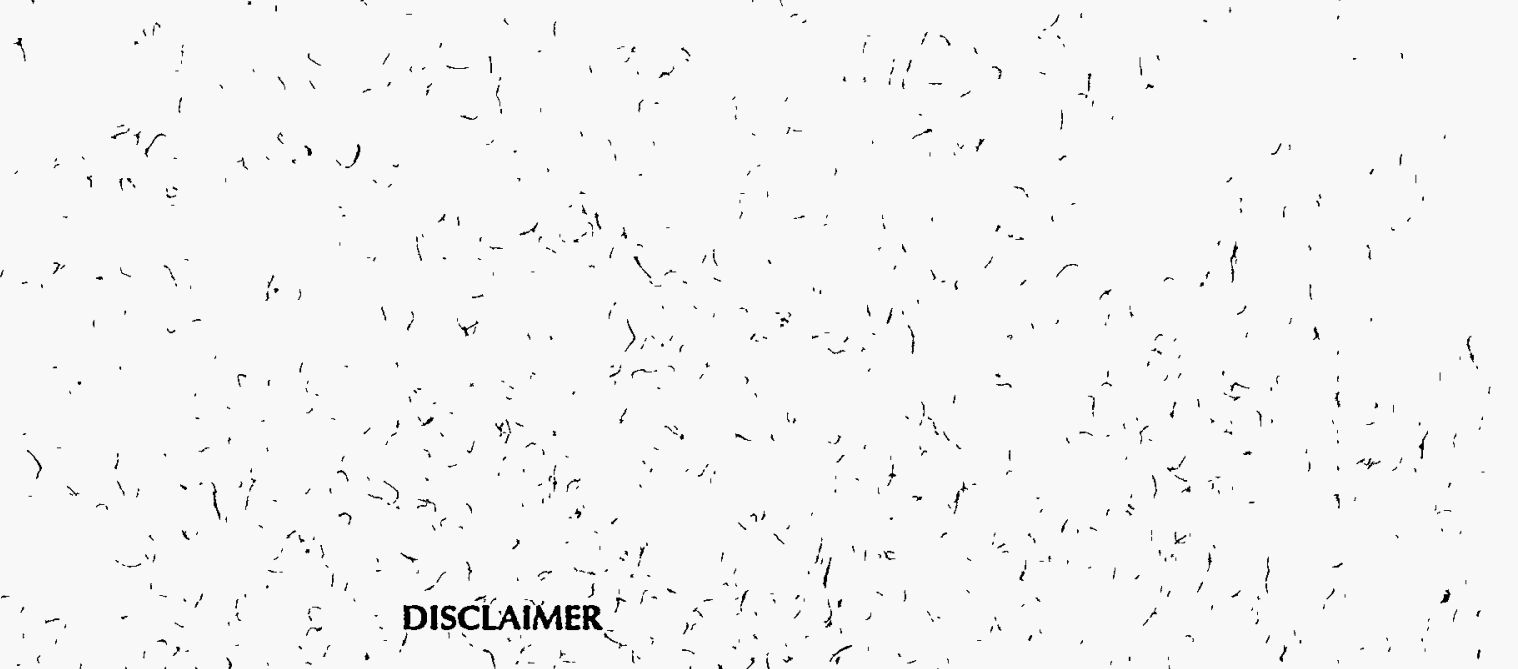

This report was prepared as an account of work sponsored by an agency of the - United States Government. Neither the United Státès Government nor any agency'. thereof, nor Battelle Memorial Institute, ñor any of their employees, makes any warranty, expressed òr ímplied, or assumes any legal liability or responsibility for. ctheaccuracy, completeness, or usefulness of any information, apparatus, product, or procešs disclosed, ố represents that its use would not infringe privately owned rightits. Referènce herein to àny śpecific commenercial product, process, or sérvice by trade name, trademark, mầnufacturere, or otherwise dóes not necessarily constitute or imply its endorsement, recommendation; or favoring by the United States Government or any agency thereof, or Battelle.Memorial Institute. The views and opinions of authors expressed herein do not necessarily state or reflect those of the United States Government of any agency,thereof.

Uni

PACIFIC NORTHWEST LABORATORY

$f:$, operated by

BATTELLE MEMÓRIAL INSTITUTE

UNITED STATES DEPARTMENT OFENERGY

$\therefore$ Yunder Contract DE-ACO6-J6RLO 1830

1.)

$\therefore \rightarrow, i$

Printed in the United States of America

Office of Scientificic and Technical Information, P.O. Box 62, Oak Ridge, TN'37831;

prices available from (615) 576-8401. FTS 626-8401.'.

? Available to the public from the National Technical Information Service,

I U.S. Dêpartment of Commerce, 5285 Porț Royal Rd., Springfield, VA 22161. 


\section{DISCLAIMER}

Portions of this document may be illegible in electronic image products. Images are produced from the best available original document. 
PNL-10614

UC-607

\section{HANFORD RADIOLOGICAL PROTECTION SUPPORT SERVICES ANNUAL REPORT FOR 1994}
M. Lyon
R. K. Piper
D. E. Bihl
T. J. Froelich
J. J. Fix
P. C. Olsen

June 1995

Prepared for

the U.S. Department of Energy

under Contract DE-AC06-76RLO 1830

Pacific Northwest Laboratory

Richland, Washington 99352 


\section{.}

-

- 


\begin{abstract}
Various Hanford Site radiation protection services provided by the Pacific Northwest Laboratory for the U.S. Department of Energy Richland Operations Office and Hanford contractors are described in this annual report for the calendar year 1994. These activities include external dosimetry measurements and evaluations, internal dosimetry measurements and evaluations, in vivo measurements, radiological record keeping, radiation source calibration, and instrument calibration and evaluation. For each of these activities, the routine program and any program changes or enhancements are described, as well as associated tasks, investigations, and studies. Program-related publications, presentations, and other staff professional activities are also described.
\end{abstract}




\section{SUMMARY}

This report describes certain radiological protection support services performed by the Pacific Northwest Laboratory (PNL) during calendar year 1994, in support of the U. S. Department of Energy (DOE) Richland Operations Office (RL) and the Hanford contractors. Projects providing these Sitewide services included 1) external dosimetry, 2) internal dosimetry. 3) in vivo measurements, 4) radiological records, 5) calibration of radiation sources traceable to the National Institute of Standards and Technology (NIST), and 6) instrument calibration and evaluation. Described in this report are the project routine tasks, any significant changes to the routine tasks, and any supporting studies performed during calendar year 1994. Also described are tasks performed by the projects that are funded by DOE Headquarters. Related professional activities, such as publications, presentations, and memberships on standards or industry committees, are also described.

The Hanford External Dosimetry Project provides external radioactive monitoring capabilities for all Hanford workers and visitors. The project reported 84,798 dose-of-record results, which is approximately $10 \%$ less than reported in 1993. Good performance was demonstrated in all external project reviews and blind audits. Changes made in the project routine program included 1) modification of the skin dose assessment levels, 2) clarification of dosimeter wearing practices while wearing protective clothing, and 3) clarification of multiple dosimetry practices. Preparations for the implementation of the new dosimetry system to be implemented on January 1,1995, were completed. DOE Laboratory Accreditation Program (DOELAP) approval was received for the new system effective. November 1, 1994. A number of studies were performed to compare dose results between the old and new systems.

The Hanford Internal Dosimetry Project provides excreta bioassay monitoring, as well as associated evaluation and documentation of internal radiological exposure and dose to Hanford workers and visitors. During 1994, the project provided oversight to 9010 excreta bioassay requests (a decrease of $1 \%$ from 1993) and 8321 successful excreta bioassay measurements. Changes to the routine project included 1) new assumptions for uranium intakes at Hanford, 2) eliminating assessment of insignificant historical bioassay results, and 3) eliminating the policy to complete year-end internal dose evaluations by February 1 of the following year. Supporting studies included 1) a uranium background study, 2) a study to determine alternatives for excreta bioassay sample collection, and 3) starting a two-year quality assurance upgrade.

The Hanford Whole Body Counting Project provides the capability to detect radioactive materials deposited in individuals using in vivo techniques. During 1994 the project performed 13,865 in vivo measurements; a decrease of $2.9 \%$ from 1993. As a part of the preparation for DOELAP accreditation the project participated in pilot testing. Some non-routine tasks performed by the project included 1) intercomparison programs with other DOE laboratories, 2) special direct radiobioassay studies for unusual potential intakes, and 3) development of a new project manual. Improvements included 1) a new counting system for the Stainless Steel Room, 2) extensive remodeling of the In Vivo Radioassay and Research Facility (IVRRF) lobby, 3) new detectors in the preview counter, and 4) a new detector support in the Iron Room. Supporting studies and programs completed included a female radiation worker study and support measurements for the U.S. Transuranium Registry. 
The Hanford Radiological Records Project preserves and administers all Hanford records of personnel radiological exposure as well as records of historical radiation protection and radiological dosimetry practices and policies. In addition to producing reports for DOE Headquarters, RL, Hanford contractors, individuals, and other authorized agencies, the project provides data for epidemiology and research projects. Changes to the project during 1994 included 1) a number of changes and enhancements made to the Radiological Exposure (REX) system, 2) some processing times reduced in REX, 3) reprogramming of REX to interface with the new external dosimetry system, and 4) several upgrades to the laser optical disk subsystem. A study was performed to determine if REX could be moved to a minicomputer.

The Radiation Standards and Calibration Project maintains radiological standards necessary for appropriate characterization and calibration for the instrument calibration and external dosimetry projects. In support of this task, special instrument and dosimeter response-characterizing equipment and supplemental radiation reference fields are maintained, as necessary. This activity provides the means to characterize response to various radiation fields encountered at Hanford and ensures the calibration fields are in accordance with recommended standards and guides. Highlights for 1994 included 1) discontinuation of the use of the low-level ${ }^{252} \mathrm{Cf}$ source for calibration of the SNOOPY reference instrument, 2) investigation of Precision Long Counter methodology for neutron constancy verification, 3) replacement of damaged encapsulation of the $50 \mathrm{mCi}^{204} \mathrm{Tl}$ source, and 4) efforts to enhance the accuracy for low-level exposure rate calibrations of gamma sources.

The Instrument Calibration and Evaluation Program provides complete and reliable radiological control instrument services for the Hanford contractors to ensure personnel safety in the workplace. Specific routine tasks performed during 1994 included 1) operating the routine instrument pool, 2) operating the Hanford Instrument Test and Evaluation project, 3) providing direct support to the HP9000 database that includes all instrument calibration records, 4) performing technical reviews of instrument calibration procedures for Hanford contractors, and 5) maintaining the Site radiation protection instrument manual. A supporting study was also conducted to determine the maximum survey speed required to detect three times the contamination values listed in the Hanford Radiological Control Manual. 


\section{ACKNOWLEDGMENTS}

The authors would like to thank the staff members whose professional skills and technical expertise ensure the success of the Hanford External Dosimetry Project, Internal Dosimetry Project, Whole Body Counting Project, Radiological Records Project, Radiation Standards and Calibrations Project, and Instrument Calibration and Evaluation Program. 


\section{ABBREVIATIONS AND ACRONYMS}

ANSI

ASSP

BCSR

CAR

CEDE

CP

CPU

CWT

CY

DEC

DOE

DOELAP

EDF

ERC

FY

GM

HCND

HED

HEDP

HEHF

HPDAC

HRRP

HSD

HSRCM

IC\&E

ICRP

IDP

IODR

IRAP

ISO

ITAS

IVRRF
American National Standards Institute

Analytical Support Services Project

Boeing Computer Services-Richland

computer-assisted retrieval

committed effective dose equivalent

cutie-pie (survey instrument)

central processing unit

chest-wall thickness

calendar year

Digital Equipment Corporation

U.S. Department of Energy

DOE Laboratory Accreditation Program

Emergency Decontamination Facility

Environmental Restoration Contractor

fiscal year

Geiger-Mueller (detector)

Hanford combination neutron dosimeter

Hanford environmental dosimeter

Hanford External Dosimetry Project

Hanford Environmental Health Foundation

Hanford Personnel Dosimetry Advisory Committee

Hanford Radiological Records Project

Hanford standard dosimeter

Hanford Site Radiological Control Manual

Hanford Instrument Calibration and Evaluation (program)

International Commission on Radiological Protection

Hanford Internal Dosimetry Project

Investigation of Dosimeter Results

Independent Review and Advisory Panel

International Standards Organization

International Technology Analytical Services

In Vivo Radioassay and Research Facility

Kaiser Engineers Hanford Company 


\begin{tabular}{|c|c|}
\hline LAN & local area network \\
\hline LaserREX & laser optical disk subsystem \\
\hline LEPD & Low Energy Photon Detector \\
\hline LLNL & Lawrence Livermore National Laboratory \\
\hline LSR & low-scatter room \\
\hline MCS & multichannel scaling \\
\hline MDAs & minimal detectable activities \\
\hline MDCRs & minimum detectable count rates \\
\hline MQA & measurement quality assurance \\
\hline NBS & National Bureau of Standards \\
\hline NIST & National Institute of Standards and Technology \\
\hline $\mathrm{NRC}$ & U.S. Nuclear Regulatory Commission \\
\hline OHE & Office of Hanford Environment \\
\hline ORNL & Oak Ridge National Laboratory \\
\hline PAM & portable alpha meter \\
\hline PFP & Plutonium Finishing Plant \\
\hline PNL & Pacific Northwest Laboratory \\
\hline PRF & Platinum Report Facility \\
\hline PTB & Physikalisch-Technische Bundesanstalt \\
\hline PTW & Physikalisch-Technische Werkstäten \\
\hline QA & quality assurance \\
\hline QC & quality control \\
\hline QUS & quick uranium soluble \\
\hline $\mathrm{RCM}$ & Radiological Control Manual \\
\hline RESL & Radiological and Environmental Systems Laboratory \\
\hline REX & Radiological Exposure (system) \\
\hline RL & U.S. Department of Energy Richland Field Office \\
\hline ROIs & regions of interest \\
\hline RS\&C & Radiation Standards and Calibrations (project) \\
\hline SOW & Statement of Work \\
\hline TBLN & tracheobronchial lymph nodes \\
\hline TE & track-etch (dosimetry) \\
\hline TL & thermoluminescent (dosimetry) \\
\hline TRU & transuranium \\
\hline UNAT & natural uranium \\
\hline USTR & U.S. Transuranium Registry \\
\hline
\end{tabular}


WBC whole-body count

WBCP Hanford Whole Body Counting Project

WHC Westinghouse Hanford Company 



\section{CONTENTS}

ABSTRACT $\ldots \ldots \ldots \ldots \ldots \ldots \ldots \ldots \ldots \ldots \ldots \ldots \ldots \ldots \ldots$ iii

SUMMARY $\ldots \ldots \ldots \ldots \ldots \ldots \ldots \ldots \ldots \ldots \ldots \ldots \ldots \ldots \ldots$

ACKNOWLEDGMENTS $\ldots \ldots \ldots \ldots \ldots \ldots \ldots \ldots \ldots \ldots \ldots \ldots$

ABBREVIATIONS AND ACRONYMS $\ldots \ldots \ldots \ldots \ldots \ldots \ldots \ldots \ldots \ldots$

1.0 INTRODUCTION $\ldots \ldots \ldots \ldots \ldots \ldots \ldots \ldots \ldots \ldots \ldots \ldots \ldots \ldots \ldots$

2.0 HANFORD EXTERNAL DOSIMETRY PROJECT $\ldots \ldots \ldots \ldots \ldots \ldots \ldots$

2.1 EXTERNAL PERFORMANCE TESTING EVALUATIONS $\ldots \ldots \ldots \ldots \ldots$

2.1.1 WHC Blind Audit Dosimeters $\ldots \ldots \ldots \ldots \ldots \ldots \ldots \ldots \ldots \ldots$

2.1.2 PNL Blind Audit Environmental Dosimeters . . . . . . . . . . . 2.2

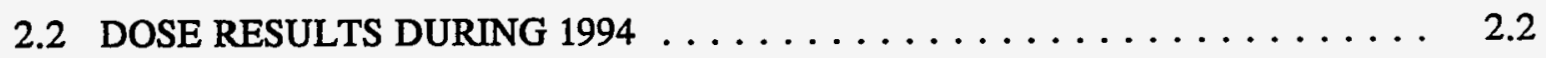

2.3 CHANGES IN ROUTINE HEDP PRACTICES FOR EXISTING
DOSIMETRY SYSTEM $\quad \ldots \ldots \ldots \ldots \ldots \ldots \ldots \ldots \ldots \ldots \ldots \ldots \ldots \ldots \ldots \ldots$

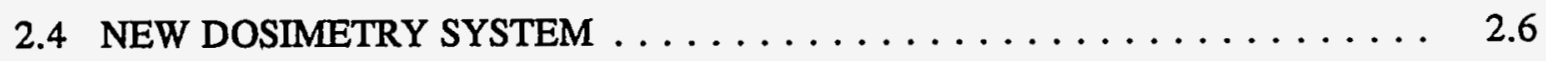

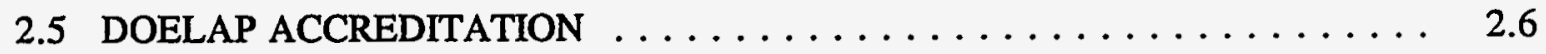

2.6 COMPARISON OF OLD AND NEW DOSIMETER RESULTS $\ldots \ldots \ldots \ldots$

2.7 CHANGES IN HEDP PRACTICES PLANNED FOR NEW

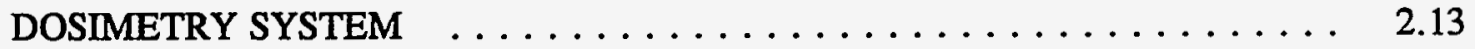

2.8 DOCUMENTATION $\ldots \ldots \ldots \ldots \ldots \ldots \ldots \ldots \ldots \ldots \ldots \ldots \ldots \ldots \ldots$

2.9 PROJECT-RELATED PROFESSIONAL ACTIVITIES $\ldots \ldots \ldots \ldots \ldots \ldots \ldots$

2.9.1 Presentations $\ldots \ldots \ldots \ldots \ldots \ldots \ldots \ldots \ldots \ldots \ldots \ldots \ldots$

2.9 .2 Publications $\ldots \ldots \ldots \ldots \ldots \ldots \ldots \ldots \ldots \ldots \ldots \ldots \ldots \ldots$

2.9.3 Professional Memberships . . . . . . . . . . . . . . . 2.15

3.0 HANFORD INTERNAL DOSIMETRY PROJECT $\ldots \ldots \ldots \ldots \ldots \ldots \ldots$

3.1 ROUTINE TASKS $\ldots \ldots \ldots \ldots \ldots \ldots \ldots \ldots \ldots \ldots \ldots \ldots \ldots \ldots$ 
3.1.1 Bioassay Capabilities $\ldots \ldots \ldots \ldots \ldots \ldots \ldots \ldots \ldots \ldots \ldots .3 .3$

3.1.2 Excreta Bioassay Contract Activities $\ldots \ldots \ldots \ldots \ldots \ldots \ldots \ldots .3 .3$

3.1.3 Excreta QC Oversight Program $\ldots \ldots \ldots \ldots \ldots \ldots \ldots \ldots \ldots .6 \ldots$

3.1.4 Project Change Records $\ldots \ldots \ldots \ldots \ldots \ldots \ldots \ldots \ldots \ldots \ldots .6$

3.1.5 Uranium Bioassay and Uranium Incident-Related Activities $\ldots \ldots \ldots \ldots$

3.1.6 10 CFR 835 Compliance Assessments $\ldots \ldots \ldots \ldots \ldots \ldots \ldots .3 .9$

3.1.7 Prioritizing Reevaluations $\ldots \ldots \ldots \ldots \ldots \ldots \ldots \ldots \ldots . .9 .9$

3.2 MONITORING AND ASSESSMENT ACTIVITIES $\ldots \ldots \ldots \ldots \ldots \ldots .3 .10$

3.2.1 Excreta Bioassay Monitoring Activities $\ldots \ldots \ldots \ldots \ldots \ldots \ldots \ldots$

3.2.2 Potential Intake Evaluations $\ldots \ldots \ldots \ldots \ldots \ldots \ldots \ldots \ldots \ldots$

3.3 SUPPORTING STUDIES $\ldots \ldots \ldots \ldots \ldots \ldots \ldots \ldots \ldots \ldots \ldots \ldots . \ldots \ldots$

3.3.1 Uranium Background Study . . . . . . . . . . . . . . 3.15

3.3.2 Alternatives for Excreta Bioassay Sample Collection ......... 3.17

3.3.3 Quality Assurance Upgrade ................... 3.17

3.4 PROJECT-RELATED PROFESSIONAL ACTIVITIES $\ldots \ldots \ldots \ldots \ldots \ldots .3 .18$

3.4.1 Presentations $\ldots \ldots \ldots \ldots \ldots \ldots \ldots \ldots \ldots \ldots \ldots \ldots \ldots \ldots \ldots \ldots \ldots \ldots .18$

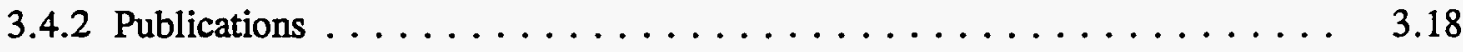

3.4.3 Professional Memberships ...................... 3.19

4.0 HANFORD WHOLE BODY COUNTING PROJECT $\ldots \ldots \ldots \ldots \ldots \ldots . . \ldots$

4.1 ROUTINE WBC TASKS $\ldots \ldots \ldots \ldots \ldots \ldots \ldots \ldots \ldots \ldots \ldots \ldots \ldots \ldots$

4.1.1 Routine In Vivo Radiobioassay $\ldots \ldots \ldots \ldots \ldots \ldots \ldots \ldots \ldots \ldots \ldots \ldots$

4.1.2 Data Administration $\ldots \ldots \ldots \ldots \ldots \ldots \ldots \ldots \ldots \ldots \ldots \ldots \ldots \ldots \ldots \ldots \ldots, 2$

4.1.3 Technical Services . . . . . . . . . . . . . . 4.2

4.1.4 Equipment Maintenance $\ldots \ldots \ldots \ldots \ldots \ldots \ldots \ldots \ldots \ldots \ldots \ldots \ldots$

4.1.5 Quality Assurance Support $\ldots \ldots \ldots \ldots \ldots \ldots \ldots \ldots \ldots .4 .4$ 


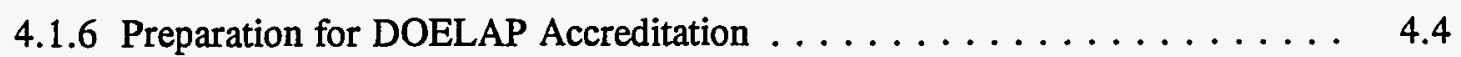

4.2 SUMMARY OF MEASUREMENTS $\ldots \ldots \ldots \ldots \ldots \ldots$

4.2.1 Summary of 1994 IVRRF Measurements $\ldots \ldots \ldots \ldots \ldots \ldots \ldots$

4.2 .2 Remote Counter $\ldots \ldots \ldots \ldots \ldots \ldots \ldots \ldots \ldots \ldots$

4.3 NON-ROUTINE TASKS $\ldots \ldots \ldots \ldots \ldots \ldots \ldots \ldots \ldots \ldots \ldots$

4.3.1 ORNL Intercomparison Program $\ldots \ldots \ldots \ldots \ldots \ldots \ldots \ldots \ldots$

4.3.2 Hanford Personnel Dosimetry Facility Design $\ldots \ldots \ldots \ldots \ldots \ldots$

4.3 .3 Palmer Cell Structural Cracking $\ldots \ldots \ldots \ldots \ldots \ldots \ldots \ldots \ldots$

4.3.4 NEXEC Software and Hardware System . . . . . . . . . . . 4.10

4.3.5 Chest Wall Thickness Modifications of LLNL Torso Phantom . . . . . . 4.10

4.3.6 Hanford Whole Body Counting Manual . . . . . . . . . . . . . 4.13

4.4 IMPROVEMENTS TO THE WHOLE BODY COUNTING PROJECT . . . . . . 4.13

4.4.1 New Stainless Steel Room Counting System . . . . . . . . . . . . . 4.13

4.4 .2 New IVRRF Lobby $\ldots \ldots \ldots \ldots \ldots \ldots \ldots \ldots \ldots \ldots \ldots$

4.4 .3 New Nal Detector in Preview Counter . . . . . . . . . . . 4.14

4.4.4 Iron Room Detector Support $\ldots \ldots \ldots \ldots \ldots \ldots \ldots . \ldots \ldots$

4.5 SUPPORTING PROGRAMS AND STUDIES AT THE IVRRF . . . . . . . . . . 4.14

4.5 .1 DOE Phantom Library . . . . . . . . . . . . . . . . 4.14

4.5.2 Female Radiation Worker Survey . . . . . . . . . . . . . . 4.15

4.5.3 U.S. Transuranium Registry Support . . . . . . . . . . . . . . 4.15

$4.5 .4{ }^{241}$ Am Deposition Case $\ldots \ldots \ldots \ldots \ldots \ldots \ldots \ldots \ldots \ldots \ldots$

4.6 PROJECT-RELATED PROFESSIONAL ACTIVITIES . . . . . . . . . . . 4.19

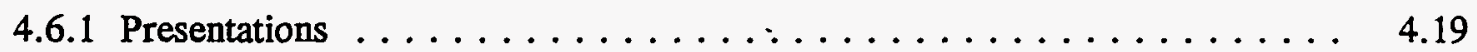

4.6.2 Professional Memberships . . . . . . . . . . . . . . . . . 4.19 
5.0 HANFORD RADIOLOGICAL RECORDS PROJECT $\ldots \ldots \ldots \ldots \ldots \ldots \ldots$

5.1 THE ROUTINE PROJECT $\ldots \ldots \ldots \ldots \ldots \ldots \ldots \ldots \ldots \ldots \ldots$

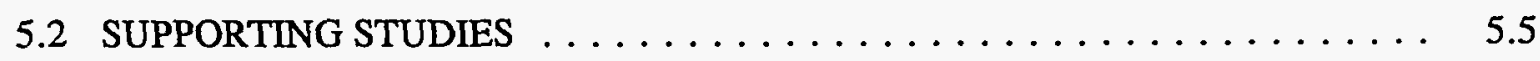

5.3 PROJECT-RELATED PROFESSIONAL ACTIVITIES $\ldots \ldots \ldots \ldots \ldots . \ldots$

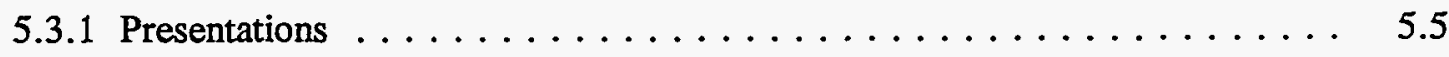

5.3 .2 Professional Memberships $\ldots \ldots \ldots \ldots \ldots \ldots \ldots \ldots \ldots \ldots$

6.0 RADIATION STANDARDS AND CALIBRATIONS PROJECT $\ldots \ldots \ldots \ldots . \ldots$

6.1 ROUTINE TASKS $\ldots \ldots \ldots \ldots \ldots \ldots \ldots \ldots \ldots \ldots \ldots \ldots \ldots \ldots$

6.1 .1 Standards and Capabilities . . . . . . . . . . . . . 6.1

6.1 .2 Traceability to National Standards $\ldots \ldots \ldots \ldots \ldots \ldots \ldots$

6.1.3 Calibrations and Constancy Checks . . . . . . . . . . . 6.9

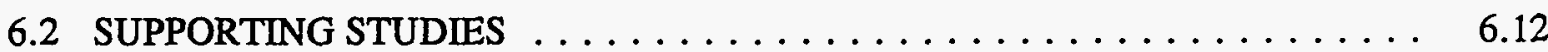

6.2.1 Discontinued Use of Low-Level ${ }^{252} \mathrm{Cf}$ Source from Calibration
of SNOOPY Reference Instrument $\ldots \ldots \ldots \ldots \ldots \ldots \ldots \ldots \ldots \ldots \ldots \ldots \ldots$

6.2.2 Investigation of Precision Long Counter Methodology for Neutron
Constancy Verification $\ldots \ldots \ldots \ldots \ldots \ldots \ldots \ldots \ldots . \ldots \ldots \ldots$

6.2.3 Damaged Encapsulation Window of $50 \mathrm{mCi}^{204} \mathrm{Tl}$ Source $\ldots \ldots \ldots . \ldots .14$

6.2.4 Low Level Exposure Rate Calibrations of Gamma Sources . . . . . . . . . 6.15

6.3 PROJECT-RELATED PROFESSIONAL ACTIVITIES $\ldots \ldots \ldots \ldots \ldots \ldots$

7.0 INSTRUMENT CALIBRATION AND EVALUATION PROGRAM $\ldots \ldots \ldots \ldots . . \ldots$

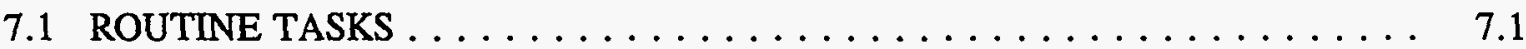

7.1.1 Routine Portable Instrument Pool $\ldots \ldots \ldots \ldots \ldots \ldots \ldots . \ldots \ldots$

7.1.2 Hanford Instrument Test and Evaluation Project $\ldots \ldots \ldots \ldots \ldots \ldots$

7.2 SUPPORTING STUDIES $\ldots \ldots \ldots \ldots \ldots \ldots \ldots \ldots \ldots \ldots \ldots \ldots \ldots \ldots$

7.3 PUBLICATIONS AND PRESENTATIONS $\ldots \ldots \ldots \ldots \ldots \ldots \ldots$

7.3.1 Publications $\ldots \ldots \ldots \ldots \ldots \ldots \ldots \ldots \ldots \ldots \ldots \ldots \ldots$ 


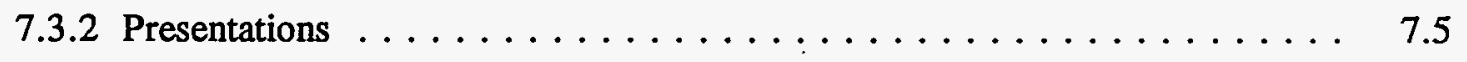

7.3.3 External Professional Activities $\ldots \ldots \ldots \ldots \ldots \ldots \ldots$

8.0 REFERENCES $\ldots \ldots \ldots \ldots \ldots \ldots \ldots \ldots \ldots \ldots \ldots \ldots \ldots \ldots \ldots \ldots$ 


\section{FIGURES}

1.1 Management Structure and Major Communication Interfaces for

Hanford Radiological Support Services in $1994 \ldots \ldots \ldots \ldots \ldots \ldots \ldots \ldots \ldots \ldots . \ldots \ldots$

2.1 Trend in Reported Hanford Personnel Dosimeter Results . . . . . . . . . . . . 2.3

2.2 HEDP Technician Operating Hanford Automated Reader System

Showing Glow Curves on Screen Above Reader System and

Time-Temperature Profiles on Monitor Behind Keyboard

2.3 HEDP Technician Conducting Eddy Current Testing of Filters

in New Dosimeter Holders $\ldots \ldots \ldots \ldots \ldots \ldots \ldots \ldots \ldots \ldots \ldots$

2.4 Monthly Exposure Estimates for Colocation Studies of the New and Old

Environmental Dosimeters at Three Locations . . . . . . . . . . . . . .

3.1 Standard and Nonstandard Excreta Requests by Month $\ldots \ldots \ldots \ldots \ldots \ldots$

3.2 Routine Urine Measurements Made from 1989 Through $1994 \ldots \ldots \ldots$. . . . . . . . . . 3.13

4.1 Scanning Coaxial Germanium System for the Detection of Mixed

Fission and Activation Product Radionuclides ................. 4.3

4.2 In Vivo Measurements Made at the IVRRF from 1989 Through $1994 \ldots \ldots \ldots$. . . . . . 4.7

4.3 ORNL Intercomparison Results for IVRRP Performance Evaluation . . . . . . . . . 4.9

4.4 NEXEC System Operational Concept Diagram $\ldots \ldots \ldots \ldots \ldots \ldots \ldots \ldots$

4.5 New Stainless Steel Cell Counting System $\ldots \ldots \ldots \ldots \ldots \ldots \ldots \ldots \ldots$

4.6 Spectral Plot From a Coaxial Germanium Scanning Measurement of the

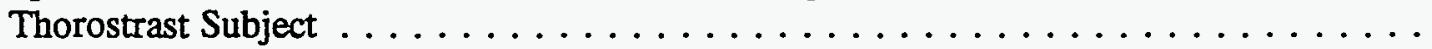

4.7 MCS Measurement Results Showing Areas of Concentrated Activity

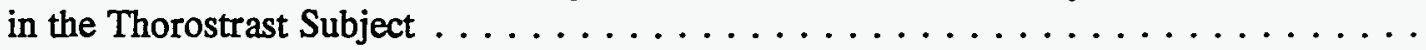

6.1 K-Fluorescence and Bremstrahlung X-ray Spectra of Similar Peak Energy . . . . . . 6.3

6.2 Typical Traceability Pathway for PNL Photon Reference Fields $\ldots \ldots \ldots \ldots$

6.3 Typical Traceability Pathway for PNL Neutron Reference Fields . . . . . . . . . . . 6.8

6.4 Typical Traceability Pathway for PNL Beta Reference Fields $\ldots \ldots \ldots \ldots$. . . . . . 6.9

6.5 Reference SNOOPY Efficiency Using Sources ${ }^{252}$ Cf Sources $318-016$ and 318-167 . . . 6.13 
6.6 Evaluation of Energy Characteristics for ${ }^{204} \mathrm{Ti}$ Source (No. 318-192) with

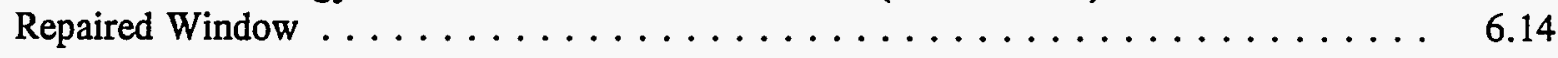




\section{TABLES}

2.1 Audit Dosimeters Processed During $1994 \ldots \ldots \ldots \ldots \ldots \ldots \ldots \ldots$

2.2 Action Levels for Potential 100-mrem Skin Dose . . . . . . . . . . . . . . 2.5

2.3 DOELAP Shallow and Deep Dose Performance Test Data . . . . . . . . . . 2.9

2.4 Summary of DOELAP Onsite Technical Assessment Concerns $\ldots \ldots \ldots \ldots$

2.5 Summary of DOELAP Onsite Technical Assessment Observations $\ldots \ldots \ldots 2.11$

3.1 Specified Minimum Detectable Activities and Screening Levels

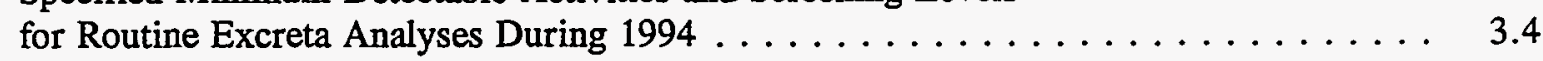

3.2 Minimum Detectable Activities and Screening Levels for Routine In Vivo Measurements During $1994 \ldots \ldots \ldots \ldots \ldots \ldots$

3.3 Specified Minimum Detectable Activities for Emergency and Expedited Excreta Bioassay During $1994 \ldots \ldots \ldots \ldots \ldots \ldots$

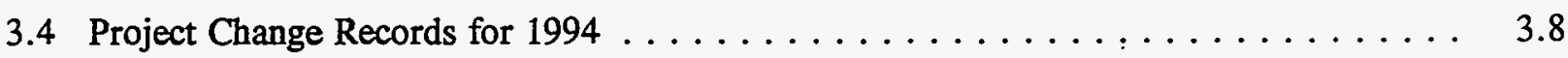

3.5 Worker Excreta Measurements Reported for 1994 Samples . . . . . . . . . . . 3.12

3.6 Summary of Potential Intake Incidents During $1994 \ldots \ldots \ldots \ldots \ldots \ldots$

3.7 Comparison of Potential Intakes By Reason Code, $1990-1994 \ldots \ldots \ldots$. . . . . . . . 3.15

3.8 Summary of Confirmed Intake Cases Identified Through the Routine Bioassay Program During $1994 \ldots \ldots \ldots \ldots \ldots \ldots$

3.9 Range of Internal Doses Assigned to the Hanford Work Force in $1994 \ldots \ldots$. . . . . . 3.16

4.1 DOELAP Pilot Testing Results for the PNL IVRRF $\ldots \ldots \ldots \ldots \ldots \ldots$

4.2 In Vivo Measurements Performed During 1994 and Recorded in the REX Database .......................... 4.6

4.3 Comparison of EXEC and NEXEC Systems $\ldots \ldots \ldots \ldots \ldots \ldots \ldots \ldots$

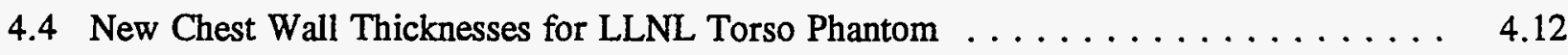

4.5 Activity Estimates from Measurements with Coaxial Germanium

Detection System $\ldots \ldots \ldots \ldots \ldots \ldots \ldots \ldots \ldots \ldots \ldots \ldots \ldots$

4.6 Comparison of $\operatorname{Organ}{ }^{241}$ Am Activity Estimates $\ldots \ldots \ldots \ldots \ldots \ldots$ 
5.1 Records Activity for Calendar Year $1994 \ldots \ldots \ldots \ldots \ldots \ldots$

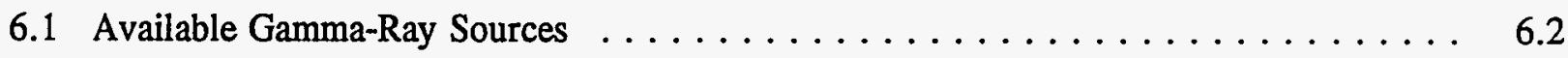

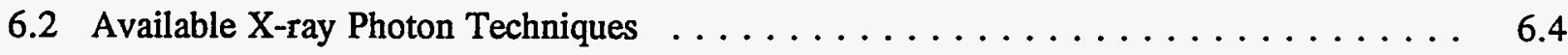

6.3 Photon Reference Fields - Calibration Performance Summary . . . . . . . . . . 6.11

7.1 Portable Instrument Usage for CY $1994 \ldots \ldots \ldots \ldots \ldots \ldots \ldots \ldots$ 


\subsection{INTRODUCTION}

This annual report documents the calendar year (CY) 1994 activities of specific radiation protection services performed by the Pacific Northwest Laboratory (PNL) ${ }^{(a)}$ for the U.S. Department of Energy (DOE) Richland Field Office (RL) and the Hanford Site contractors. These Sitewide services are provided by projects in 1) external dosimetry, 2) internal dosimetry, 3) whole body counting, 4) radiological records, 5) calibration of radiation sources traceable to the National Institute of Science and Technology (NIST) and 6) instrument calibration and evaluation. All of these services fall within the purview of the Health Protection Department.

Although some of the projects described in this report are involved in activities funded by other sources, only those activities funded by RL, DOE Headquarters, or the Hanford contractors are addressed here. Services provided for non-RL activities are performed only to the extent that they do not adversely affect services to DOE and its contractors. These non-RL services provide funds that support the overall program and reduce costs to RL. They also reduce costs to the Hanford contractors, which comprise Boeing Computer Services - Richland (BCSR), the Hanford Environmental Health Foundation (HEHF), Kaiser Engineers Hanford Company (KEH), PNL, Bechtel Hanford, Inc. (hereinafter referred to as the Environmental Restoration Contractor [ERC]), and Westinghouse Hanford Company (WHC).

Each of the six Hanford projects is described in a separate section of this report. Project descriptions include

- the routine program, including any significant changes or improvements

- investigations, studies, and tasks performed in support of the routine program

- other project-related activities, such as publications, presentations, and professional memberships.

The PNL and RL management structure and communication interfaces during 1994 for each PNLoperated project are shown in the organizational chart in Figure 1.1. The RL Quality, Safety, and Health Programs are responsible for PNL services in this area.

(a) Pacific Northwest Laboratory is operated by Battelle Memorial Institute for the U.S. Department of Energy under Contract DE-AC06-76RLO 1830. 


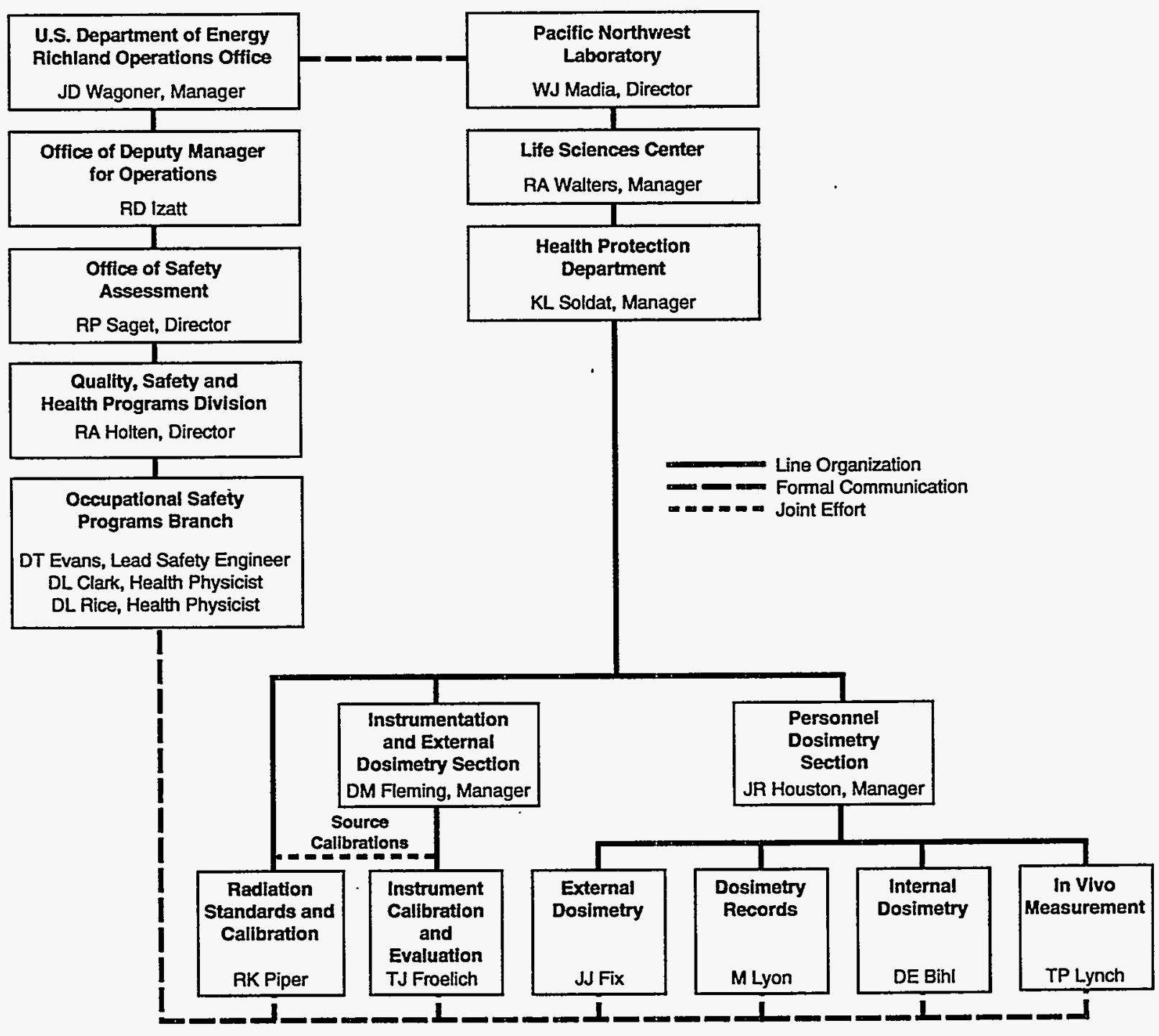

$\$ 9504069.1$

Figure 1.1. Management Structure and Major Communication Interfaces for Hanford Radiological Support Services in 1994 


\subsection{HANFORD EXTERNAL DOSIMETRY PROJECT}

The Hanford External Dosimetry Project (HEDP) is a multifaceted effort involving all Hanford contractors. Dose-of-record information from external radiation for Hanford personnel is provided by this project in compliance with U.S. Department of Energy (DOE) requirements as set forth in 10 CFR Part 835, "Occupation Radiation Protection" (DOE 1993); the "Hanford Site Services Handbook" (RL 1993) (through 1994); the Hanford Site RCM (RL 1994), DOE 5480.11, "Radiation Protection for Occupational Workers" (DOE 1990a); and DOE 5480.15, "Department of Energy Accreditation Program for Personnel Doșimetry" (DOE 1989). HEDP dosimeter results provide the means used by contractor personnel to project, control, and measure radiation doses received by personnel. Project staff also provide site-wide nuclear accident dosimetry in compliance with 10 CFR 835 and DOE 5480.11 requirements and environmental dosimetry in compliance with DOE 5400.5, "Radiation Protection of the Public and the Environment" (DOE 1990b).

During 1994, official dose-of-record information was conducted using the original Hanford personnel dosimetry system, consisting of basic, beta/photon, and multipurpose dosimeters, while efforts were underway to prepare a new Hanford dosimetry system for implementation effective January 1, 1995. The new system consists of a commercially procured thermoluminescent dosimetry system (manufactured by Bicron/Harshaw) ${ }^{(a)}$ and a Pacific Northwest Laboratory (PNL)-developed track etch (TE) dosimetry system. The new dosimetry system consists of a Hanford standard dosimeter (HSD), a Hanford combination neutron dosimeter (HCND), and a Hanford environmental dosimeter (HED). All personnel assigned a personnel dosimeter will receive the HSD, except for those personnel potentially exposed to neutron radiation where a HCND will be assigned. The HSD does have a neutron response capability which detects exposure to neutron radiation even though no official dose is determined. For extremity dosimetry, the Hanford two-chip ring dosimeter will continue to be used.

\subsection{EXTERNAL PERFORMANCE TESTING EVALUATIONS}

Two external reviews of HEDP reported doses were conducted during 1994 as discussed in the following sections.

\subsubsection{WHC Blind Audit Dosimeters}

Westinghouse Hanford Company (WHC) routinely submits several audit dosimeters to be processed along with their personnel dosimeters. The PNL External Dosimetry Project successfully passed each monthly blind audit dosimeter evaluation conducted by WHC during 1994. The program also passed each of the quarterly evaluations conducted by WHC using the DOE Laboratory Accreditation Program (DOELAP) methodology and criteria. During the entire year, no personnel dosimeter results exceeded

(a) Bicron, Saint-Gobain/Norton Industrial Ceramics Corporation, Solon, Ohio. 
established tolerance limits for the DOELAP accredited testing categories. The results of these audits are provided by WHC to the Hanford Radiation Protection Historical Files operated by the Hanford Radiological Records Project (HRRP).

\subsubsection{PNL Blind Audit Environmental Dosimeters}

PNL Environmental Surveillance Program staff routinely submit audit environmental dosimeters to be processed along with their quarterly exchanged environmental dosimeters. The given exposure ranges between 15 and $25 \mathrm{mR}$ of ${ }^{137} \mathrm{Cs}$ gamma radiation. A result is noted as abnormal if the given exposure is outside of the calculated $95 \%$ confidence interval for each audit dosimeter based upon twelve environmental dosimeter components (i.e., each environmental dosimeter has 12 responsive elements). Based on this criteria, approximately $20 \%$ of the reported results were noted as abnormal. It is instructive to note this criteria does not account for uncertainty in the given low-level exposure and becomes more difficult as the precision of the calculated dose improves. Results of these audits are routinely included in the annual Hanford environmental surveillance reports (Dirkes et al. 1994) and in HEDP project files.

\subsection{DOSE RESULTS DURING 1994}

During 1994, HEDP reported 84,798 official dose results. This is a decrease of approximately $10 \%$ from the previous year total of 93,242 and reverses the trend of a 5\% average annual growth rate observed during recent years. The volume of results are illustrated in Figure 2.1 for 1989-1994 for each type of dosimeter. The decline in 1994 was attributable to less use of the single-chip basic dosimeter whereas the use of multi-chip dosimeters continues to show an increase. Ring dosimeter processing has stayed constant for several years.

Actual dosimeter processing exceeded the 84,798 official dose results reported due to quality control practices used to ensure the accuracy of the reported personnel dose as follows:

- processing a minimum of two quality-control dosimeters within every 50 personnel dosimeters and every 25 dosimeters when determining chip sensitivity factors

- reprocessing, prior to issue, any personnel dosimeter which has been stored more than 75 days to minimize environmental dose buildup

- reprocessing any dosimeter with an observed reader count greater than 650 counts in any dosimeter position

- conducting acceptance testing of new dosimeter inserts and holders

- updating chip sensitivity factors for dosimeters (requires two processings: before irradiation and after). 
•ə[ц [eग!I015!4

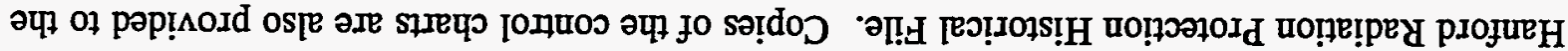

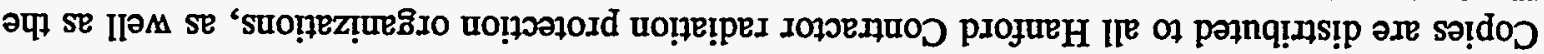

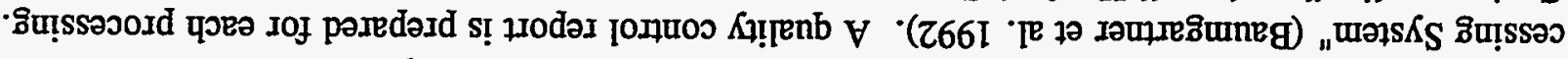
-old łuәวsəu!

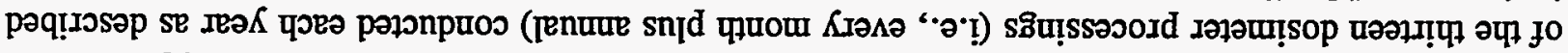

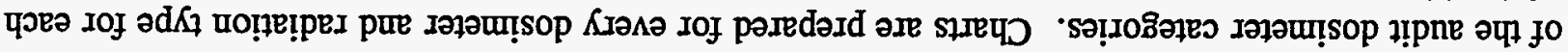

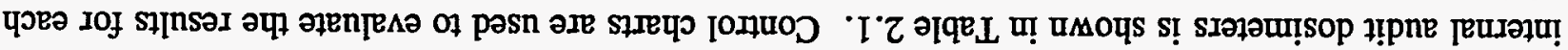

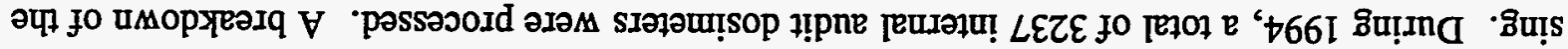

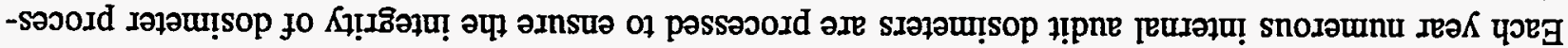

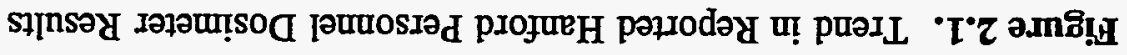

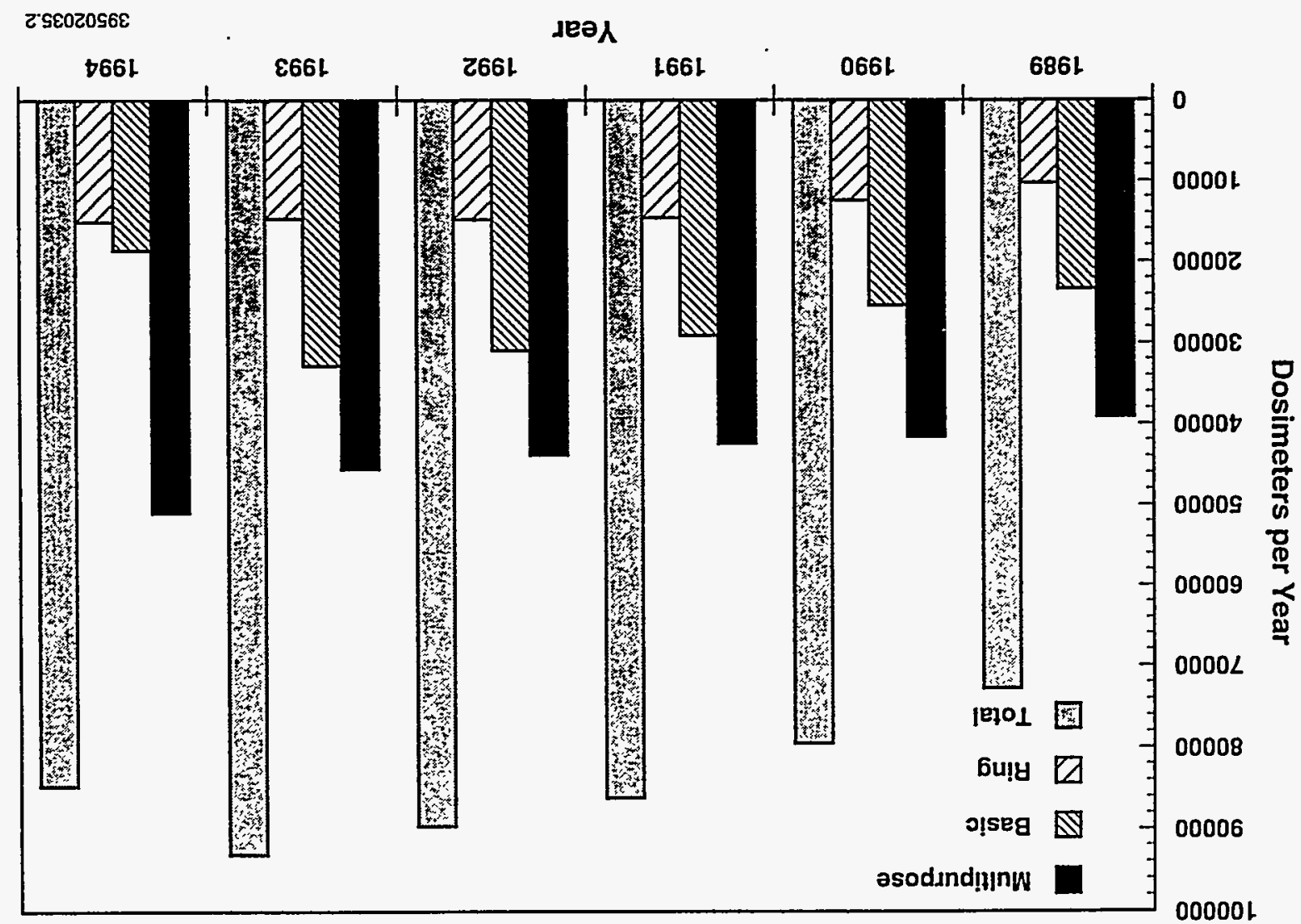


Table 2.1. Audit Dosimeters Processed During 1994

\begin{tabular}{lcccc}
\hline & \multicolumn{4}{c}{ Dose Category } \\
\cline { 2 - 5 } \multicolumn{1}{c}{ Dosimeter } & Shallow & Deep & Fast Neutron & Blank \\
\hline Basic & $\mathrm{NA}^{(\mathrm{a})}$ & 400 & NA & 180 \\
Beta/Photon & 130 & 65 & NA & NA \\
Multipurpose & 419 & 498 & 549 & 686 \\
Rings & NA & 330 & NA & Controls \\
\hline
\end{tabular}

(a) $\mathrm{NA}=$ Not Applicable

\subsection{CHANGES IN ROUTINE HEDP PRACTICES FOR EXISTING DOSIMETRY SYSTEM}

Changes to HEDP practices are discussed during meetings of the Hanford Personnel Dosimetry Advisory Committee (HPDAC). Changes in routine project practices determined during 1994 are described in the following:

Dosimeter Wearing Practice The primary dosimeter should always be worn on the front of the chest, on or between the waist and the neck consistent with Article 511.6 requirements of the Hanford Site Radiological Control Manual (HSRCM) (RL 1994). When protective clothing is worn, the practice should be to wear the primary dosimeter as close as reasonable to the skin, generally under the protective clothing. For example, the dosimeter may be worn on a lanyard or placed in the pocket of, or clipped to, modesty clothing. If it is necessary to place the dosimeter on the outside of the protective clothing or in a pocket of the protective clothing, the dosimeter must be protected from contamination, for example by being placed in a plastic bag.

Multiple Dosimeter Practice - A clarification was adopted to the existing HPDAC multiple dosimeter practice. Normally, the primary dosimeter is removed and processed. In the event the multiple dosimeter assignment is for one day or less, there is an option to not process the primary dosimeter. The primary use of this practice is expected at the Plutonium Finishing Plant (PFP) where temporary Hanford combination neutron dosimeters may be used by some staff when entering PFP. The Hanford primary dosimeter would be left at the entry center for retrieval upon exit.

Hot Particle Definition - The Hanford Radiation Protection Forum (HRPF) adopted a definition of $10 \mu \mathrm{Ci}$ for hot particles to satisfy Article 348.1 of the HSRCM to define a "hot particle." This definition is based on the following rationale:

1. National Council on Radiation Protection and Measurements (NCRP) Report No. 106, "Limit for Exposure to 'Hot Particles' on the Skin" contains a recommendation that exposures to hot particles be limited to $75 \mu \mathrm{Ci}$-h (NCRP 1989). 
2. The maximum duration for a normal entry into a surface contamination area is four hours.

3. A limit of $40 \mu \mathrm{Ci}$-h (i.e., $10 \mu \mathrm{Ci} \times 4$ hours) is approximately half of the NCRP recommended limit.

The NCRP limit of $75 \mu \mathrm{Ci}-\mathrm{h}$ results in a skin dose of about $300 \mathrm{rad}$ for a nuclide emitting a 1-MeV beta particle for each disintegration. The definition of hot particle is distinct from the determination of a screening level for skin contamination covering a larger area as addressed in the next section.

Portable Instrument Screening Level - A portable instrument screening level was determined to identify cases where potential skin doses of $100 \mathrm{mrem}$ or greater may occur. This was done to comply with requirements of Article 541.5 of the HSRCM (RL 1994). Doses were calculated to $1 \mathrm{~cm}^{2}$ and to $100 \mathrm{~cm}^{2}$, depending upon the source size. The action levels specifically apply to the case of contamination on skin but not to include the case of hot particles, as described in the previous section. Measurements with the Eberline Model 260 pancake probe and Eberline Model RO-2 and Model RO-3B ion chambers, as used at Hanford, were performed on calibrated disk (those used to routinely calibrate Pancake Probe instruments at Hanford) and slab sources. Shallow dose was calculated with the VARSKIN MOD2 computer code (Durham 1992). Based on this work, conservative action levels were determined that satisfy the HSRCM requirement for the skin dose assessment for each instrument as shown in Table 2.2. Assumptions used to determine these action levels include

Table 2.2. Action Levels for Potential 100-mrem Skin Dose

\begin{tabular}{|c|c|c|}
\hline \multirow[b]{2}{*}{ Instrument } & \multicolumn{2}{|c|}{ Action Levels } \\
\hline & Small Source ${ }^{(a)}$ & Large Source ${ }^{(b)}$ \\
\hline Eberline Model 260 Pancake Probe & $2,500 \mathrm{cpm}$ & $25,000 \mathrm{cpm}$ \\
\hline $\begin{array}{l}\text { Eberline Model RO-2 Ion Chamber } \\
\text { (Open Window) }\end{array}$ & $0.2 \mathrm{mrad} / \mathrm{h}^{(\mathrm{c})}$ & $2 \mathrm{mrad} / \mathrm{h}$ \\
\hline $\begin{array}{l}\text { Eberline Model RO-3B Ion Chamber } \\
\text { (Open Window) }\end{array}$ & $0.1 \mathrm{mrad} / \mathrm{h}^{(\mathrm{c})}$ & $1 \mathrm{mrad} / \mathrm{h}$ \\
\hline
\end{tabular}

(a) Action levels for small sources are based on measurements of dose from $0.2 \mathrm{~cm}^{2}$ sources. The tabled value is the most conservative case for Hanford nuclides which in all cases was ${ }^{90} \mathrm{Sr} /{ }^{90} \mathrm{Y}$.

(b) Action levels for large sources are determined by multiplying the action level for the small sources by a factor of ten. For comparison, measurements of large $225 \mathrm{~cm}^{2}$ sources showed action levels of $63,300 \mathrm{cpm}, 6 \mathrm{mrad} / \mathrm{h}$, and $4.7 \mathrm{mrad} / \mathrm{h}$, respectively, for the tabled instruments.

(c) These values are provided for information only; the Pancake probe should be used when such low dose rates are measured with the ionization chamber instruments. 
1) The area of contamination is

Small Source - It is assumed that instrument response to the $0.2 \mathrm{~cm}^{2}$ sources can be used to represent skin contamination less than the probe area $\left(15.5 \mathrm{~cm}^{2}\right)$ but greater than $1 \mathrm{~cm}^{2}$. Smaller source areas are assumed to be equivalent to hot particle considerations.

Large Source - Because the measured instrument response is for sources $\left(225 \mathrm{~cm}^{2}\right)$ much larger than the probe area, the tabled values for small sources was multiplied by a factor of ten to determine reasonable action levels when the skin contamination is greater than the probe area $\left(15.5 \mathrm{~cm}^{2}\right)$.

2) The contamination is resident for a period of two hours.

3) The probe survey is done at a distance of $1 \mathrm{~cm}$.

When an instrument measurement exceeds the respective action level, a skin dose assessment is required to comply with the requirements established in Appendix 2C of the HSRCM (RL 1994).

\subsection{NEW DOSIMETRY SYSTEM}

Extensive testing of the new Hanford Thermoluminescent (TL)/TE Dosimetry system was conducted throughout 1994. The new TL dosimetry system consists of 4 Harshaw 8800 hot-gas reader systems (shown in Figure 2.2), two Harshaw 6600 hot-gas reader systems, and approximately 80,000 personnel, environmental, and extremity dosimeters. The TL system was commercially procured from Harshaw and the TE system was developed by PNL. Numerous studies have been conducted on the performance of this equipment including reader stability, dose response, light sensitivity, readout protocol, etc. An example of the testing conducted is shown in Figure 2.3 where an Eddy Current Meter is being used to check the type and thickness of the metallic filters used in Hanford dosimeter holders. Less than $1 \%$ of the holders which were received showed inappropriate filters.

\subsection{DOELAP ACCREDITATION}

HEDP formally participated in the DOELAP for the new dosimetry system as required by DOE Order 5480.15 (DOE 1989). Hanford successfully passed all requested categories for the new Hanford standard and combination neutron dosimeters. The results are summarized in Table 2.3. Performance testing covered a period of nearly six months and involved approximately 350 dose evaluations for a variety of single- and mixed-exposure conditions. Exposures included personnel and accident level (as high as 500 rem) doses. Excellent performance was shown by the Hanford dosimeters, as demonstrated in Table 2.3, by comparing the calculated performance of the respective dosimeters against DOELAP criterion in each irradiation category. In every category, the Hanford performance is well below the 0.3 or 0.4 DOELAP criterion. In every category, the Hanford dosimetry performance is below a 0.1 performance quotient with the exception of the mixed high-energy and beta category. 


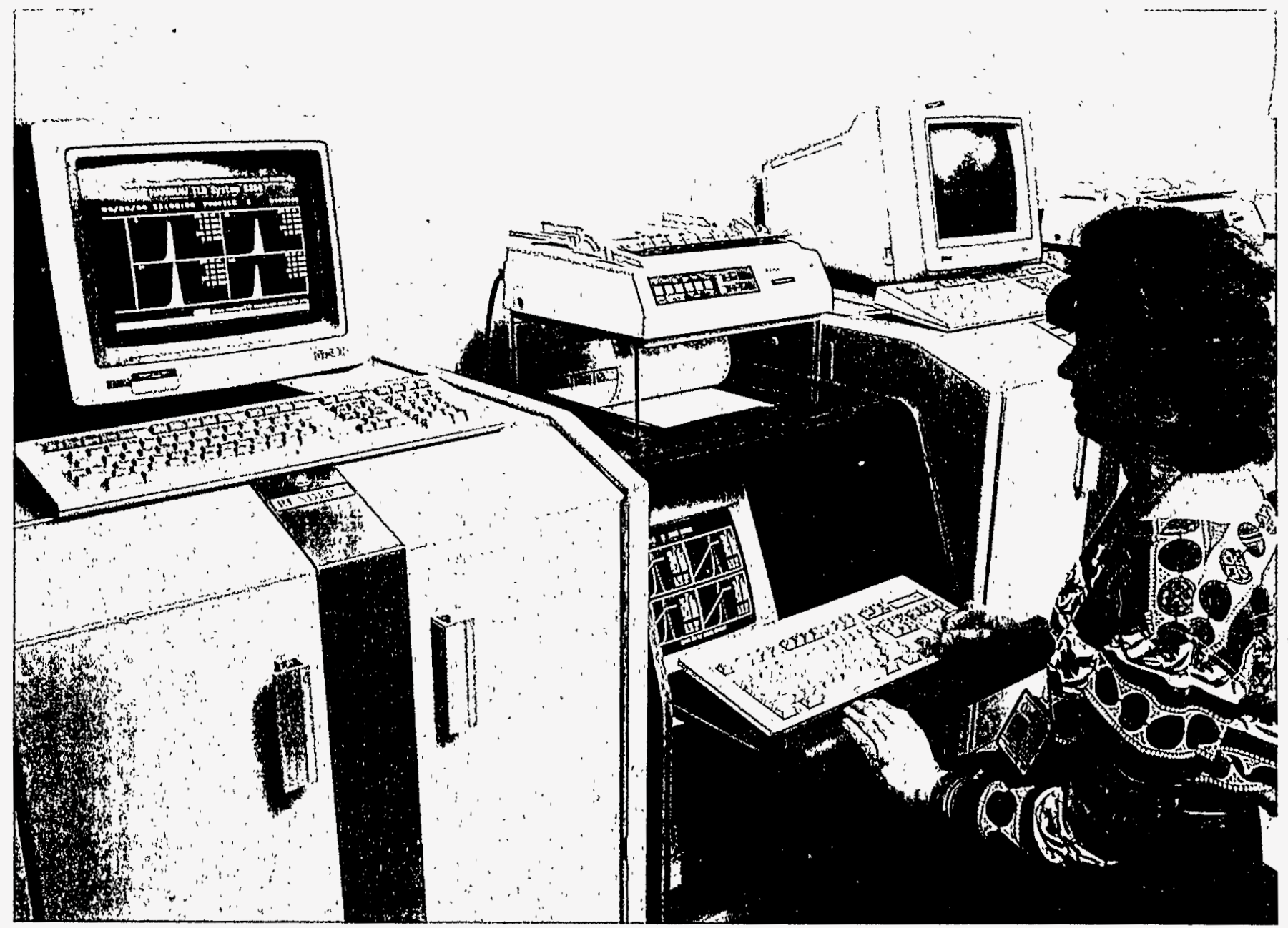

Figure 2.2. HEDP Technician Operating Hanford Automated Reader System Showing Glow Curves on Screen Above Reader System and Time-Temperature Profiles on Monitor Behind Keyboard 


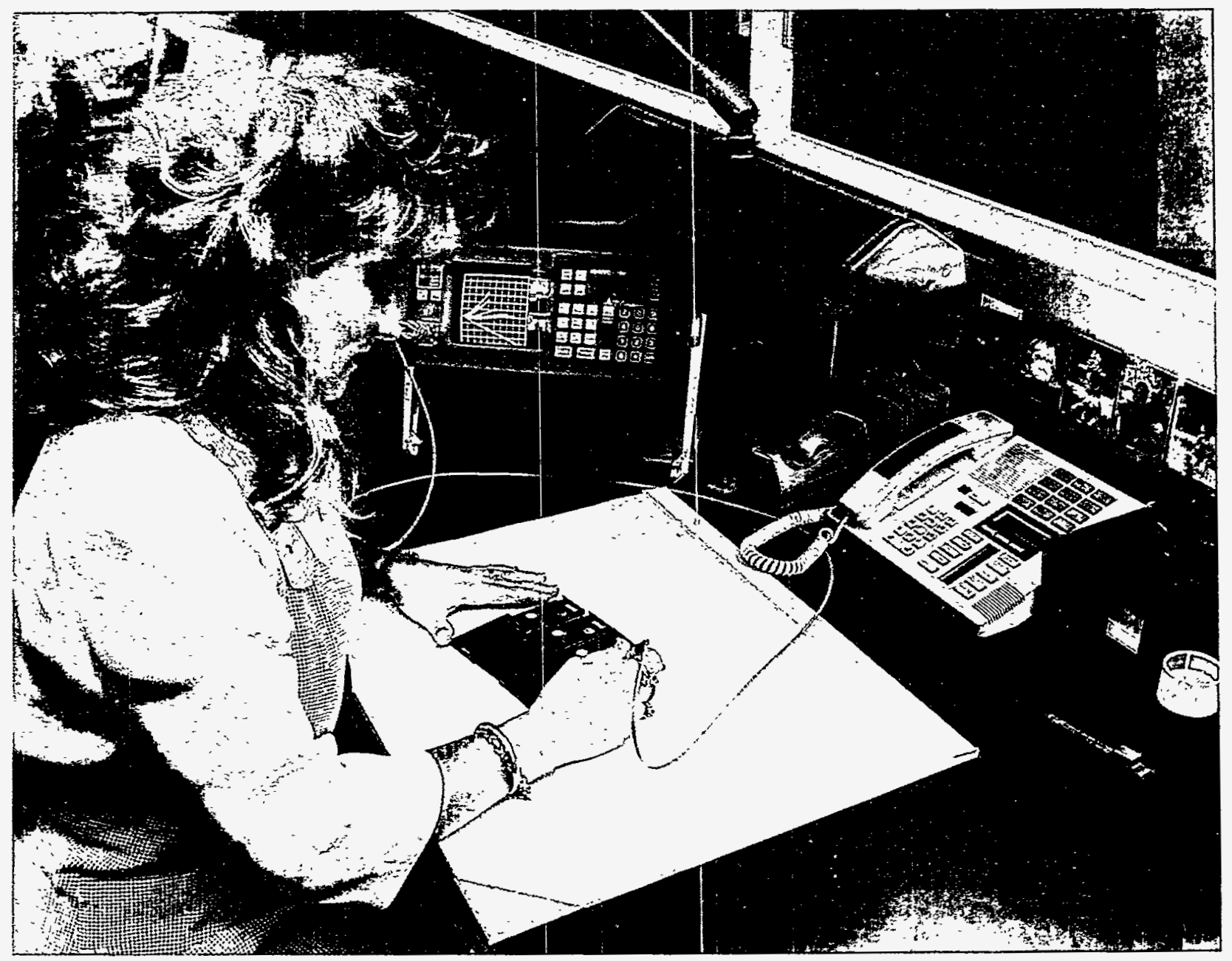

Figure 2.3. HEDP Technician Conducting Eddy Current Testing of Filters in New Dosimeter Holders

The onsite technical program assessment was conducted during September 27-29, 1994, to examine program documentation and practices relative to the requirements of the DOELAP Handbook (DOE 1986). Two concerns and seven observations were noted during the assessment. These are summarized in Tables 2.4 and 2.5 , respectively. A formal response was submitted to RL on October 20 , 1994, describing HEDP response and completion times for each of the concerns shown in Table 2.4. None of the concerns questioned the quality of Hanford personnel dose estimates but were directed at improving documentation of and training on the Hanford external dosimetry system. The HEDP response described program practices and documentation which fully satisfied each of the concerns. Although not required, efforts to respond to each of the observations noted in Table 2.5 are scheduled for completion during the nexi year.

J. R. Hall, Acting Director, Quality Safety and Health Programs Division, RL, communicated receipt of the DOELAP Certificate of Accreditation, dated November 1, 1994, to the Director of PNL in a 
Table 2.3. DOELAP Shallow and Deep Dose Performance Test Data

\begin{tabular}{lccccc}
\hline & & \multicolumn{4}{c}{ Performance ${ }^{(\mathrm{a})}$} \\
\cline { 3 - 6 } \multicolumn{1}{c}{ DOELAP Category Description } & & \multicolumn{2}{c}{ HSD } & HCND \\
\cline { 3 - 6 } \cline { 4 - 6 } & DOELAP & & & \\
& Criterion & Shallow & Deep & Shallow & Deep \\
\hline Low-Energy Photons, Accident Levels & 0.3 & N/A & 0.008 & N/A & -0.003 \\
High-Energy Photons, Accident Levels & 0.4 & N/A & N/A & N/A & 0.021 \\
Low-Energy Photons, Plutonium Environments & 0.3 & 0.065 & 0.067 & 0.099 & N/A \\
High-Energy Photons, ${ }^{137}$ Cs & 0.3 & 0.053 & N/A & 0.039 & N/A \\
Beta Particles, General & 0.4 & -0.017 & N/A & 0.010 & N/A \\
Neutrons, Unmoderated ${ }^{252}$ Cf & 0.3 & N/A & N/A & N/A & 0.065 \\
Mixtures: & & & & & \\
Low-Energy Photons + High Energy Photons & 0.4 & 0.035 & N/A & 0.063 & N/A \\
Low-Energy Photons + Beta & 0.4 & 0.089 & N/A & 0.084 & N/A \\
Low-Energy Photons + Neutrons & 0.4 & N/A & N/A & N/A & -0.007 \\
High-Energy Photons + Beta & 0.4 & 0.237 & N/A & 0.182 & N/A \\
High-Energy Photons + Neutrons & 0.4 & N/A & N/A & N/A & 0.021 \\
\hline
\end{tabular}

(a) Performance quotients (P) for Hanford Standard Dosimeter (HSD) and Hanford Combination Neutron Dosimeter (HCND). are calculated as $P=|B|+S-E$ where $B$ is the systematic error in the reported dose, $S$ is the random error and $\mathrm{E}$ is the uncertainty in the delivered dose. Dosimeter performance quotients must be less than the DOELAP criterion in each category for satisfactory performance.

letter dated November 29, 1994. This certificate recognized the program's successful completion of the DOELAP performance testing and onsite technical assessment as required by DOE 5480.15 (DOE 1989). Program re-accreditation is required every two years. The next scheduled program performance testing will begin during January 1996.

\subsection{COMPARISON OF OLD AND NEW DOSIMETER RESULTS}

Tests were conducted to determine changes in reported dose for the existing and new personnel and environmental dosimetry systems, respectively. This is described in the following:

Collocated Environmental Dosimeters - Collocation of new and old environmental dosimeters began in July 1994. Three locations were chosen with higher than normal ambient dose levels for monthly exchange of the new and old dosimeters. This information is shown in Figure 2.4 where closed symbols are used for the old dosimeter and the corresponding open symbol for the new system. The precision of the new system from month to month is apparent in the plotted data. Based on this information, observed dose estimates with the new dosimeter are anticipated to 
Table 2.4. Summary of DOELAP Onsite Technical Assessment Concerns ${ }^{(a)}$

DOELAP

Category Description

Quality Concern \#1 - The QA Plan (LSC-022), although containing the elements of a complete

Assurance plan, exists in draft form. It is necessary to have an approved QA plan prior to using the new system as Dose-Of-Record. HEDP personnel have indicated that the QA Plan is scheduled to be issued by November 1, 1994. (DOELAP Handbook Section 4.3.1).

HEDP Response This document will be finalized by November 1, 1994, along with the scheduled publication of PNL-MA-568, "Hanford External Dosimetry Project Manual," and PNL-MA-841, "Hanford External Dosimetry Project Procedures Manual."

Finalization of these three documents is coordinated to better ensure consistency of documentation for the new dosimetry system. This commitment is identical to the project milestone schedule currently established with DOE-RL.

Dosimeters Concern \#2 - Determination of the dosimetry system's lower limit of detectability has not been completed. Although calculations have been performed using an unirradiated background signal representing about one day, the calculations should be completed using dosimeters which are placed in an unshielded environment for a time sufficient to obtain an unirradiated background signal typical for routine processed dosimeters. (Dosimeters General 5).

HEDP Response Dosimeter data for non-occupationally exposed dosimeters exchanged monthly, quarterly, or annually with Hanford Contractor organizations, as part of the routine dosimetry system, would be the best source of data to satisfy this concern. At this time, estimates of the lower level of detection for each exchange period will be documented using other data, such as a recently completed one-year fade study. This documentation will be submitted to the DOELAP Performance Evaluation Testing Administrator by October 19, 1994.

(a) HEDP actions noted in this table were completed as planned. No concerns were noted in personnel, equipment and facilities, equipment maintenance and calibration, processing procedures, and reports and record keeping sections of the assessment.

average approximately $15 \%$ (i.e., 1-2 mrem) less than for the old system for these low levels of exposure. The ambient exposure level for naturally occurring environmental radiation in the Hanford environs is approximately $0.18 \mathrm{mR} /$ day or a little less than one-half the exposure rates for the locations shown in Figure 2.4.

Parallel Assignment of Personnel Dosimeters - Parallel wearing of new and old personnel dosimeters for about 90 WHC personnel began in October 1994. Extensive measurements have been made at PFP to base dose calibration of the HCND on performance in the actual radiation work environment. In addition, efforts continued during 1994 to evaluate the performance of HCND dose results for seven to ten WHC PFP personnel. These personnel were assigned both the new HCND and the old Hanford Multipurpose Dosimeter. This effort originally began in December 1990 at PFP to evaluate the new Hanford combination neutron dosimeter design. Elements of this effort were discussed in previous annual reports (Lyon et al. 1992, 1993, 1994). 
Table 2.5. Summary of DOELAP Onsite Technical Assessment Observations ${ }^{(a)}$

\begin{tabular}{|c|c|}
\hline $\begin{array}{l}\text { DOELAP } \\
\text { Category }\end{array}$ & Description \\
\hline \multirow[t]{2}{*}{ Personnel } & $\begin{array}{l}\text { Observation \#1 - The draft QA Plan (QA Plan No. LSC-022) does not contain sufficient } \\
\text { information on 1) practices for ensuring the competency of staff members, 2) a training } \\
\text { program that prepares staff members to conduct processing protocols, and 3) staff retraining } \\
\text { requirements. }\end{array}$ \\
\hline & $\begin{array}{l}\text { Observation \#2 - Dosimetry staff training records are documented using a "Group Training } \\
\text { Documentation Form" which shows a list of procedures and the names of employees who } \\
\text { have been trained for the procedures. The training documentation should include infor- } \\
\text { mation on the actual content of the qualification process which may include equipment } \\
\text { knowledge, safety measures, equipment maintenance, equipment operation, and system/ } \\
\text { procedures qualification. }\end{array}$ \\
\hline \multirow[t]{2}{*}{$\begin{array}{l}\text { Equipment } \\
\text { and Facilities }\end{array}$} & $\begin{array}{l}\text { Observation \#3 - The backup equipment is stored in proximity of the routine processing } \\
\text { equipment. Consideration should be given to relocating the backup equipment to another } \\
\text { area to provent the catastrophic loss of processing capability. }\end{array}$ \\
\hline & $\begin{array}{l}\text { Observation \#4 - The TLD system configuration logbook does not have supervisory or } \\
\text { technical staff signatures or initials on data sheets containing critical system parameters } \\
\text { (e.g., QC check parameters, Time-Temperature Profiles). Evidence of review and approval } \\
\text { of the initial copies or future revisions of these data sheets by appropriate technical } \\
\text { leadership is recommended. }\end{array}$ \\
\hline \multirow[t]{3}{*}{$\begin{array}{l}\text { Processing } \\
\text { Procedures }\end{array}$} & $\begin{array}{l}\text { Observation \#5 - Facility specific calibration codes for neutron fields as identified in the } \\
\text { Hanford External Dosimetry Project Manual (PNL-MA-568) should be implemented with } \\
\text { the cooperation of Hanford contractors. }\end{array}$ \\
\hline & $\begin{array}{l}\text { Observation \#6 - The calculational algorithms developed for the dosimeters were con- } \\
\text { structed using a wealth of empirical data and sensitivity testing has been conducted. } \\
\text { However, it is recommended that this information be formally documented. The draft } \\
\text { internal document "Dose Calculation Methodology for the Hanford Dosimetry System" } \\
\text { (B.A. Rathbone, September } 25,1994) \text { should be combined with the algorithm sensitivity } \\
\text { testing results and DOELAP Performance Test data to form a software validation and } \\
\text { verification document for the algorithm. }\end{array}$ \\
\hline & $\begin{array}{l}\text { Observation \#7 - HEDP procedures call for utilizing the TLD neutron dosimetry results } \\
\text { above } 1000 \text { mrem and not processing CR-39. It is, in fact, more accurate to utilize TLD } \\
\text { neutron dosimetry results above } 1000 \text { mrem compared to CR- } 39 \text { due to saturation problems; } \\
\text { however, the CR-39 should still be processed and recorded at this level for the following } \\
\text { reason. Even advanced albedo neutron dosimetry techniques may be subject to erroneous } \\
\text { high results in very thermalized neutron fields. Recording that the CR-39 result is at or } \\
\text { near the saturation level will verify either that the TLD is the appropriate measurement or } \\
\text { that thermal neutron interference occurred. }\end{array}$ \\
\hline
\end{tabular}

(a) No observations were noted in quality assurance, equipment maintenance and calibration, dosimeters, and reports and record keeping sections of the assessment.

Dosimeters were exchanged monthly for all employees. The results obtained during 1994 again confirmed the general trend of substantially lower neutron doses for the TE component of the HCND compared to the TL component. Comparisons between the new and old personnel TL 


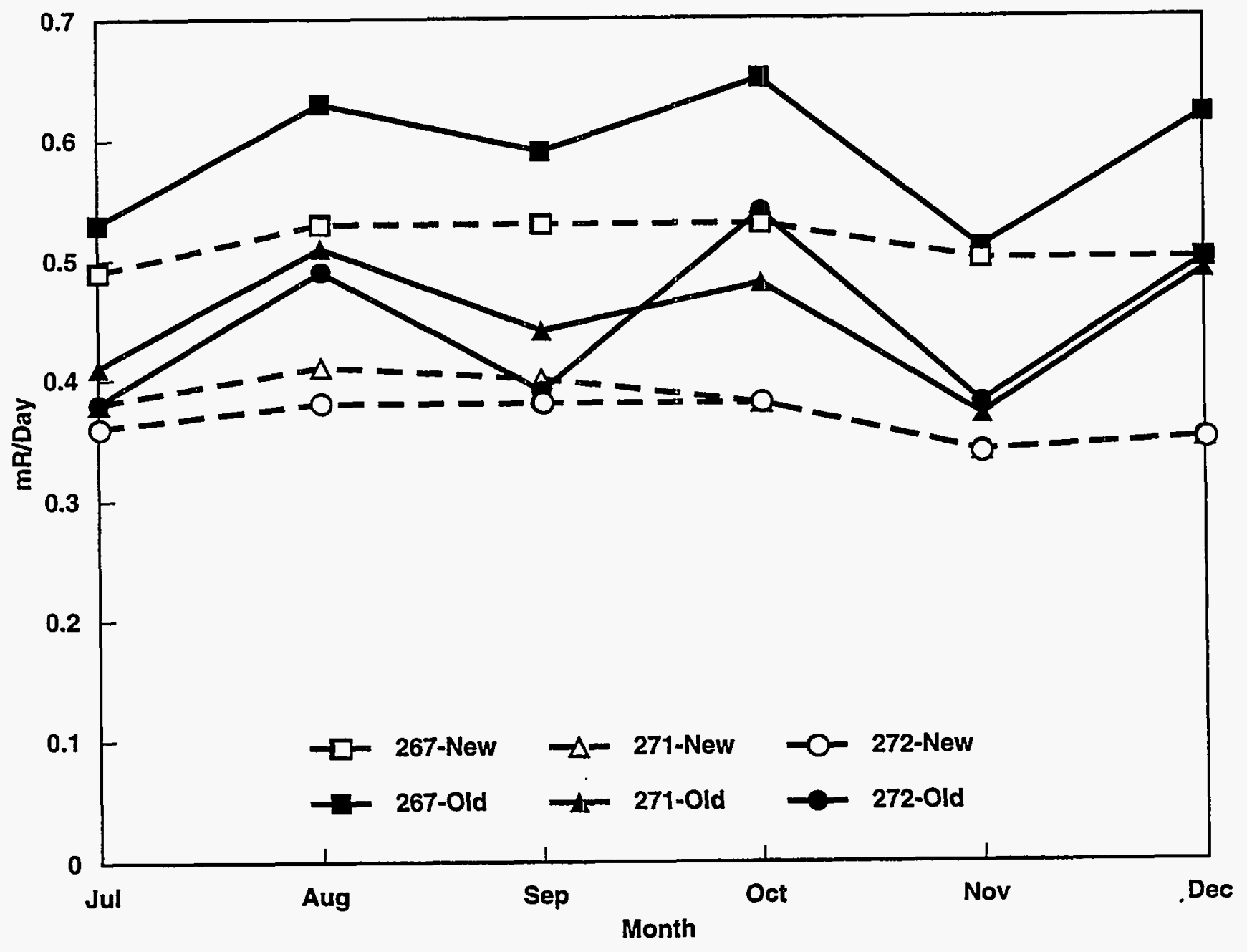

39503014.1

Figure 2.4 Monthly Exposure Estimates for Colocation Studies of the New and Old Environmental Dosimeters at Three Locations

dosimeter results, based on the limited data available and generally low personnel dose, indicate a general trend of higher reported shallow dose, higher reported deep dose, and lower reported neutron dose. The shallow dose increase is expected to be directly attributable to the lower energy beta radiation capabilities of the new dosimeter. Similarly, the lower reported neutron dose is anticipated because of the significantly greater capabilities of the new combination neutron dosimeter. 


\subsection{CHANGES IN HEDP PRACTICES PLANNED FOR NEW DOSIMETRY SYSTEM}

Planned practices for the new dosimetry system were coordinated through the HPDAC. Notable changes planned with implementation of this system on January 1, 1995, include

Lens-of-Eye Dose - The dose at $300 \mathrm{mg} / \mathrm{cm}^{2}$ (i.e., lens of eye) is routinely reported in addition to the shallow, deep, and, as appropriate, neutron dose. This practice was adopted because of the HSRCM requirement to assess the annual lens-of-eye dose. The dosimeter would measure the dose for the usual circumstances of uniform exposure. This approach was considered to be more practical than trying to determine an annual lens-of-eye dose on an "as applicable" basis then, if significant lens-of-eye dose was measured, retroactively examining previous dosimeter results to assess a total lens-of-eye dose for the year. The dose assessment would be conducted using:

$$
\text { lens-of-eye dose }=\left(300 \mathrm{mg} / \mathrm{cm}^{2} \text { dose }\right)+(\text { neutron dose })
$$

In the event a supplemental lens-of-eye dosimeter was also worn, this dose would be added to the routine lens-of-eye dose assessment. This is the same approach used to record Hanford extremity doses.

Adjustments could be made to the $300 \mathrm{mg} / \mathrm{cm}^{2}$ dose for glasses or face shield, if it were warranted, to determine the proper correction factors; however, generally, the $300 \mathrm{mg} / \mathrm{cm}^{2}$ dose will be small compared to the eye dose limit.

Suspect Dosimeter Result Form - A "suspect dosimeter result" form will be used to document suspect dosimeter results. This form will replace the letters previously written for notecode 50 (i.e., Contractor must determine dose) and 53 (i.e., External Dosimetry recommends dose based on some modification to actual processing data) dosimeter results. A copy of each form originated by HEDP staff is provided to HRRP staff for their use in tracking the receipt of needed information from the respective contractor organizations. This form is originated only by HEDP staff. Hanford contractor dosimetry organizations must still complete the Investigation of Dosimeter Results (IODR) form for each situation of abnormal dosimeter results describing the dose to be recorded for the individual. Contractors continue to use the IODR form to document any evaluation conducted by them.

Facility Calibration Factor - Facility or job specific calibration factors can be used with the new dosimetry system. Presently, the factor is used for neutron radiation. The more conservative ${ }^{252} \mathrm{Cf}$ calibration algorithm will be used unless HEDP staff are notified specifically to use the $\mathrm{PuF}_{4}$ algorithm. This algorithm is based on measurements conducted at the PFP during the past year (Endres et al. 1995).

\subsection{DOCUMENTATION}

All documentation for the HEDP was updated during 1994 in preparation of implementation of the new dosimetry system. A summary of all project manuals follows: 
1. PNL-MA-568. Hanford External Dosimetry Project Manual. Pacific Northwest Laboratories, Richland, Washington (internal manual).

2. PNL-MA-583. Location of Criticality Alarms and Nuclear Accident Dosimeters at Hanford. Pacific Northwest Laboratories, Richland, Washington (internal manual).

3. PNL-MA-841. Hanford External Dosimetry Project Procedures Manual. Pacific Northwest Laboratories, Richland, Washington (internal manual).

In addition, a fourth document is scheduled for publication in early 1995 as follows:

PNL-MA-842. Hanford External Dosimetry Project Technical Basis Manual. Pacific Northwest Laboratories, Richland, Washington (internal manual).

The HEDP Quality Assurance Plan, LSC-022, (a) was also formally issued during 1994.

\subsection{PROJECT-RELATED PROFESSIONAL ACTIVITIES}

Staff presentations, publications, and professional memberships during 1994 are listed in this section.

\subsubsection{Presentations}

A. W. Endres, L. W. Brackenbush, and W. V. Baumgartner. 1994. Site Specific Calibration of the Hanford Personnel Neutron Dosimeter. PNL-SA-24010, Pacific Northwest Laboratory, Richland, Washington.

J. J. Fix, E. S. Gilbert, and W. V. Baumgartner. 1994. Estimates of Bias and Uncertainty in Recorded External Dose. PNL-SA-24011, Pacific Northwest Laboratory, Richland, Washington.

B. A. Rathbone, A. W. Endres, and E. J. Antonio. 1994. Evaluation of New and Conventional Thermoluminescent Phosphors for Environmental Monitoring Using Automated Thermoluminescent Dosimeter Readers. PNL-SA-24009, Pacific Northwest Laboratory, Richland, Washington.

\subsubsection{Publications}

Fix, J. J., E. S. Gilbert, and W. V. Baumgartner. 1994. An Assessment of Bias and Uncertainty in Recorded Dose From External Sources of Radiation For Workers at the Hanford Site. PNL-10066, Pacific Northwest Laborațory, Richland, Washington.

(a) Internal manual, LSC-022, Quality Assurance Plan for Hanford External Dosimetry Project, Pacific Northwest Laboratory, Richland, Washington. 


\subsubsection{Professional Memberships}

Endres, A. W., and J. J. Fix. Members of DOE ad hoc working group to develop extremity dosimeter performance standard.

Fix, J. J. Member of DOE Comprehensive Epidemiologic Data Resource status group.

Fix, J. J. Member of DOELAP Oversight Board as identified in DOE Order 5480.15, "Department of Energy Laboratory Accreditation Program for Personnel Dosimetry."

Fix, J. J. Member of DOE ad hoc working group to revise DOELAP personnel dosimeter performance standard.

Fix, J. J. Voting member of Health Physics Society Standards Committee.

Fix, J. J. Consultant to ANSI N13.29, "American National Standard for Dosimetry - Environmental Dosimetry Performance Criteria for Testing."

Rathbone, B. A., and J. J. Fix. DOELAP Technical Assessors. 


\subsection{HANFORD INTERNAL DOSIMETRY PROJECT}

The Hanford Internal Dosimetry Project (IDP) was initiated in 1946 to provide for the assessment and documentation of occupational doses from intakes of radionuclides at the Hanford Site. The program is administered in support of Hanford radiation protection programs, as required by DOE 5480.11, "Radiation Protection for Occupational Workers" (DOE 1990a); the Hanford Site Radiological Control Manual, HSRCM-1 (RL 1994); and the "Hanford Site Services Handbook" (RL 1993) (through 1994). The project provides the following internal dosimetry services:

- administration of a routine bioassay monitoring program

- investigation and assessment of potential internal exposures

- monitoring performance of the excreta bioassay laboratories

- selection and application of models, procedures, and practices for evaluating internal exposures

- technical support to RL and to Site contractors

- 24-hour, single-point-of-contact technical support for radiological incidents at Hanford.

\subsection{ROUTINE TASKS}

Intakes of radionuclides are generally prevented by containment or other protective measures; therefore, intakes are generally assumed to result from an acute intake. Dose assessment is based on this assumption, although, historically, exceptions occurred for work with tritium and uranium. Tritium intake is generally assumed to occur chronically throughout the period of exposure, and urine samples are generally obtained at the beginning and ending of discrete work periods.

For years, chronic exposure conditions were also assumed for uranium work. However, with the changing mission at Hanford, increased emphasis on reducing intakes, and reduction of sources of contamination in buildings, the assumed nature of exposure to uranium changed. Many Westinghouse Hanford Company (WHC) workers were placed on quarterly, as opposed to monthly, uranium urinalysis because they rarely entered uranium contaminated zones. Their urinalysis results were interpreted assuming a possible acute intake. The Uranium Trioxide $\left(\mathrm{UO}_{3}\right)$ Plant had a processing campaign (Phase I Deactivation) underway from the start of the year until early March 1994. Workers involved in that campaign were placed on a frequency of every three weeks, and any observed activity was assumed to be from chronic intake. Otherwise, acute intakes were assumed for any potential uranium intakes. 
Other operational aspects of the IDP are described in the following documents:

- the technical aspects of internal dose calculations are established in the Technical Basis for Internal Dosimetry at Hanford, Rev. 1 (Sula, Carbaugh, and Bihl 1991)

- the protocols and practices for operation of the project and coordination with the Site contractors are established in the Hanford Internal Dosimetry Project Manual. ${ }^{\text {(a) }}$ Revision 1 of this document was issued in January 1994.

- detailed procedures are contained in the Hanford Internal Dosimetry Procedures Manual ${ }^{(b)}$; although many of the procedures in this manual were not applicable during 1994 because of the switch from the Occupational Radiation Exposure (ORE) system to the Radiological Exposure (REX) database in April 1993. The procedures manual was being completely revised during 1994, including a completely new format, as part of a 2-year effort to enhance Quality Assurance aspects of the IDP (see Section 3.3.3).

- the technical agreements with the excreta lab are established by a Statement of Work (SOW).

The practices and technical aspects of operating the Hanford Whole Body Counting Project are established in the Whole Body Counting Manual, ${ }^{(\mathrm{c})}$ and the "In Vivo Bioassay Statement of Work." (d) Individual assessments of internal dose are documented in each individual's file in the Hanford Radiological Records Project (HRRP) files. Bioassay measurement results and internal doses are maintained in the REX database, which is operated by the HRRP.

Some facility operations that potentially impacted the IDP during 1994 are listed below.

- A new prime contractor, the Environmental Restoration Contract team (ERC) - a consortium headed by Bechtel Hanford Incorporated, officially started work in July 1994. Some of the cleanup work, and associated workers, formerly performed by WHC was transferred to the ERC team. The dosimetry needs for the ERC team were handled by Thermo Analytical, Inc., one of the consortium companies.

- WHC became responsible for the dosimetry needs of Kaiser Engineers Hanford Company (KEH).

- The cleanup and deactivation of the Uranium Trioxide Plant and the 203A at PUREX resulted in ceasing bioassay requirements for those facilities in June 1994.

(a) Internal manual, PNL-MA-552, Pacific Northwest Laboratory, Richland, Washington.

(b) Internal manual, PNL-MA-565, Rev. 0, Pacific Northwest Laboratory, Richland, Washington.

(c) Internal manual, PNL-MA-574, Pacific Northwest Laboratory, Richland, Washington.

(d) T. P. Lynch, J. A. MacLellan, and D. E. Bihl. 1992. "In Vivo Bioassay Statement of Work." (A copy is available in the Hanford Radiation Protection Historical Files.) 
- Phase I Deactivation of N-Cell at PUREX was underway during 1994 (and was completed in early 1995).

- Sludge stabilization at the Plutonium Finishing Plant (PFP) began in November 1994. Sludge stabilization is a process that thermally stabilizes containers of reactive plutonium-bearing scrap, converting the plutonium to plutonium oxide.

\subsubsection{Bioassay Capabilities}

Bioassay monitoring is performed regularly for workers who might inhale, ingest, or absorb radionuclides into their bodies in the course of their jobs. Measurement types and frequencies are based on the radionuclides of concern and their anticipated physical and chemical form. Minimum detectable activities (MDAs) and followup levels for routine excreta and in vivo bioassay measurements are shown in Tables 3.1 and 3.2. MDAs for other categories of excreta analyses are shown in Table 3.3. All values in the tables remained unchanged since 1992. A new routine excreta analysis was added to the list, for ${ }^{232} \mathrm{Th}$, because of some anticipated work with thorium at Pacific Northwest Laboratory (PNL).

The first use of the Low Energy Photon Detector (LEPD) analysis for ${ }^{241}$ Am occurred in response to a potential plutonium intake incident in December 1994. Fecal samples analyzed by the LEPD method are first compressed into a standard geometry container while still in the plastic collection bag, and then direct counted on a thin-window, lithium drifted germanium [GeLi] detector. The $\mathrm{x}$-ray spectrum is analyzed to determine the ${ }^{241} \mathrm{Am}$ content of the sample. Use of the LEPD analysis is recommended in the Hanford Site Internal Contamination Incident Response Plan as a rapid, early indication of the severity of an intake of plutonium or americium:

\subsubsection{Excreta Bioassay Contract Activities}

An Independent Review and Advisory Panel (IRAP) was established in 1992 to provide periodic peer review of the Analytical Support Services Project (ASSP) of the PNL Office of Hanford Environment (OHE). ASSP provided the interface between PNL and the outside analytical firms that perform the measurements for PNL sample collection and analysis tasks, of which International Technology Analytical Services (ITAS) was one. In August of 1992, the IRAP completed a report on ASSP operations, with 14 recommendations for improvement applicable to IDP. In February of 1994, the Personnel Dosimetry Section was given the opportunity to respond to each recommendation. The Upper Management Oversight Committee for OHE recommended in March 1994 that further peer review be suspended until a significant portion of the recommendations had been implemented. The most significant response to the review applicable to IDP was the initiation of informal weekly meetings with the ITAS project manager to discuss problems and concerns. These meetings have played an important role in improving ITAS' performance over the last year. ITAS completed bioassay analyses in a timely manner throughout 1994.

ITAS reported and later corrected a contamination problem in the uranium laboratory. Changes in the laboratory ventilation system had disturbed old uranium containing dust. ITAS also reported that commercial software it had used for alpha spectrometry since the beginning of the contract produced 
Table 3.1. Specified Minimum Detectable Activities and Screening Levels for Routine Excreta Analyses During 1994

\begin{tabular}{|c|c|c|}
\hline Analysis $^{(a)}$ & $\begin{array}{l}\text { Contractual } \\
\mathrm{MDA}^{(\mathrm{b}, \mathrm{c})}\end{array}$ & $\begin{array}{l}\text { Screening Level and } \\
\text { Sampling Frequency }{ }^{(\mathfrak{c}, d)}\end{array}$ \\
\hline${ }^{238} \mathrm{Pu},{ }^{239} \mathrm{Pu}$ & $0.02 \mathrm{dpm}$ & $0.01 \mathrm{dpm}(\mathrm{A})$ \\
\hline${ }^{90} \mathrm{Sr}$ & $10 \mathrm{dpm}$ & $\begin{array}{l}26 \mathrm{dpm}(\mathrm{A}) \\
11 \mathrm{dpm}(\mathrm{BE})\end{array}$ \\
\hline${ }^{234} U^{(e)},{ }^{238} U$ & $0.02 \mathrm{dpm}$ & $0.15 \mathrm{dpm}(\mathrm{A}, \mathrm{Q})^{(\mathrm{t})}$ \\
\hline${ }^{235} \mathrm{U}$ & $0.02 \mathrm{dpm}$ & $\begin{array}{l}0.01(\mathrm{~A}) \\
0.02 \mathrm{dpm}(\mathrm{Q})\end{array}$ \\
\hline${ }^{241} \mathrm{Am},{ }^{242} \mathrm{Cm}$ & $0.02 \mathrm{dpm}$ & $0.01 \mathrm{dpm}(\mathrm{A})$ \\
\hline${ }^{228} \mathrm{Th},{ }^{230} \mathrm{Th},{ }^{232} \mathrm{Th}$ & $0.10 \mathrm{dpm}$ & $\begin{array}{l}0.05 \mathrm{dpm} \\
\text { (not established) }\end{array}$ \\
\hline Elemental U & $0.06 \mu \mathrm{g}$ & $\begin{array}{l}0.2 \mu \mathrm{g}(\mathrm{Q})^{(\mathrm{f}, \mathrm{g})} \\
0.5 \mu \mathrm{g}(\mathrm{Q})^{(\mathrm{h})}\end{array}$ \\
\hline Elemental U (QUS) & $0.5 \mu \mathrm{g}$ & $\begin{array}{l}11 \mu \mathrm{g}(\mathrm{BW}) \\
1 \mu \mathrm{g}(\mathrm{M})^{(\mathrm{l})} \\
4 \mu \mathrm{g}(\mathrm{M})^{(\mathrm{h})}\end{array}$ \\
\hline Tritium & $20 \mathrm{dpm} / \mathrm{mL}$ & $80 \mathrm{dpm} / \mathrm{mL}^{(\mathrm{j})}$ \\
\hline
\end{tabular}

(a) Analysis of urine samples, unless otherwise indicated.

(b) Specified MDA based on Type I and Type II errors of 5\%, as described in the SOW (a copy is available in the Hanford Radiation Protection Historical Files).

(c) Amount per total sample volume, unless otherwise indicated.

(d) Investigation of a potential internal exposure is performed when this value is exceeded (routine bioassay monitoring frequency: A-annual, BE-biennial, BW-biweekly, M-monthly, Q-quarterly).

(e) The lab cannot discriminate between ${ }^{233} U$ and ${ }^{234} U$ and reports the results as ${ }^{234} U$ (beginning in 1994).

(f) Upper level of expected environmentally derived uranium in urine for the Hanford region.

(g) When this level is exceeded, the worker's results are evaluated at the end of the year for possible chronic intake for some operations and as a possible acute intake for other operations.

(h) When this level is exceeded, an immediate investigation for a possible acute intake is started.

(i) When this level is exceeded, the worker's results are evaluated at the end of the year for possible chronic intake.

(j) Special screening levels are established for short-term tritium work where beginning and ending work samples are obtained instead of monthly routine sampling.

questionable results in some circumstances. Seven isotopic uranium and 21 isotopic plutonium samples ultimately required recalculation, but no cases were found for either element where a reported result differed by more than two standard deviations from the recalculated value, or where the positive result flag changed. 
Table 3.2. Minimum Detectable Activities and Screening Levels for Routine In Vivo Measurements During 1994

\begin{tabular}{lcc}
\hline $\begin{array}{l}\mathrm{MDA}^{(\mathrm{b})} \\
\text { Measurement/Radionuclide }\end{array}$ & $\begin{array}{c}\text { Screening Level } \\
(\mathrm{a})\end{array}$ \\
\hline Whole-Body Count ${ }^{(\mathrm{d})}$ & & \\
& & \\
${ }^{60} \mathrm{Co}$ & 6 & 8 \\
${ }^{154} \mathrm{Eu}$ & 12 & 9 \\
${ }^{137} \mathrm{Cs}$ & 3 & \\
Lung Count & & \\
${ }^{235} \mathrm{U}$ & 0.2 & Any detected \\
${ }^{238} \mathrm{U}$ (by $\left.{ }^{234} \mathrm{Th}\right)$ & 3 & $\begin{array}{c}\text { Any detected } \\
\text { Any detected }\end{array}$ \\
${ }^{241} \mathrm{Am}$ & 0.12 & Am
\end{tabular}

(a) For selected radionuclides. (The detection of radionuclides not listed resulted in follow-up.)

(b) For each in vivo count, the decision levels (approximately half of the MDAs) were reported under "detection limit" to REX, but, in terms of overall detectability for all measurements, these MDAs were still applicable.

(c) Level for which an investigation of internal exposure was considered. Any detected activity above background (i.e., above the decision level) was reported to the IDP.

(d) MDAs apply to the preview counter only; lower MDAs were obtained using the germanium array which is used when activity is first detected using the preview counter.

Implementation of the third-year SOW was delayed by ITAS' inability to provide an adequate costbased accounting system. Such an accounting system is needed to validate any changes in unit prices. Performance testing of the low-level isotopic plutonium procedure was completed. The analysis was approved for routine implementation after an error in the calibration standard prepared by the PNL Analytical Chemistry Laboratory was discovered and corrected. Isotopic thorium urine and fecal analyses were also added to the contract. Unit prices for routine fecal elemental uranium and isotopic plutonium-americium analyses were added to allow quality control testing of fecal analyses at a reasonable cost.

As a means of identifying specific causes for problems with ITAS' bioassay kit delivery and providing appropriate documentation to expedite corrective actions, an inspection of services was conducted by the PNL Process Quality Department in 1993. The inspection included a thorough review of the ITAS scheduling and record keeping functions and an extended surveillance of the ITAS drivers while they delivered and retrieved the bioassay kits. As a result of the inspection, ITAS made significant improvements to their written procedures and committed to improved management oversight of the delivery functions of the contract. All findings were closed after a followup inspection in August 1994. 
Table 3.3. Specified Minimum Detectable Activities for Emergency and Expedited Excreta Bioassay During 1994

\begin{tabular}{|c|c|c|}
\hline \multirow[b]{2}{*}{ Analysis $^{(\mathrm{a})}$} & \multicolumn{2}{|c|}{$\begin{array}{c}\text { MDA } \\
\text { (per sample) }\end{array}$} \\
\hline & Urine & Feces \\
\hline \multicolumn{3}{|l|}{ Emergency Analyses ${ }^{(b)}$} \\
\hline $\begin{array}{l}\text { Isotopic plutonium by alpha spectrometry } \\
\text { Isotopic uranium by alpha spectrometry } \\
{ }^{241} \mathrm{Am} \text { by alpha spectrometry } \\
{ }^{241} \mathrm{Am} \text { by LEPD } \\
\text { Total radiostrontium } \\
\text { Elemental uranium } \\
\text { Tritium }\end{array}$ & $\begin{array}{l}0.5 \mathrm{dpm} \\
1.0 \mathrm{dpm} \\
1.0 \mathrm{dpm} \\
20 \mathrm{dpm} \\
80 \mathrm{dpm} \\
7 \mu \mathrm{g} \\
100 \mathrm{dpm} / \mathrm{mL}\end{array}$ & $\begin{array}{l}9 \mathrm{dpm} \\
12 \mathrm{dpm} \\
20 \mathrm{dpm} \\
20 \mathrm{dpm} \\
450 \mathrm{dpm} \\
8 \mu \mathrm{g} \\
\end{array}$ \\
\hline \multicolumn{3}{|l|}{ Expedited Analyses $^{(\mathrm{d})}$} \\
\hline $\begin{array}{l}\text { Isotopic plutonium by alpha spectrometry } \\
\text { Isotopic uranium by alpha spectrometry } \\
{ }^{241} \mathrm{Am} \text { by alpha spectrometry } \\
{ }^{241} \mathrm{Am} \text { by LEPD } \\
\text { Total radiostrontium } \\
\text { Elemental uranium } \\
\text { Tritium }\end{array}$ & $\begin{array}{l}0.08 \mathrm{dpm} \\
0.12 \mathrm{dpm} \\
0.08 \mathrm{dpm} \\
5 \mathrm{dpm} \\
50 \mathrm{dpm} \\
0.5 \mu \mathrm{g} \\
100 \mathrm{dpm} / \mathrm{mL}\end{array}$ & $\begin{array}{l}3 \mathrm{dpm} \\
4 \mathrm{dpm} \\
6 \mathrm{dpm} \\
5 \mathrm{dpm} \\
150 \mathrm{dpm} \\
5 \mu \mathrm{g} \\
-\end{array}$ \\
\hline
\end{tabular}

\footnotetext{
(a) For the more critical analyses only. The list does not contain all the analyses covered in the contract.

(b) Verbal reporting time was generally within 8 hours after receipt of the sample; reporting times were even shorter for some analyses.

(c) Low Energy Photon Detector; direct counting of $\mathrm{x}$-rays without radiochemical separation.

(d) Verbal reporting time was by 9:00 a.m. on the second business day after receipt of the sample.
}

ITAS announced that they and Corning would merge their analytical operations into a new, jointly held corporation. The new corporation (Quanterra) was formed, but novation of the contract to Quanterra was withheld pending legal approval. Battelle's contract for bioassay analytical services is still with ITAS, but the actual work is now done by Quanterra.

\subsubsection{Excreta QC Oversight Program}

Two quality control reports were completed in 1994. The first report covered fiscal year (FY) 1993, continuing the history of having reports cover the government's fiscal year. The reporting period of what normally would have been the FY 1994 report was shortened so that, in the future, the reporting period would cover the same period as the quality control data reported in ITAS' quality control report. Hence, the second report covered October 1, 1993, through June 30, 1994. 
A total of 454 urine samples with known amounts of various radionuclides (blanks and spikes) were submitted to ITAS by IDP during the 21 months covered by the two reports. (a) The samples were used to check the accuracy, precision, and detection levels of their urinalyses for tritium, ${ }^{90} \mathrm{Sr},{ }^{238} \mathrm{Pu}$, ${ }^{239} \mathrm{Pu},{ }^{241} \mathrm{Am},{ }^{234} \mathrm{U},{ }^{235} \mathrm{U},{ }^{238} \mathrm{U}$, and elemental uranium analyses. No quality control fecal samples were submitted to ITAS during the reporting period.

Results from the single blind (Oak Ridge National Laboratory intercomparison) samples and double blind (PNL quality control [QC]) samples did not show any appreciable differences, and were combined for statistical analysis. The QC samples submitted during the report period represented about 3\% of the total samples submitted. This is down slightly from the FY 1992 samples submitted (4\%).

In addition to the samples provided by IDP, ITAS was also required to conduct their own QC program and submit the results of analyses to IDP. ITAS' reported performance in analyzing for tritium, ${ }^{90} \mathrm{Sr}$, ${ }^{238} \mathrm{Pu},{ }^{239} \mathrm{Pu},{ }^{241} \mathrm{Am}$, and elemental uranium met or exceeded the specifications in the SOW of the contract with ITAS.

The mass of natural uranium was determined by two different methods: quick uranium soluble (QUS) and natural uranium (UNAT). ITAS now uses laser phosphorimetry for both mass uranium analyses, the only analytical difference being the size of the samples submitted (QUS sample size is approximately one-half the UNAT sample size). Because the same size aliquot is taken from each sample, the QUS MDA per sample is expected to be one-half the UNAT MDA. In FY 1993, IDP statistics suggested a problem with ITAS' aliquoting procedure for the more sensitive method. In the second reporting period, both methods exceeded all performance criteria. The aliquoting step of this procedure will receive more attention when the next operational year SOW is in place.

The calculated MDA for the ${ }^{241} \mathrm{Am}$ analyses $(0.03 \mathrm{dpm})$ exceeded the contractual level $(0.02 \mathrm{dpm})$ during the second reporting period. ITAS' calculated value was based on a population of 10 blanks and IDP's on 2 blanks. More blanks will be submitted to ITAS in the coming year to further test the detection sensitivity of the procedure. Failure of this criterion is not considered crucial to the bioassay program at Hanford because ${ }^{241} \mathrm{Am}$ analyses are generally associated with accidental intakes where the expected ${ }^{241} \mathrm{Am}$ excretion level is higher than the MDA.

WHC dosimetry personnel performed a surveillance of the PNL QC program for evaluating the analysis of Hanford bioassay samples by ITAS. Reviewed were the results of the QC samples and checks on bias and precision. WHC personnel agreed the frequency for single-blind and double-blind samples was sufficient, and PNL's QC program was found to meet the American National Standards Institute (ANSI) recommendations in the draft ANSI performance standard, N13.30 (ANSI 1993). There were no observations or findings identified for program improvement.

(a) In the future, data from the QC oversight program will be analyzed by contract-year, July through June. 


\subsubsection{Project Change Records}

Small-scope changes to the practices or technical aspects of the IDP are documented by Project Change Records. Ultimately, these changes become incorporated into the Technical Basis for Internal Dosimetry at Hanford (Sula, Carbaugh, and Bihl 1991), the Hanford Internal Dosimetry Project Manual, ${ }^{(a)}$ or the Hanford Internal Dosimetry Procedures Manual. ${ }^{(b)}$ The Project Change Record identifies the change, its effective date, and the reasons for and impacts of the change. A copy of the record is placed in the Hanford Radiological Protection Historical Files. Project Change Records issued by the IDP in 1994 are shown in Table 3.4.

\subsubsection{Uranium Bioassay and Uranium Incident-Related Activities}

Dose assessments issued in August 1994 for two workers having high routine uranium urinalysis results initiated a Class $\mathrm{C}$ investigation into work conditions at the 333 Building. The high routine samples were identified independently of each other and the workers subsequently tracked back to the same job. Issues raised included timeliness of reporting, adequacy of facility radiological controls, the dosimetry investigation process, environmental background levels of uranium, and possible augmentations of the uranium bioassay program.

Table 3.4. Project Change Records for 1994

\begin{tabular}{ccll}
\hline $\begin{array}{c}\text { PCR } \\
\text { No. }\end{array}$ & $\begin{array}{c}\text { Effective } \\
\text { Date }\end{array}$ & \multicolumn{1}{c}{ Title } & \multicolumn{1}{c}{ Affected Areas of Project } \\
\hline $94-001$ & $08-01-94$ & $\begin{array}{l}\text { New Assumptions for } \\
\text { Uranium at Hanford }\end{array}$ & $\begin{array}{l}\text { Changed default assumption from } \\
\text { chronic to acute intake and } \\
\text { implemented a flowchart for review of } \\
\text { elemental uranium results. }\end{array}$ \\
$94-002$ & $11-11-94$ & $\begin{array}{l}\text { Eliminate Assessment } \\
\text { of Insignificant } \\
\text { Historical Bioassay } \\
\text { Results }\end{array}$ & $\begin{array}{l}\text { Reports of past detectable bioassay } \\
\text { data will not be assessed for internal } \\
\text { dose unless Internal Dosimetry staff } \\
\text { judge the resulting doses as likely to } \\
\text { be pertinent to current employment. }\end{array}$ \\
& $11-16-94$ & $\begin{array}{l}\text { Remove Policy to } \\
\text { Complete Year-End } \\
\text { Evaluations by } \\
\text { February 1 }\end{array}$ & $\begin{array}{l}\text { Eliminated requirement for end-of- } \\
\text { calendar-year preliminary dose } \\
\text { estimates for all open cases. }\end{array}$ \\
\hline
\end{tabular}

(a) Internal manual, PNL-MA-552, Rev. 1, Pacific Northwest Laboratory, Richland, Washington.

(b) Internal manual, PNL-MA-565, Rev 0, Pacific Northwest Laboratory, Richland, Washington. 
At the request of $R L$, a letter report ${ }^{(a)}$ was written to consider alternatives for improving uranium bioassay at Hanford. The report emphasized that there was no single simple solution that will provide sensitive monitoring without a large number of false-positive investigations. Decreasing the number of workers on routine uranium bioassay was considered the most direct method to reduce the number of investigations. The current screening level of $0.2 \mu \mathrm{g} /$ day was concluded to be a reasonable level, pending completion of the uranium background study (described in Section 3.3.1). One potentially valuable new bioassay tool was identified: inductively coupled plasma mass spectrometry analysis for ${ }^{236} \mathrm{U}$, the presence of which would imply uranium of Hanford origin. The technology had been demonstrated in water but a development effort was needed for urinalysis: The IDP provided funding for that development effort by PNL Analytical and Molecular Sciences, with completion expected in 1995.

\subsubsection{CFR 835 Compliance Assessments}

Title 10 Code of Federal Regulations Part 835 (DOE 1993) was published as a final rule on December 14, 1993, with an effective date of January 13, 1994. Full compliance is required by January 1, 1996. During 1994 each contractor was working on a Radiological Protection Plan, which was, in essence, a compliance and implementation plan for 10 CFR 835 and for the previously issued RCM. With agreement from DOE-RL and the Hanford contractors, 10 CFR 835 compliance requirements that fell under the purview of plant-wide dosimetry services were addressed in PNL's Radiological Protection Plan. In 1994 IDP performed a self assessment relative to internal-dosimetry-related requirements in 10 CFR 835 and provided compliance status and corrective actions to PNL's Radiological Control Department for inclusion in the Radiological Protection Plan. Only a few areas of non or partial compliance were identified.

In December 1994 a team from the Hanford contractors, with representatives from WHC, PNL Radiological Control Department, ERC team, and HEHF, audited the IDP and the Whole Body Counting Project as an independent assessment for compliance with 10 CFR 835 and the RCM. For the IDP, no non or partial compliance issues were discovered beyond those already identified through the prior self assessment.

\subsubsection{Prioritizing Reevaluations}

Hanford internal dose cases with committed effective dose equivalents (CEDEs) in excess of 5 rem were prioritized for reevaluation in response to a concern expressed by DOE-Nuclear Safety. Five priorities for reevaluation were established for the total of 59 cases exceeding the 5-rem criterion. The categories, listed in descending order of priority and with the number of cases included were as follows:

1) specially requested by contractor dosimetry organizations (no cases)

(a) Letter report by E. H. Carbaugh, October 1994, entitled, "Issues and Options for Uranium Bioassay at Hanford." 
2) workers for whom a factor of two increase in an assigned CEDE would cause them to exceed their lifetime control level (4 cases)

3) workers exceeding their lifetime control level and for whom the CEDE is a major contributor to lifetime dose ( 8 cases)

4) workers for whom a factor of two increase in an assigned CEDE would not cause them to exceed their lifetime control level (18 cases)

5) workers for whom the assigned CEDE has little impact on their lifetime control level or who have large CEDEs but little or no likelihood for additional future exposure (29 cases).

IDP plans to have all the reevaluations completed by 1998 . A recommendation regarding the need for an additional five-year reevaluation will be included in each reevaluation.

\subsection{MONITORING AND ASSESSMENT ACTIVTTIES}

The IDP excreta bioassay monitoring and internal dose assessment activities during 1994 are summarized in this section. The Whole Body Counting Project and its associated statistics are discussed in Chapter 4.0, "Hanford Whole Body Counting Project."

\subsubsection{Excreta Bioassay Monitoring Activities}

Sample requests can be categorized as standard or nonstandard. Standard requests are those generated by REX from a predetermined, routine schedule (e.g., a worker may be scheduled for an annual sample collected every April). These requests are downloaded from REX and electronically transferred to the ITAS laboratory just before the start of each month. All other requests are considered nonstandard requests. Contractors and IDP enter the nonstandard requests into REX manually. IDP staff check the nonstandard request file in REX for input errors and perform the electronic transfer of the requests to the laboratory. Figure 3.1 shows the monthly distribution of standard and nonstandard requests for 1994. A total of 9010 samples were requested in 1994, down 1\% from the 1993 requests. Even though the number of samples requested was approximately the same as in 1993, the graph in Figure 3.1 indicates a slight downward trend toward the end of the year. The majority of the samples (62\%) were standard requests, with $38 \%$ being nonstandard. The respective percentages in 1993 were $57 \%$ and $43 \%$.

During FY 1994, 8321 excreta bioassay measurements were successfully performed in support of Hanford activities, excluding cancellations, no-samples, samples without valid results, and QC samples. Of these, $96 \%$ were classified as routine (including measurements on visitors) and $4 \%$ were due to special circumstances, such as response to unplanned potential intakes or followup analyses to high routine measurements. 


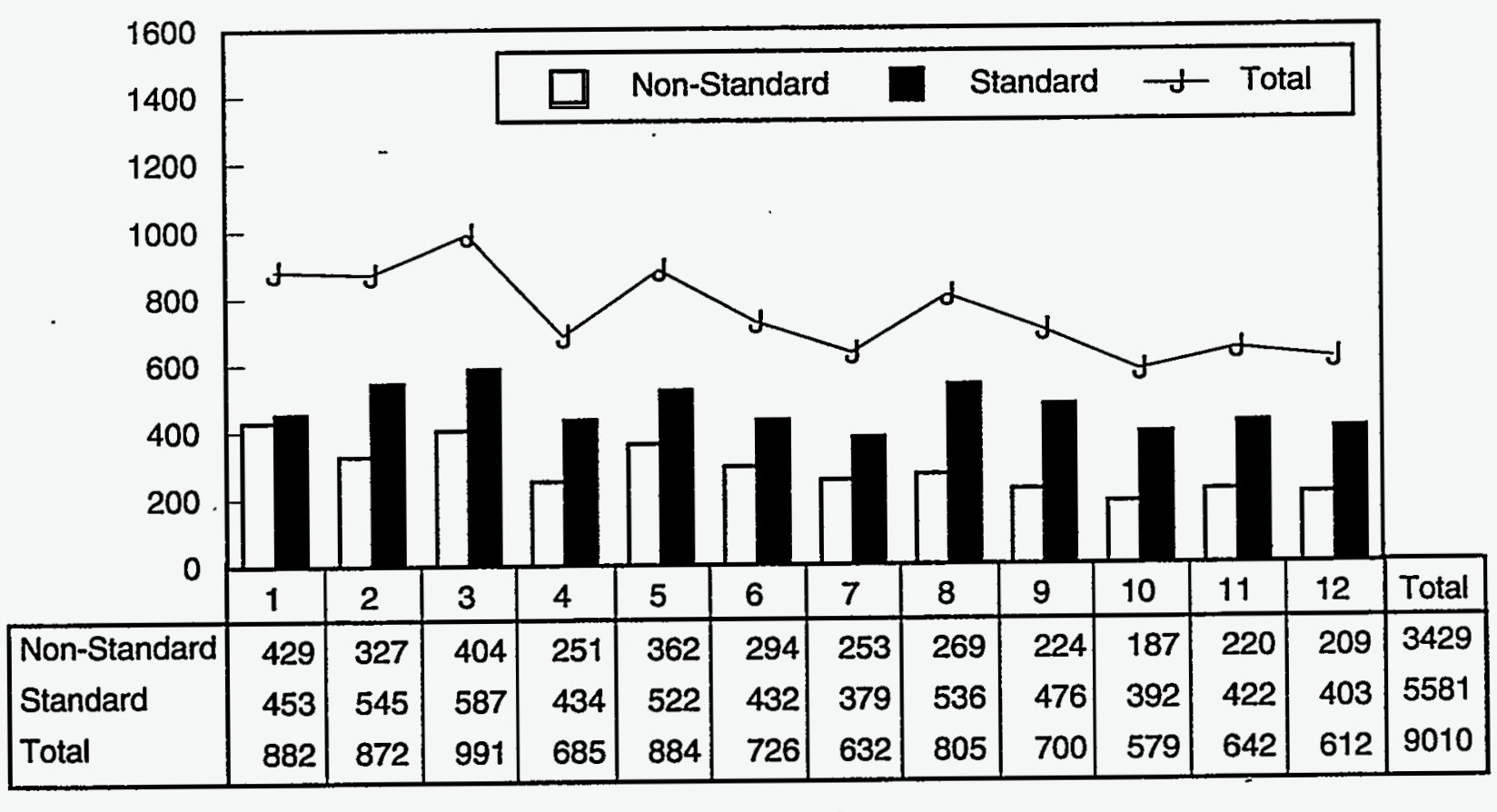

1994

$\$ 9504057.4$

Figure 3.1. Standard and Nonstandard Excreta Requests by Month

The 1994 excreta results statistics are summarized in Table 3.5. The total number of measurements remained essentially the same. However the totals reflect the redistribution of the work force from WHC and KEH in 1993 to WHC, KEH, and ERC in 1994.

As depicted in Figure 3.2, the routine urine measurement trends reported in 1993 continued into 1994. The number of routine transuranic (plutonium, americium and curium) urine measurements has remained fairly stable since 1991 . The number of uranium analyses continued to increase, increasing $7 \%$ over 1993 . The number of tritium and strontium analyses continue to decrease, $48 \%$ and $18 \%$ respectively. Overall, there was a $1.5 \%$ decrease over 1993 in the total number of routine measurements.

In addition, a total of 1269 excreta sample analysis requests were designated as no-result samples for 1994. Unsuccessful sample collections (their associated no-result code and percentage of the total no-results) were attributed to the following causes: kit not delivered (ND, 8\%), no sample received (NS, 20\%), lost container (LC, 50\%), insufficient sample volume (IS, 14\%), and lost in lab (LL, 8\%).

The unsuccessful-sample retrieval rate of $14 \%$ for 1994 was significantly lower than the rate for the preceding year (23\%). The decrease in the unsuccessful-sample rate can be attributed to the analytical support laboratory gaining more experience with the home sample kit delivery system and a concerted effort on the part of the contractors' and IDP bioassay schedulers and the analytical laboratory. 
Table 3.5. Worker Excreta Measurements Reported for 1994 Samples

\begin{tabular}{|c|c|c|c|c|c|c|c|}
\hline Type/Reason & DOE & $\mathrm{KEH}$ & PNL & WHC & ERC & Other & Total \\
\hline \multicolumn{8}{|l|}{${ }^{3} \mathrm{H}$-urine } \\
\hline Routine schedule $\mathrm{e}^{(\mathrm{a})}$ & 0 & 12 & 275 & 37 & 0 & 10 & 334 \\
\hline Special request ${ }^{(b)}$ & 0 & 1 & 1 & 14 & 0 & 0 & 16 \\
\hline \multicolumn{8}{|l|}{${ }^{90} \mathrm{Sr}$} \\
\hline Routine schedule & 9 & 159 & 36 & 795 & 7 & 23 & 1029 \\
\hline Special request & 0 & 2 & 0 & 8 & 0 & 0 & 10 \\
\hline \multicolumn{8}{|l|}{ Uranium-urine } \\
\hline Routine schedule & 34 & 1067 & 156 & 2109 & 33 & 95 & 3494 \\
\hline Special request & 0 & 52 & 39 & 57 & 4 & 0 & 152 \\
\hline \multicolumn{8}{|l|}{ Plutonium-urine } \\
\hline Routine schedule & 28 & 560 & 266 & 2070 & 17 & 47 & 2988 \\
\hline Special request & 0 & 23 & 15 & 66 & 0 & 0 & 104 \\
\hline \multicolumn{8}{|l|}{ Other TRU-urine } \\
\hline Routine schedule & 0 & 64 & 74 & 18 & $\mathbf{0}$ & 0 & 156 \\
\hline Special request & 0 & 14 & 3 & 5 & 0 & 0 & 22 \\
\hline \multicolumn{8}{|l|}{ Plutonium-fecal } \\
\hline Routine schedule & 0 & 0 & 0 & 2 & 0 & $\mathbf{0}$ & 2 \\
\hline Special request & 0 & 0 & 1 & 13 & 0 & 0 & 14 \\
\hline Analyses Totals & 71 & 1954 & 866 & 5194 & 61 & 175 & 8321 \\
\hline \multicolumn{8}{|l|}{ Recounts or Reanalysis } \\
\hline Plutonium - urine & 0 & 12 & 8 & 36 & 0 & 0 & 56 \\
\hline${ }^{90} \mathrm{Sr}$ - urine & 0 & $\mathbf{0}$ & 0 & 0 & 2 & 0 & 2 \\
\hline${ }^{3} \mathrm{H}$ - urine & $\mathbf{0}$ & 0 & 0 & 0 & 0 & 0 & 0 \\
\hline Uranium - urine & 0 & 18 & 23 & 20 & 1 & 0 & 62 \\
\hline Other - urine & 0 & 8 & 2 & 0 & 0 & 0 & 10 \\
\hline
\end{tabular}

(a) Routine measurements include those with reason codes of routine (PR), baseline (BL), contractor request (CR), ending work (EA) and termination (TM).

(b) Special measurements include those with reason codes of special (SP), recount (R1 or $R 2$ ) and reanalysis (RA or $R B)$. 


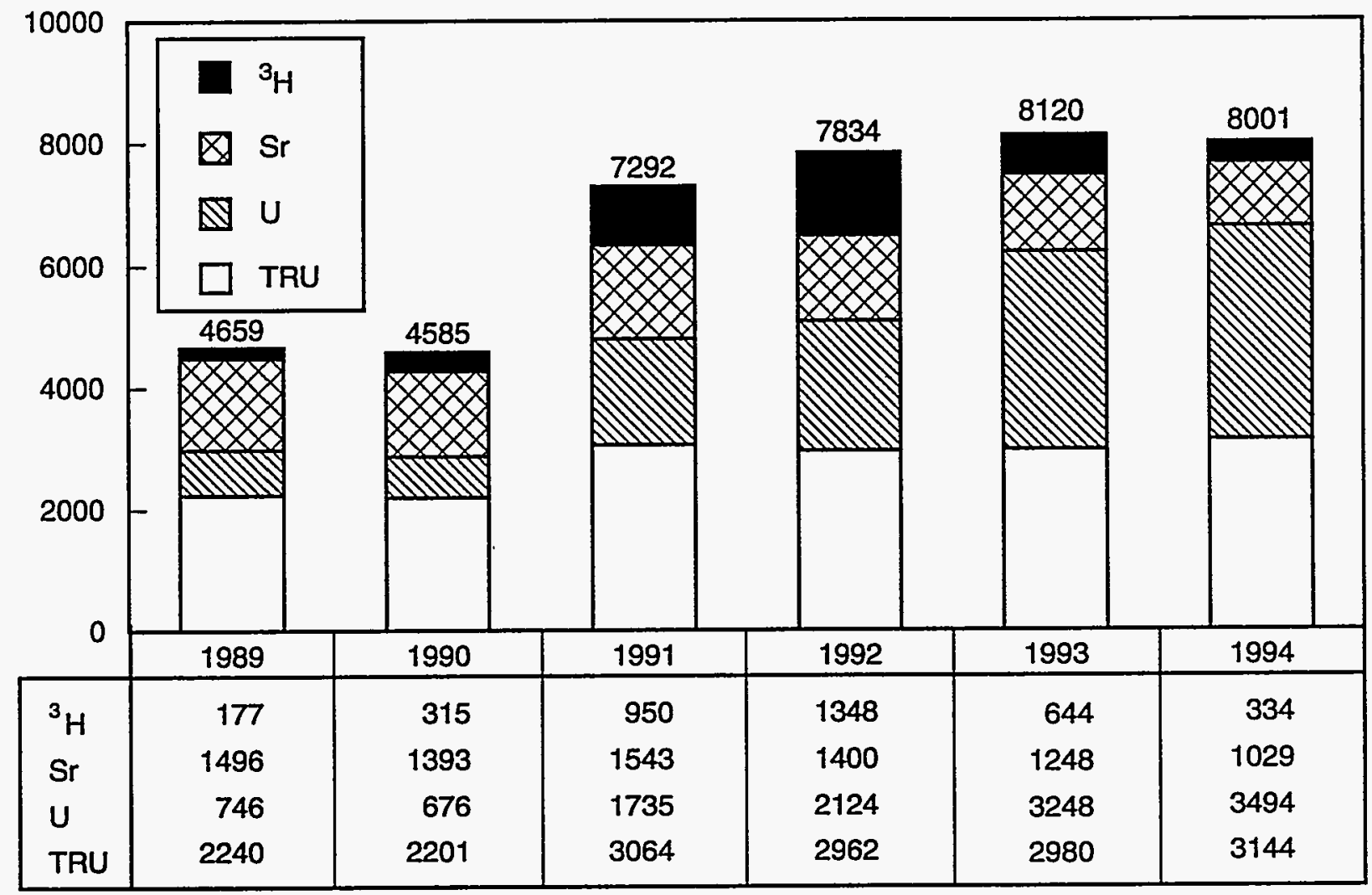

S9504057.3

Figure 3.2. Routine Urine Measurements Made from 1989 Through 1994

\subsubsection{Potential Intake Evaluations}

Investigations of possible radionuclide intakes are performed following an indication from a routinely scheduled bioassay measurement or for a potential exposure incident identified in the workplace.

Potential exposure incidents are identified by workplace indicators such as air sampling, contamination surveys, nasal smears, or smears from potentially contaminated wounds. Specially requested bioassay measurements are also performed at the request of workers through the contractor dosimetry group.

During FY 1994, 19 incidents with the potential for intake, involving 33 workers, were identified through workplace monitoring. Of the workers involved in the incidents, no confirmation of intake was determined for 26 workers, and intakes were confirmed for 7 workers. The highest calculated dose among the 7 workers was 210 mrem CEDE. The radionuclides and groups involved included ${ }^{137} \mathrm{Cs}$ and/or ${ }^{90} \mathrm{Sr}$ (13 incidents with 23 workers), TRU (4 incidents with 8 workers), U (1 incident with 1 worker), and tritium ( 1 incident with 1 worker). Table 3.6 shows the incident breakdown by contractor, area, and facility. Trends for the last five years are included in Table 3.7.

Initial evaluations were issued for the following radionuclides or groups: TRU ( 30 cases), ${ }^{137} \mathrm{Cs}$ and/or ${ }^{90} \mathrm{Sr}$ ( 27 cases), U and/or ${ }^{234} \mathrm{Th}$ (91 cases), tritium (1 case), and other radionuclides (13 cases). Of these, 105 cases received no occupational internal doses (i.e., no confirmation of any occupational 
Table 3.6. Summary of Potential Intake Incidents During 1994

\begin{tabular}{|c|c|c|c|c|c|c|}
\hline \multicolumn{2}{|c|}{ Facility } & \multirow[b]{2}{*}{ Custodian } & \multirow{2}{*}{$\begin{array}{c}\text { Number of } \\
\text { Incidents }\end{array}$} & \multirow{2}{*}{$\begin{array}{c}\text { Number of } \\
\text { Workers } \\
\end{array}$} & \multirow{2}{*}{$\begin{array}{c}\text { Worker } \\
\text { Contractor }\end{array}$} & \multirow{2}{*}{$\begin{array}{l}\text { Principal } \\
\text { Nuclide }\end{array}$} \\
\hline Area & ID & & & & & \\
\hline $100 \mathrm{~K}$ & $100 \mathrm{KE}$ & WHC & 2 & 2 & WHC & ${ }^{137} \mathrm{Cs}$ \\
\hline \multirow[t]{5}{*}{$200 E$} & $203-A$ & WHC & 1 & 1 & WHC & ${ }^{239} \mathrm{Pu}$ \\
\hline & 209-E & WHC & 1 & 3 & WHC & ${ }^{137} \mathrm{Cs}$ \\
\hline & 241-AY & WHC & 1 & 1 & WHC & ${ }^{90} \mathrm{Sr}$ \\
\hline & $241-C$ & WHC & 1 & 3 & WHC & ${ }^{137} \mathrm{Cs}$ \\
\hline & $801-8 X A$ & WHC & 1 & 1 & WHC & ${ }^{137} \mathrm{Cs}$ \\
\hline \multirow[t]{4}{*}{$200 W$} & $221-\mathrm{T}$ & WHC & 2 & 3 & WHC & ${ }^{137} \mathrm{Cs}$ \\
\hline & $231-Z$ & WHC & 1 & 3 & WHC & ${ }^{137} \mathrm{Cs}$ \\
\hline & $233-S$ & WHC & 1 & 1 & WHC & ${ }^{239} \mathrm{Pu}$ \\
\hline & $234-5 Z$ & WHC & 1 & 5 & WHC & ${ }^{239} \mathrm{Pu}$ \\
\hline \multirow[t]{4}{*}{300} & 333 & WHC & 1 & 1 & WHC & U-nat \\
\hline & 324 & PNL & 2 & 5 & PNL, KEH & ${ }^{137} \mathrm{Cs}$ \\
\hline & 325 & PNL & 2 & 2 & PNL, KEH & ${ }^{239} \mathrm{Pu},{ }^{137} \mathrm{Cs}$ \\
\hline & 327 & PNL & 1 & 1 & PNL & ${ }^{137} \mathrm{Cs}$ \\
\hline \multirow[t]{2}{*}{$\mathrm{RCHN}$} & LSL & PNL & 1 & 1 & PNL & ${ }^{3} \mathrm{H}$ \\
\hline & & Total & 19 & 33 & & \\
\hline
\end{tabular}

intake), 6 cases are still open, 35 cases received CEDEs less than 100 mrem, and 16 cases received CEDEs greater than 100 mrem. Table 3.8 shows internal dose evaluations for 1994 resulting from high routine-bioassay results (i.e., those not associated with known incidents or known potentialchronic-exposure situations, and exceeding the criteria for investigation).

There were no workers who had been identified as having potential chronic exposures to uranium or tritium.

The range of internal doses assigned to the Hanford work force in 1994 is summarized in Table 3.9.

\subsection{SUPPORTING S'TUDIES}

Special studies and investigations conducted by the Hanford IDP are described in the following subsections. 
Table 3.7. Comparison of Potential Intakes By Reason Code, 1990-1994

\begin{tabular}{|c|c|c|c|c|c|}
\hline & 1990 & 1991 & 1992 & 1993 & 1994 \\
\hline $\begin{array}{l}\text { Incident, Total } \\
\text { Confirmed } \\
\text { Unconfirmed }\end{array}$ & 30 & 90 & 30 & $\begin{array}{l}51 \\
17 \\
34\end{array}$ & $\begin{array}{c}33 \\
7 \\
26\end{array}$ \\
\hline $\begin{array}{l}\text { High Routine, Total } \\
\text { Confirmed } \\
\text { Unconfirmed } \\
\text { Open }\end{array}$ & 93 & 69 & 141 & $\begin{array}{c}65 \\
0 \\
62 \\
3\end{array}$ & $\begin{array}{l}91 \\
14 \\
72 \\
5\end{array}$ \\
\hline $\begin{array}{l}\text { Contractor Request, Total } \\
\text { Confirmed } \\
\text { Unconfirmed }\end{array}$ & 5 & 0 & 0 & $\begin{array}{l}1 \\
1 \\
0\end{array}$ & $\begin{array}{l}3 \\
0 \\
3\end{array}$ \\
\hline $\begin{array}{l}\text { Chronic Exposure, Total } \\
\text { Confirmed } \\
\text { Unconfirmed }\end{array}$ & 95 & 30 & 4 & $\begin{array}{l}6 \\
0 \\
6\end{array}$ & $\begin{array}{l}0 \\
0 \\
0\end{array}$ \\
\hline $\begin{array}{l}\text { Pre-Hanford } \\
\text { Confirmed } \\
\text { Unconfirmed } \\
\text { Open }\end{array}$ & - & - & 20 & $\begin{array}{l}3 \\
3 \\
0\end{array}$ & $\begin{array}{c}35 \\
30 \\
4 \\
1\end{array}$ \\
\hline $\begin{array}{l}\text { Reevaluation } \\
\text { Completed } \\
\text { Open }\end{array}$ & 5 & 1 & 4 & $\begin{array}{l}3 \\
0 \\
3\end{array}$ & $\begin{array}{l}10 \\
6 \\
4\end{array}$ \\
\hline $\begin{array}{l}\text { Total }^{(a)} \\
\text { Confirmed } \\
\text { Unconfirmed } \\
\text { Open }\end{array}$ & 223 & 189 & 195 & $\begin{array}{c}126 \\
21 \\
102 \\
3\end{array}$ & $\begin{array}{c}162 \\
51 \\
105 \\
6\end{array}$ \\
\hline
\end{tabular}

(a) Excludes reevaluations

\subsubsection{Uranium Background Study}

Workers are potentially exposed to Class $Y$ depleted or natural uranium. Since trace amounts of uranium are naturally present in urine excretion, the bioassay program must be able to discern occupational exposure from naturally occurring uranium. This requires establishing the range of urinary excretion of uranium from natural sources to which Hanford workers would be exposed. In the spring of 1994, a group of twenty nonoccupationally exposed male Hanford workers from the TriCities and the surrounding areas were asked to provide a simulated 24-hour urine sample and a concurrent sample of their drinking water for analysis. A lognormal probability analysis was performed on the elemental uranium, ${ }^{238} \mathrm{U}$, and ${ }^{234} \mathrm{U}$ urine excretion data.

Preliminary indications based on the first 20 samples indicate that the previously established screening level of $0.2 \mu \mathrm{g} /$ day is appropriate for most individuals, although a small percentage of unexposed workers may significantly exceed the screening level. The use of the ${ }^{238} U$ to ${ }^{234} U$ ratio as a 
Table 3.8. Summary of Confirmed Intake Cases Identified Through the Routine Bioassay Program During 1994

\begin{tabular}{llcccccc}
\hline \multicolumn{2}{c}{ Facility } & \multicolumn{3}{c}{ Number of } & \multicolumn{3}{c}{ Principal } \\
Area & Building & Custodian & Workers & Contractor & Nuclide & Reason \\
\hline 100 & $100 \mathrm{~N}$ & WHC & 1 & WHC & U & High Routine \\
$200 \mathrm{~W}$ & $221 \mathrm{~T}$ & WHC & 1 & ERC & U & High Routine \\
$200 \mathrm{~W}$ & $224 \mathrm{U}$ & WHC & 1 & KEH & U & High Routine \\
$200 \mathrm{~W}$ & $224 \mathrm{U}$ & WHC & 1 & WHC & U & High Routine \\
300 & 325 & PNL & 1 & KEH & U & High Routine \\
300 & 333 & WHC & 1 & KEH & U & High Routine \\
300 & 333 & WHC & 1 & WHC & U & High Routine \\
Unknown & & & 3 & KEH & U & High Routine \\
Unknown & & & 3 & WHC & U & High Routine \\
& & Non-Hanford & 1 & PNL & $137 \mathrm{CS}$ & New Hire \\
\cline { 3 - 7 } & & Total & 14 & & & \\
\hline
\end{tabular}

Table 3.9. Range of Internal Doses Assigned to the Hanford Work Force in 1994

\begin{tabular}{cllllll}
\hline & \multicolumn{6}{c}{ Numbers of Workers } \\
\cline { 2 - 7 } Dose (mrem) ${ }^{(\mathrm{a})}$ & DOE & KEH & PNL & WHC & ERC & Total \\
\hline$<100$ & $1(1)^{(b)}$ & $8(3)$ & $5(3)$ & $19(9)$ & $2(1)$ & $35(17)$ \\
$100-<500$ & 0 & $2(2)$ & $1(1)$ & $7(5)$ & $1(1)$ & $11(9)$ \\
$500-<2000$ & 0 & $1(1)$ & $1(1)$ & $3(2)$ & 0 & $5(4)$ \\
$2000-<5000$ & 0 & 0 & 0 & 0 & 0 & 0 \\
$>5000$ & 0 & 0 & 0 & 0 & 0 & 0 \\
\hline
\end{tabular}

(a) CEDE. Based on 1994 evaluations, although the intake could have occurred in any year.

(b) Number in parenthesis refers to assessed doses due to offsite exposures.

coindicator of Hanford occupational exposure does not appear feasible due to the fact that the natural composition of Hanford uranium cannot be readily distinguished from environmental sources by examining the isotopic analysis. 
Results of correlation analyses between the amount of uranium in the urine sample and the amount of uranium in the drinking water samples show no significant correlation for low concentrations. There was a weak correlation when the uranium in water concentration was high. (A water source effect has been observed in some workers when the uranium in urine exceeded the screening level.) Private well water typically exhibits higher uranium concentrations than large municipal drinking water sources. There does not appear to be a correlation between geographic location of residence within the Yakima River Valley and daily excretion of uranium. This study is continuing into 1995 to determine if there is a seasonal fluctuation in background uranium excretion levels.

\subsubsection{Alternatives for Excreta Bioassay Sample Collection}

A kit delivery-options report was submitted to the HPDAC for review and comment. The report summarized the excreta bioassay kit collection methods used at DOE sites, and evaluated the merits of continuing home kit delivery and retrieval for Hanford workers.

All DOE sites other than Hanford have the worker pick up bioassay kits on site; none have the kit delivered to the worker's home. A majority of other sites use tamper seals on the bioassay kits, even though there is no requirement in Federal regulations, DOE Orders, or other directives for formal chain of custody for bioassay samples. Non-binding standards and guides applicable to dosimetry are also silent on the subject.

The report showed that ITAS was performing at or above the historical norm for the bioassay kit delivery service, and further improvements in the completion rate for bioassay analyses would result only from improved compliance by the workers. Continuation of the present bioassay kit delivery procedure was therefore recommended, although change to an onsite delivery and retrieval system with at home sampling has the potential for savings of about $\$ 40,000$ the first year, and over $\$ 60,000$ per year thereafter. The savings would not be guaranteed, but would be contingent on negotiating appropriate unit-price reductions to correspond with the reduction in services by the analytical contractor. A period with a diminished sample collection rate would be expected during implementation of a new system.

With the present home delivery system, the use of security seals on bioassay kits was not recommended. Experience with the Hanford bioassay program had not identified any incident where tampering with a bioassay kit was suspected. However, the implementation of an onsite bioassay kit distribution procedure was not recommended without an associated security seal procedure. Security seals would be needed to provide evidence of tampering.

The HPDAC tabled further discussion on this topic until preparation for contract renewal begins in 1995.

\subsubsection{Quality Assurance Upgrade}

A two-year effort to upgrade the quality assurance (QA) aspects of the IDP was started in 1994. Accomplishments in 1994 include the writing of a QA guidance document for all site-wide radiological services and performing a QA risk assessment of IDP processes. Both the QA guidance document and 
the risk assessment were intended to provide information to help direct the writing of the IDP-specific QA plan and rewriting of project procedures in 1995. The guidance document provided the overall format and functional areas for the IDP-specific QA plan, and the risk assessment provided the relative importance and risk of failure of each the project's processes to better judge which process or steps in processes needed enhanced QA.

\subsection{PROJECT-RELATED PROFESSIONAL ACTIVITIES}

IDP staff presentations, publications, and professional memberships during 1994 are listed in this section.

\subsubsection{Presentations}

Bihl, D. E. 1994. A Dose-Averted Approach to Intervention Levels for Intakes of Plutonium. PNL-SA-23491 A. Poster presented at the 39th Annual Meeting of the Health Physics Society, June 26-30, San Francisco, California.

Carbaugh, E. H. 1994. Internal Dosimetry at Hanford - Past, Present, and Future. PNL-SA-23577A. Health physics seminar presented at the Savannah River Site, January 31, 1994, Aiken, South Carolina.

Carbaugh, E. H. 1994. Practical Applications of Internal Dose Calculations. PNL-SA-24300. Lecture at the Health Physics Society Summer School on Internal Dosimetry, June 20-24, Davis, California.

Hill, R. L. and E. H. Carbaugh. 1994. Experience in Using Fecal Bioassay Following Accidental Inhalation of Plutonium. PNL-SA-23546, Presented at the 39th Annual Meeting of the Health Physics Society, June 26-30, San Francisco, California.

Long, M. P, E. H. Carbaugh, and N. L. Fairrow. 1994. Practical Issues In Discriminating Between Environmental And Occupational Sources In A Uranium Bioassay Program. PNL-SA-24340.

Presentation at the 40th Annual Conference on Bioassay, Analytical, and Environmental Radiochemistry, November 13-17, Cincinnati, Ohio.

MacLellan, J. A. 1994. A Feasibility Study of Work Group Monitoring for Hanford. PNL-SA-2381-A. Presented at the 39th Annual Meeting of the Health Physics Society, June 26-30, San Francisco, California.

\subsubsection{Publications}

Carbaugh, E. H. 1994. "Practical Applications of Internal Dose Calculations." Chapter 24 of Internal Radiation Dosimetry, Otto G. Raabe, ed. Medical Physics Publishing, Madison, Wisconsin. 
Carbaugh, E. H., D. E. Bihl, J. A. MacLellan, and M. P. Long. 1994. Hanford Internal Dosimetry Project Manual. PNL-7001, Rev 1. Uncontrolled document version of PNL-MA-552. Pacific Northwest Laboratory, Richland, Washington.

MacLellan, J. A. 1994. A Feasibility Study of Work Group Monitoring for Hanford. PNL-9468, Pacific Northwest Laboratory, Richland, Washington.

Selby, J., M. M. Lardy, E. H. Carbaugh, T. P. Lynch, and D. J. Strom. 1994. "Internal Dosimetry Monitoring Equipment - Present and Future." Radiation Protection Dosimetry, 53(1):49-58.

Internal Dosimetry Programs for Tritium Exposure - Minimum Requirements, HPS N13.14-1994. Health Physics Society, MacLean, Virginia. (E. H. Carbaugh was a member of the committee that wrote this document.)

\subsubsection{Professional Memberships}

Bihl, D. E. Chair ANSI Standards Committee N13.39, Internal Dosimetry Programs.

Carbaugh, E. H. Member ANSI Standards Committee N13.25, Internal Dosimetry Standards for Plutonium.

MacLellan, J. A. Member ANSI Standards Committee N13.30, Performance Criteria Against Which Rabiobioassay Laboratories Will Be Tested.

MacLellan, J. A. Chair of the American Academy of Health Physics Nominating Committee. 


\subsection{HANFORD WHOLE BODY COUNTING PROJECT}

The Hanford Whole Body Counting Project (WBCP) (called the Hanford In Vivo Measurement Program in previous annual reports) has been an integral part of worker radiation protection for the Hanford Site since 1959. As part of the Hanford Site Services Program operated by Pacific Northwest Laboratory (PNL), the project provides for the detection of radionuclides from Hanford activities in workers by direct (in vivo) measurement, and the associated management, operation, and maintenance of the in vivo facilities and equipment on site. The project operates and maintains equipment in the 747-A building, the 747-A Trailer-1 (a mobile whole body counting trailer), and the Emergency Decontamination Facility (EDF) located next to Kadlec Hospital in Richland, Washington. Collectively, the facilities are known as the In Vivo Radioassay and Research Facility (IVRRF). Project requirements for the WBCP are outlined in the Whole Body Counting Manual ${ }^{(\mathrm{a})}$ and the "Hanford Site Services Handbook" (Ri 1993) (through 1994).

The activities of the project, which include routine measurements of Hanford workers, special request studies, and measurement instrumentation development work are described in this chapter. The primary function of the WBCP is to provide accurate, highly sensitive, well-documented, and timely measurements of workers potentially exposed to radionuclides encountered from occupational sources at Hanford. The quantification of potential intakes of radioactive material provides the Hanford Internal Dosimetry Project (DP) with measurement data which is used to derive dose estimates. All measurement results and calibration data are transmitted as permanent records to the Hanford Radiological Records Project (HRRP), and are stored on the REX database. Information copies of the measurement records are kept on file at the IVRRF.

The routinely used measurement facilities at the IVRRF include the Preview Counter (used for rapid screening, whole-body measurements); the Iron Room, Stainless Steel Room, and Lead Room (each containing germanium lung counting systems); and the Palmer Room (containing the scanning germanium whole body counter). Operating hours are currently from 7:30 a.m. to 4:00 p.m. on weekdays. For special requests, additional hours can be scheduled to cover off-shift or after-work counts. The facilities and equipment are also available on an on-call basis for incident response during off-hours.

\subsection{ROUTINE WBC TASKS}

Routine activities of the WBCP for 1994 included project management, technical services for direct radiobioassay, equipment maintenance, data processing, and quality assurance support.

(a) Internal Manual, PNL-MA-574, Pacific Northwest Laboratory, Richland, Washington. 


\subsubsection{Routine In Vivo Radiobioassay}

Many different types of direct bioassay measurements are performed for the work force at the Hanford Site. Both routine (periodic) measurements and special request or incident analyses are supported. Frequency of these measurements for occupational workers is determined by DOE requirements and/or limits for radiation exposure. The frequency of measurements for personnel is governed by the contractor internal dosimetry representatives. The Hanford Environmental Health Foundation (HEHF) schedules routine measurements with the IVRRF using the Hanford Health Scheduling system, a computerized scheduling system that reports a daily roster of personnel scheduled to be counted.

The type of measurement is determined by the exposure scenario or the physiological location of a potential intake. Generally, if an employee does not work in areas where uranium or transuranium (TRU) radionuclides are located, a whole-body count (WBC) is performed on the Preview Counter to detect the higher-energy gamma rays emitted by fission products or activation products. Verification of any positive result is performed with the scanning coaxial germanium system, in order to quantify the activity of mixed fission-activation products in the body. Figure 4.1 depicts the scanning coaxial germanium system.

If the work involves transuranium (TRU) radionuclides or insoluble uranium isotopes, both lung and whole-body counts are completed. Radioactivity that is detected by either of these measurements is verified by a second count. Several other types of counts may also be done to provide more accurate quantification and localization of the intake.

All of the routine counting systems are interfaced to Acquisition Interface Modules which are connected by a local area network (LAN) to two Digital Equipment Corporation (DEC) Model 3100 workstations. The workstations control the counting functions and retrieve the completed data. Computer codes developed at PNL are used to evaluate each spectra result collected with the in vivo measurement. Additional commercial software residing on the DEC Model 3100 workstations (Genie System Spectroscopy Applications) obtained from Canberra Industries and written for VAX/VMS can be used to analyze spectra. The VAX workstations are in turn interfaced by LAN to an IBM RISC 6000 minicomputer that operates as a database for all IVRRF measurement results. The database also sends results to the REX system database.

\subsubsection{Data Administration}

Data administration for the IVRRF provides for the maintenance of the computer hardware and software related to the analysis and storage of in vivo measurement results. Verification of PNLdeveloped software that is run on the computer platforms used at the IVRRF is also performed. New software written to augment and replace existing algorithms is verified, validated, and documented prior to routine use. Repair or replacement of computer hardware or components is also performed. Database management is performed at IVRRF to store, archive, backup, and analyze all measurements. The database currently runs Oracle ${ }^{\text {th }}$ software, and backups are performed both daily and weekly. 


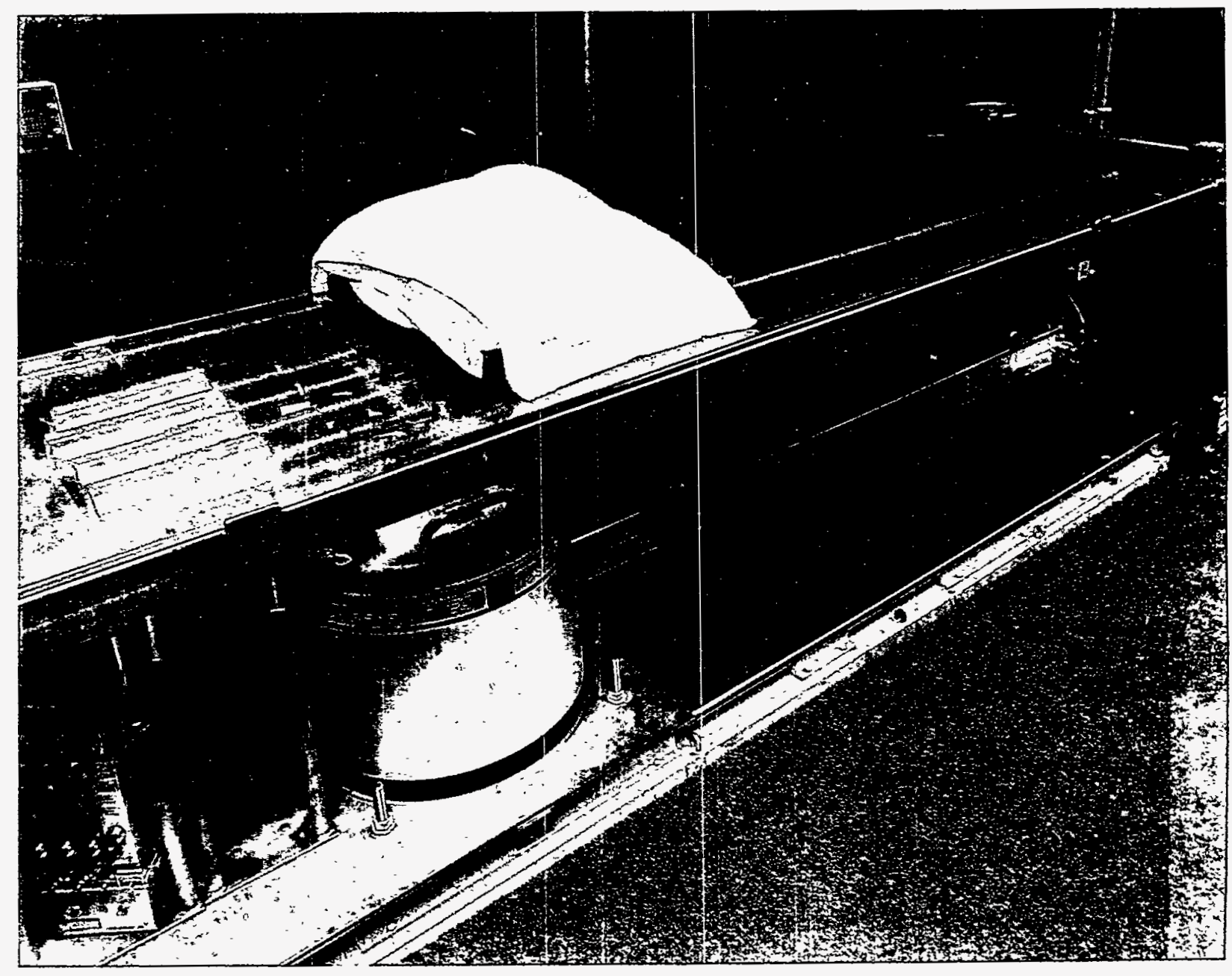

Figure 4.1. Scanning Coaxial Germainium System for the Detection of Mixed Fission and Activation Product Radionuclides

\subsubsection{Technical Services}

Routine technical services are provided to support the operation of the IVRRF. These services support the project objectives of the performance, analysis, and documentation of over 12,000 annual routine measurements. Additionally, 2500 calibration and daily quality control (QC) measurements are performed on an annual basis. Technical services include the calibration, operation, procurement, and routine maintenance of the counting systems; the record-keeping and receptionist duties of the operating station; and the training, qualification, and testing of technical personnel.

The counting systems at IVRRF include 3 low-energy lung monitoring systems (Lead, Iron, and Stainless Steel Rooms), 2 WBC systems (Palmer Room and Preview Counter); wound, thyroid, and organ monitoring detectors; 2 counting systems (Stand Up and Shadow Shield Lung Monitor) in the remote WBC trailer located in the 200 East area; and several WBCs and detection systems at the Emergency Decontamination Facility (EDF). 


\subsubsection{Equipment Maintenance}

Specific preventative maintenance is performed by PNL Craft Services personnel on the many counting systems used at the IVRRF. Maintenance is also required for counting systems that require repair or replacement of electronic components. The procurement of expense-funded equipment necessary to keep the counting instrumentation and associated computer systems operating reliably is also performed. Due to the high number of routine measurements performed at the IVRRF, new electronic equipment is often necessary to replace older, worn equipment. Components that require periodic replacement include power supplies, preamplifiers, line amplifiers, analog-to-digital converters, signal routers, and LAN interface modules.

\subsubsection{Quality Assurance Support}

Quality Assurance (QA) and QC measures impact every part of the routine counting program. The WBCP has a formal QA program based on specifications of the Quality Assurance Manual (a) and other current guidance. The WBCP has historically been designated as a QA Impact Level III project. However, it became clear based on the issuance of DOE Order 5700.6C (DOE 1991) and the pending issuance of ANSI N13.30 (ANSI 1993) that the WBCP would not achieve DOE Laboratory Accreditation Program (DOELAP) accreditation without upgrades in the QA area. As part of a risk assessment performed this year, the WBCP processes were flow charted, the processes were reviewed and failure modes impacting the quality of the product (i.e., in vivo measurement results and supporting data) identified, and the mechanisms to prevent or mitigate the failures were then identified. The results from the risk assessment are being incorporated into the revisions being made to the operating procedures. Work began on revising the current project QA plan to meet the requirements in DOE 5700.6C using the guidance contained in HDP-001. ${ }^{(b)}$ Detailed procedures have been removed from the Whole Body Counting Manual ${ }^{(c)}$ and upgraded to a new Procedures Manual (currently in draft form). Reviews of project quality are performed by outside QA engineers, and supplemented by industry QA inspections from independent subject experts from other DOE radiobioassay facilities. Additional reviews of program quality are performed in accordance with 10 CFR 835; which requires a planned functional audit of the project every 3 years. The Hanford contractors also perform joint audits of the WBCP.

\subsubsection{Preparation for DOELAP Accreditation}

One of the major areas of emphasis in the routine monitoring program is preparation for the DOELAP, as specified in the draft standard, ANSI N13.30, "Performance Criteria for Radiobioassay" (ANSI 1993). DOE plans to implement the accreditation program in an official capacity in FY 1997, which means failure to pass the performance testing criteria of the draft standard restricts the radiobioassay laboratory from performing measurements for DOE or DOE contractor personnel. The ANSI standard

(a) Internal manual, PNL-MA-70, Rev. 2, Pacific Northwest Laboratory, Richland, Washington.

(b) Internal manual, HDP-001, "Quality Assurance Guidance Document for Hanford Dosimetry Projects", Pacific Northwest Laboratory, Richland, Washington.

(c) Internal manual, PNL-MA-574, Pacific Northwest Laboratory, Richland, Washington. 
sets forth the requirements for accreditation of bioassay laboratories, based on performance criteria and program quality measures. Planning for this accreditation required upgrading several areas of the routine program operations.

The WBCP staff participated in the round of DOELAP pilot testing conducted through the Radiological and Environmental Sciences Laboratory (RESL) at the Idaho Falls operations office. The testing included measurements of Bottle Manikin Absorption Phantoms to determine the measurement bias and precision related to quantifying fission and activation product activity in the body. The WBCP performance met the bias and precision criteria in the draft ANSI N13.30 for ${ }^{134} \mathrm{Cs}$ and ${ }^{137} \mathrm{Cs}$. Table 4.1 indicates the performance of all DOE laboratories that participated in the pilot study, by coded letter. PNL results are indicated by the letter "K."

Table 4.1. DOELAP Pilot Testing Results for the PNL IVRRF

\begin{tabular}{ccccc} 
& \multicolumn{2}{c}{ Bias } & \multicolumn{2}{c}{ Precision } \\
\cline { 2 - 5 } DOE Lab Code & ${ }^{134} \mathrm{Cs}$ & ${ }^{137} \mathrm{Cs}$ & ${ }^{134} \mathrm{Cs}$ & ${ }^{137} \mathrm{Cs}$ \\
\hline A & $17.7 \%$ & $18.1 \%$ & $4 \%$ & $6 \%$ \\
B & $18.8 \%$ & $8.7 \%$ & $0.5 \%$ & $5 \%$ \\
C & $13.0 \%$ & $18.7 \%$ & $4 \%$ & $3 \%$ \\
D & $9.7 \%$ & $12.4 \%$ & $2 \%$ & $2 \%$ \\
E & $-1.9 \%$ & $3.9 \%$ & $3 \%$ & $2 \%$ \\
F & $-9.3 \%$ & $-7.6 \%$ & $4 \%$ & $1 \%$ \\
G & $19.3 \%$ & $7.7 \%$ & $3 \%$ & $5 \%$ \\
H & $-26.4 \%$ & $-21.6 \%$ & $5 \%$ & $4 \%$ \\
I & $4.1 \%$ & $4.8 \%$ & $1 \%$ & $4 \%$ \\
J & $12.3 \%$ & $13.8 \%$ & $2 \%$ & $2 \%$ \\
K & $10.8 \%$ & $8.1 \%$ & $1 \%$ & $1 \%$ \\
Average & $+6.2 \%$ & $+6.1 \%$ & $3 \%$ & $3 \%$ \\
\hline
\end{tabular}

(a) PNL is coded $\mathrm{K}$.

Although well within the DOELAP criteria of $-25 \%$ to $+50 \%$, the measurement biases were unacceptably high. Investigation revealed that the bias values were elevated because the background counts in the peak regions of interest (ROIs) were underestimated using the counts in the peak ROI from the measurements of the phantom containing ${ }^{40} \mathrm{~K}$ only. The bias values decreased to a more respectable value of 5\% when the IVRRF background prediction method of estimating the peak ROI baseline from a ROI directly above the peak ROI was used. The question of how the peak ROI baseline count rate 
will be determined for actual testing purposes was discussed with the RESL representative; the peak ROI baseline count rate will likely be determined using the facilities' methods and the blank phantom measurement data.

\subsection{SUMMARY OF MEASUREMENTS}

Measurements taken at the IVRRF and remote counter locations during 1994 are summarized below.

\subsubsection{Summary of 1994 IVRRF Measurements}

The total number and type of measurements made on personnel during 1994 are given in Table 4.2. In 1994, a total of 13,865 measurements were made for $\mathrm{RL}$ and the Hanford contractors representing a $2.9 \%$ decrease from the number performed in 1993. This decrease represents several changes to the IDP and WBCP. Specifically, improvements in the false pasitive rate requiring re-counts of personnel and reductions in the total personnel requiring chest and WBCs were made. Figure 4.2 depicts the in vivo measurements made at the IVRRF during the past six years.

Table 4.2. In Vivo Measurements Performed During 1994 and Recorded in the REX Database

\begin{tabular}{|c|c|c|c|c|c|c|c|c|c|}
\hline \multirow{2}{*}{$\begin{array}{c}\text { Count Type \& } \\
\text { Reason }\end{array}$} & \multicolumn{8}{|c|}{ Contractor Code } & \multirow[b]{2}{*}{ Total } \\
\hline & BCSR & ERC & DOE & HEHF & KEH & PNL & USACE & WHC & \\
\hline \multicolumn{10}{|l|}{ Whole-Body Count } \\
\hline Routine schedule & 92 & 268 & 251 & 18 & 1,983 & 1,897 & 20 & 5,893 & 10,422 \\
\hline Special request & 0 & 0 & 1 & 0 & 9 & 8 & 0 & 35 & 53 \\
\hline Visitors & 0 & 22 & 332 & 1 & 12 & 46 & 0 & 143 & 556 \\
\hline TOTAL & 92 & 290 & 584 & 19 & 2,004 & 1,951 & 20 & 6,071 & 11,031 \\
\hline \multicolumn{10}{|l|}{ Chest Count } \\
\hline Routine schedule & 28 & 19 & 16 & 0 & 760 & 332 & 0 & 1,547 & 2,702 \\
\hline Special request & 0 & 0 & 0 & 0 & 5 & 10 & $\mathbf{0}$ & 31 & 46 \\
\hline Visitors & 0 & 0 & 1 & 0 & 0 & 0 & 0 & 3 & 4 \\
\hline TOTAL & 28 & 19 & 17 & 0 & 765 & 342 & 0 & 1,581 & 2,752 \\
\hline \multicolumn{10}{|l|}{ Other } \\
\hline Routine schedule & 0 & 0 & 0 & 0 & 0 & 5 & 0 & 8 & 13 \\
\hline Special Request & $\mathbf{0}$ & 0 & 0 & $0^{\text {s }}$ & 3 & 4 & 0 & 58 & 65 \\
\hline Visitors & 0 & 0 & 0 & 0 & $\mathbf{0}$ & $\mathbf{0}$ & $\mathbf{0}$ & 4 & 4 \\
\hline TOTAL & 0 & 0 & 0 & 0 & 3 & 9 & 0 & 70 & 82 \\
\hline GRAND TOTAL & 120 & 309 & 601 & 19 & 2,772 & 2,302 & 20 & 7,722 & 13,865 \\
\hline
\end{tabular}




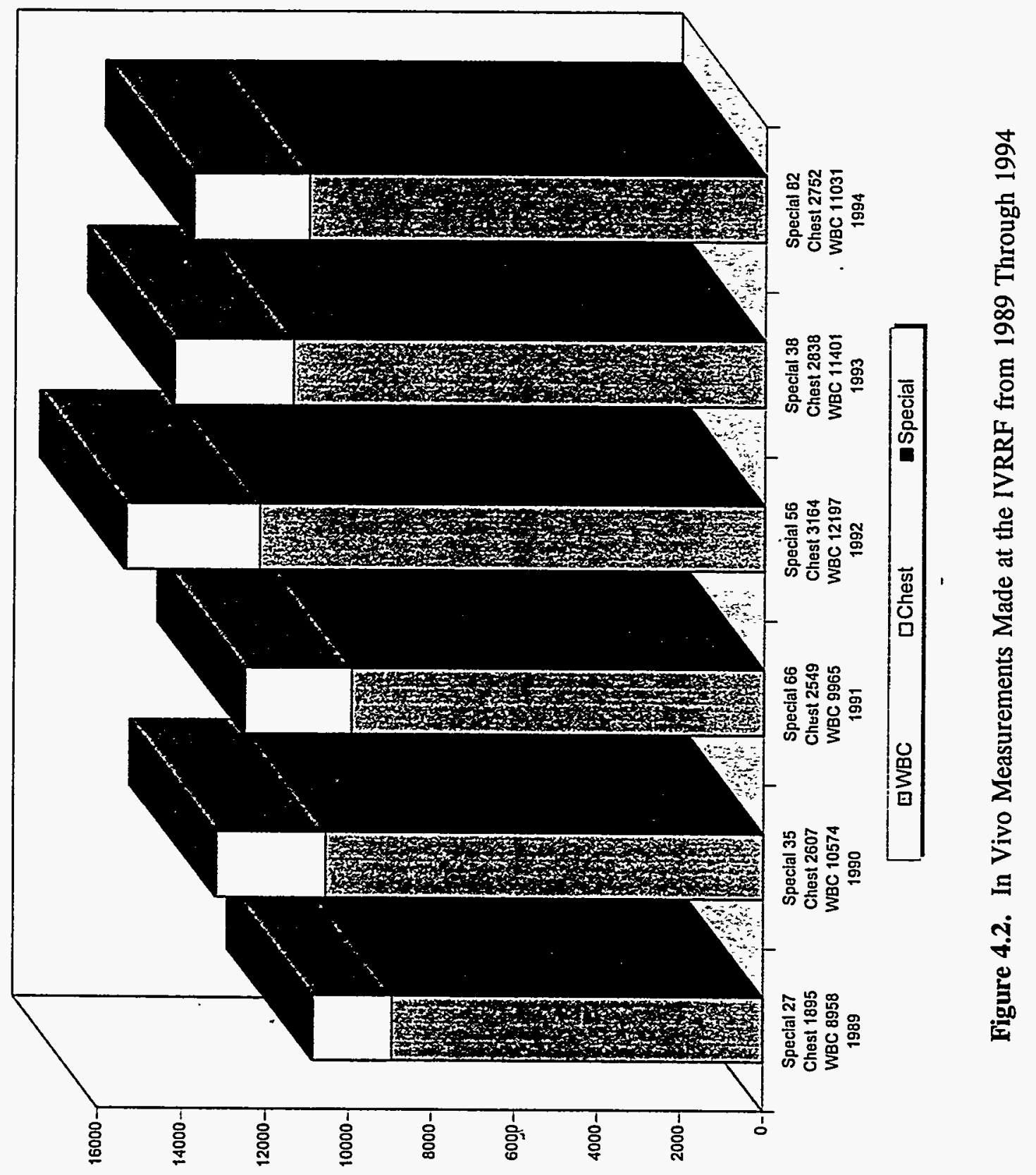




\subsubsection{Remote Counter}

The trailer housing the remotely operated in vivo counter is located in the 200 East area. The primary function of the remote counter is to facilitate WBCs for workers in the 200 areas, thus reducing the amount of time required if the testing were conducted in Richland. The remote counter is a stand-up multi-detector $\mathrm{NaI}(\mathrm{Tl})$ counting system, connected to an IBM Model 25 in the trailer. This equipment is interfaced with the main facility at the 747-A Building via telephone modem. Technicians in 747-A remotely control the operation of the counting system without having to physically be present at the remote location. During remote measurements, continuous audio and visual communications are maintained with the subjects in the trailer. Visual images are transmitted to 747-A via a photophone system, while a dedicated phone line between the trailer and 747-A provides audio communications. Personnel from WHC are trained to assist in the setup for the performance tests conducted before the system is used. This eliminates the need for IVRRF staff to travel to and from the counter for routine operations. The remote trailer WBC system is operated one day per week. In 1994 a total of 407 remote counter measurements were made, a decrease of $18 \%$ from 1993.

\subsection{NON-ROUTINE TASKS}

Several supporting tasks were performed in 1994. These included an intercomparison program with another DOE laboratory, development of a new computer system, chest-wall thickness modifications, and development of a new project manual for the WBCP.

\subsubsection{ORNL Intercomparison Program}

The IVRRF participated again this year in a radiobioassay intercomparison program operated by Oak Ridge National Laboratory (ORNL). Selections containing unknown activities of radioactive material are sent quarterly to program participants for analysis. The bottles fit inside the cavities of a plexiglass block phantom. Measurements of the unknowns in the phantom, while not representative of human in vivo bioassay measurements, provide an indication of the measurement precision and bias and serve as a training aide for technicians.

In 1994, four sets of unknowns were analyzed using the coaxial germanium scanning system. Figure 4.3 displays a summary of the 1994 analyses from ORNL for the 5 radioisotopes analyzed this year $\left({ }^{133} \mathrm{Ba},{ }^{57} \mathrm{Co}\right.$, and ${ }^{88} \mathrm{Y}$ were added to the program in the 4 th quarter of 1994).

\subsubsection{Hanford Personnel Dosimetry Facility Design}

In early 1994, a request was received from RL to participate in the design of a new Hanford Entry Center being planned for improved access to Hanford operations. A detailed design and engineering plan was developed for a facility that included the IVRRF operations, laboratory and equipment repair space, and storage capabilities. The completion of the facility was later deferred by RL for cost savings reasons. 


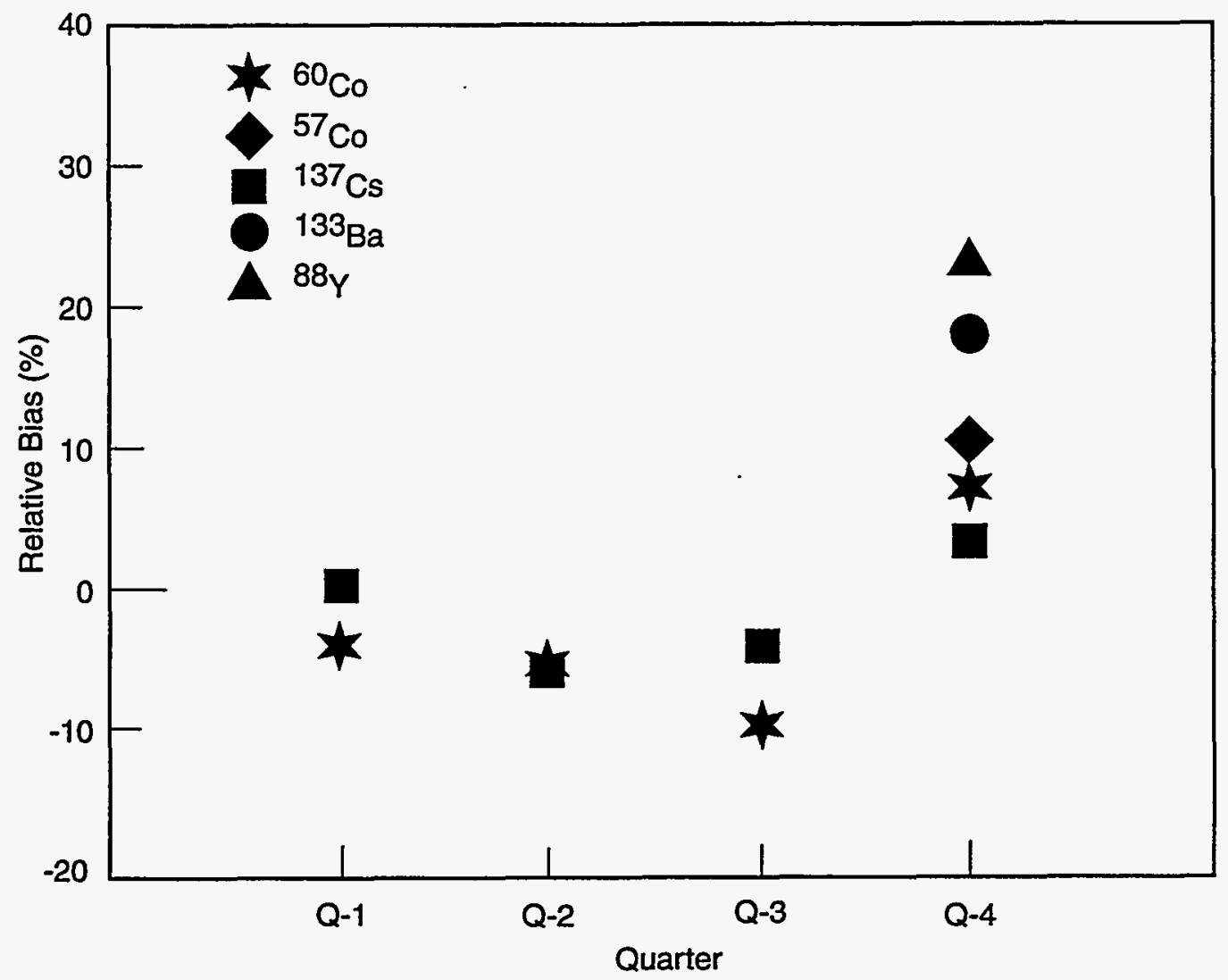

\begin{tabular}{|c|l|l|l|r|}
\hline Quarter & Isotope & \multicolumn{1}{|c|}{ Actual } & \multicolumn{1}{|c|}{ Measured } & $\%$ Bias \\
\hline Quarter 1 & $60 \mathrm{Co}$ & $29.9 \pm 1.5$ & $28.5 \pm 8.6$ & $-4.7 \%$ \\
& $137 \mathrm{Cs}$ & $192.3 \pm 9.6$ & $195.4 \pm 58.6$ & $1.6 \%$ \\
\hline Quarter 2 & $60 \mathrm{Co}$ & $135.2 \pm 6.8$ & $128.3 \pm 38.5$ & $-5.1 \%$ \\
& ${ }^{137} \mathrm{Cs}$ & $80.7 \pm 4.0$ & $79.4 \pm 23.8$ & $-1.6 \%$ \\
\hline Quarter 3 & $60 \mathrm{Co}$ & $499.9 \pm 25.0$ & $451.0 \pm 135.0$ & $-9.8 \%$ \\
& $137 \mathrm{Cs}$ & $499.8 \pm 25.0$ & $485.0 \pm 146.0$ & $-3.0 \%$ \\
\hline Quarter 4 & $133 \mathrm{Ba}$ & $63.6 \pm 3.2$ & $75.0 \pm 22.5$ & $17.9 \%$ \\
& $60 \mathrm{Co}$ & $107.0 \pm 5.4$ & $115.0 \pm 34.5$ & $7.5 \%$ \\
& $57 \mathrm{Co}$ & $151.7 \pm 7.6$ & $167.0 \pm 50.0$ & $10.1 \%$ \\
& $137 \mathrm{Cs}$ & $31.0 \pm 1.6$ & $32.0 \pm 9.6$ & $3.2 \%$ \\
& $.88 \mathrm{Y}$ & $282.3 \pm 14.1$ & $351.0 \pm 105.0$ & $24.3 \%$ \\
\hline
\end{tabular}

$\$ 9504057.2$

Figure 4.3. ORNL Intercomparison Results for IVRRF Performance Evaluation 


\subsubsection{Palmer Cell Structural Cracking}

Cracks were discovered in the left wall of the Palmer Cell near the hinges of the left door. These cracks and others subsequently identified resulted in a lockout tag being applied to the cell. The Palmer Cell was designated off limits by Facilities Management due to safety reasons. After several weeks, the cracks were inspected, but no definitive answer was given as to the safety of the assembly. Magnetic particle testing of the steel identified extensive surface cracking in the shield. Ultrasonic examination showed some cracks extend two inches deep. The original fabrication of this type of armor plate (pre-WWII battleship armor) provided the most plausible explanation for the cracks. It was surmised that the armor plate had been made under hurried wartime conditions and was not a highquality material. In addition, the hardening process embrittles the steel making it susceptible to cracking. The room was placed back in service after it was determined that there was no chance of the cell collapsing. The cracking in the steel is now monitored periodically.

\subsubsection{NEXEC Software and Hardware System}

The development of the new IVRRF computer system named NEXEC (for New EXEC) started in 1993 and continued during 1994. The detailed design for the system was completed and the code was written for each of the three platforms (i.e., PC running Windows-based Visual Basic, VAX WS 3100 running VMS, and the IBM RS6000 running AIX), their interfaces, and the interface with the Oracle database management system that resides on the RS 6000. Figure 4.4 is a diagram that depicts the high level structure and interfaces for the NEXEC system.

A contract was placed with Strategix Inc. in 1994 to provide the graphical user interface programming support on the PCs. A demonstration of the new system was given to representatives from RL and the contractors in September 1994. Because of delays in development and other project priorities, the milestone date for putting NEXEC into operation was moved from September 1, 1994, to March 1, 1995. Acceptance testing of the NEXEC system was scheduled for early 1995 . A considerable amount of time was required to write the code to allow multiple analyzers to be controlled. The interfaces with the VAX system due to the age of the 3100 s remain a liability for the system. A comparison of some of the features of the EXEC and NEXEC systems are summarized in Table 4.3.

\subsubsection{Chest Wall Thickness Modifications of LLNL Torso Phantom}

The purchase of two arrays of large-area planar germanium detectors was completed this year to increase the sensitivity of the counting measurements. Figure 4.5 shows the new Stainless Steel Room Counting Array. The larger sensitive area of these detectors required a change in the calibration factors used in chest counting, and a related recalibration of the Lawrence Livermore National Laboratory (LLNL) torso phantom used to calibrate the detectors. The torso phantom uses a polyurethane tissue-substitute to mimic the chest wall of a worker, and additional layers of "overlay" tissue substitute are used to build up the thickness for different-sized workers. The recalibration of the phantom required precision micrometer measurements of each $1 \mathrm{~cm}^{2}$ of the overlays and base chest plate that lies under the new, larger detector array. The chest-wall thickness (CWT) values for the new 4-detector and 6-detector arrays are shown in Table 4.4. 


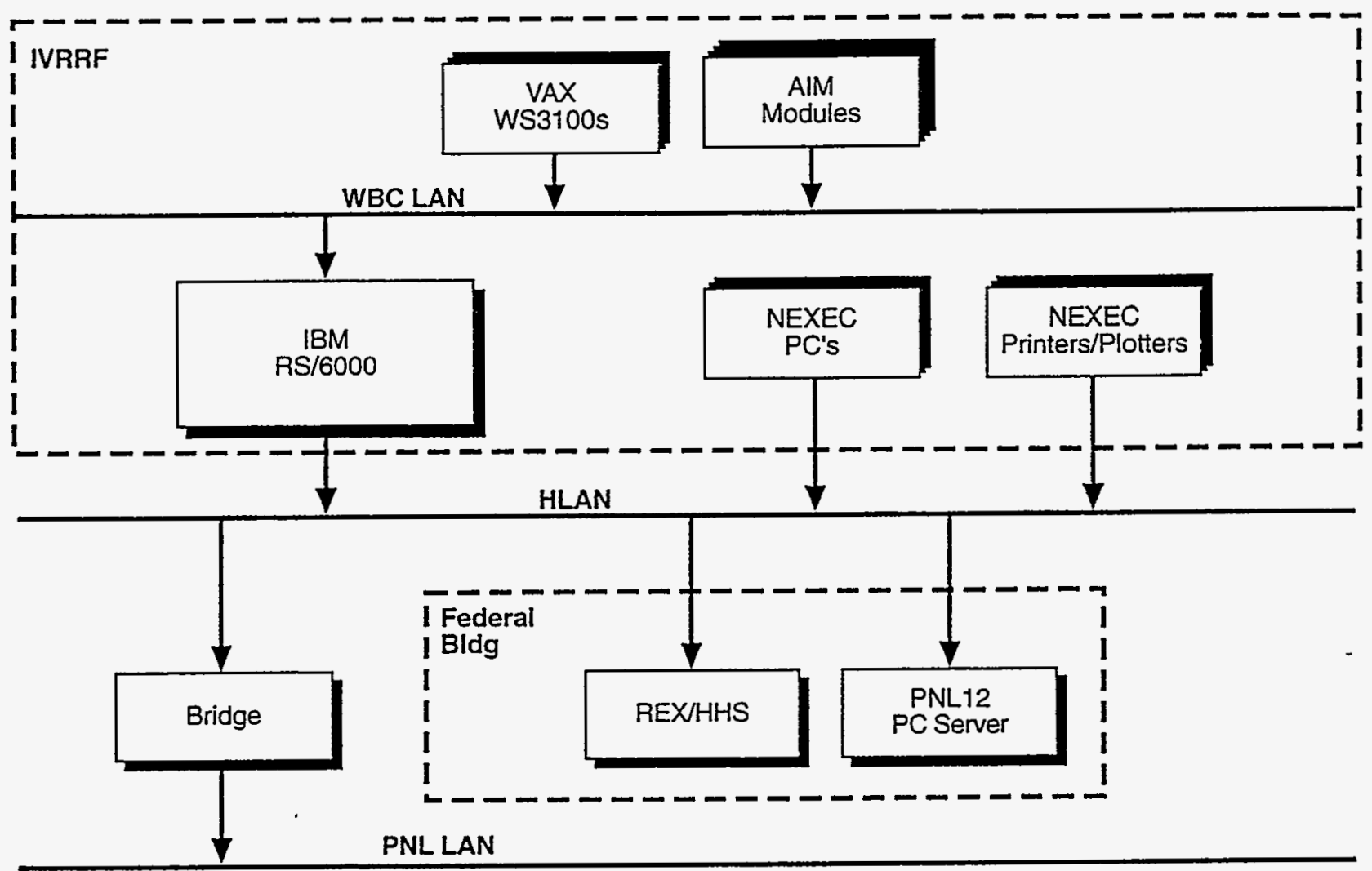

$\$ 9504057.6$

Figure 4.4. NEXEC System Operational Concept Diagram

Table 4.3. Comparison of EXEC and NEXEC Systems

\begin{tabular}{|c|c|}
\hline EXEC & NEXEC \\
\hline Mainframe with dumb terminals & Client - server technology \\
\hline Stand alone system & $\begin{array}{l}\text { Integrated into local network and to } \\
\text { HHS \& REX over HLAN }\end{array}$ \\
\hline Non-relational database & Oracle relational database \\
\hline Menu-driven applications & Windows-based applications \\
\hline Algorithms written in Fortran & Algorithms written in Visual $\mathrm{C}++$ \\
\hline Inefficient data storage and retrieval & $\begin{array}{l}\text { Extremely efficient data storage and } \\
\text { retrieval }\end{array}$ \\
\hline No on-screen plotting & On-screen plotting capability \\
\hline $\begin{array}{l}\text { Manual spectral data transfer from } \\
\text { analyzer }\end{array}$ & $\begin{array}{l}\text { Automatic spectral data transfer from } \\
\text { analyzer }\end{array}$ \\
\hline
\end{tabular}




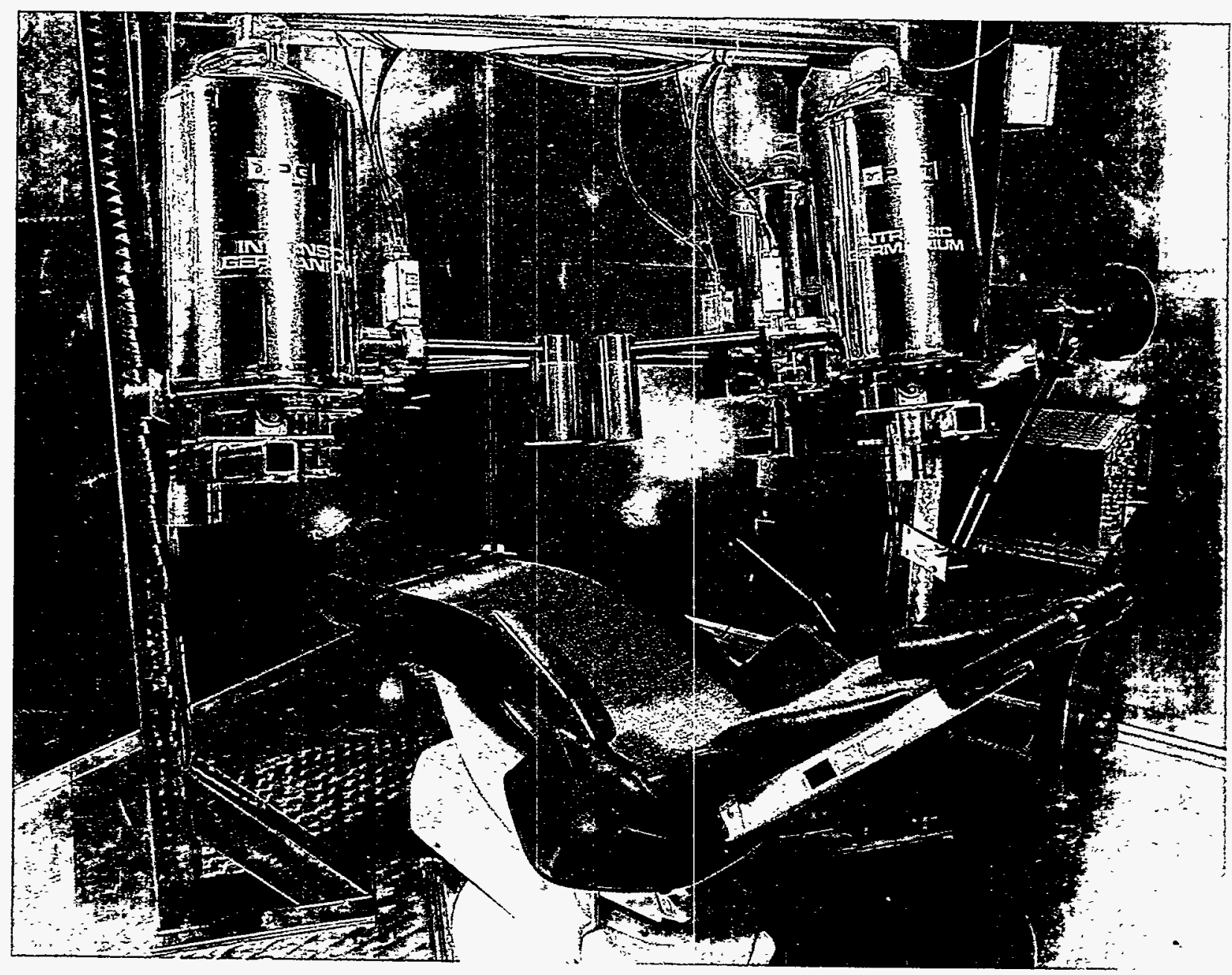

Figure 4.5. New Stainless Steel Cell Counting System

Tabie 4.4. New Chest Wall Thicknesses for LLNL Torso Phantom

\begin{tabular}{lcc}
\hline Phantom Overlay & New CWT & Previous 6-Detector CWT \\
\hline Bare Phantom (C-108): & $1.62 \mathrm{~cm}$. & $1.63 \mathrm{~cm}$. \\
w/ \#1 Overlay: & $2.31 \mathrm{~cm}$. & $2.26 \mathrm{~cm}$. \\
w/ \#2 Overlay: & $2.90 \mathrm{~cm}$. & $3.17 \mathrm{~cm}$. \\
w/ \#3 Overlay: & $3.42 \mathrm{~cm}$. & $3.58 \mathrm{~cm}$. \\
w/ \#4 Overlay: & $4.11 \mathrm{~cm}$. & $4.3 \mathrm{icm}$. \\
\hline
\end{tabular}


A new polynomial equation fitted to the data for the new CWT measurements was also developed. The equation expresses the fraction of transmitted Pu x-rays when activity is located in the lungs. The attenuation equation is

$$
\begin{aligned}
\mathrm{I} / \mathrm{I}_{\mathrm{o}}= & 1.01045-1.28258 \mathrm{X}+.838006 \mathrm{X}^{2}-0.345726 \mathrm{X}^{3}+0.0937023 \mathrm{X}^{4}-0.0165166 \mathrm{X}^{5} \\
& +0.00181059 \mathrm{X}^{6}-0.0001114 \mathrm{X}^{7}+2.94917 \mathrm{E}-6 \mathrm{X}^{8}
\end{aligned}
$$

where $I=$ intensity of Pu X-rays at chest surface

$I_{0}=$ original (unshielded) intensity of $x$-rays

$\mathrm{X}=$ Chest wall thickness in $\mathrm{cm}$.

\subsubsection{Hanford Whole Body Counting Manual}

Revisions to the Hanford Whole Body Counting Manual ${ }^{(a)}$ were started in 1994 . The revised manual will contain policy and technical basis information but will not contain procedures. The detailed operating procedures will be compiled in a separate procedures manual. This allows two improvements to the WBCP: individual procedures can be updated and kept current in a timely fashion, and the WBC manual becomes a guide to the services offered by the WBCP and a description of the project technical basis. The controlled version of the manual will be issued in 1995 .

\subsection{IMPROVEMENTS TO THE WHOLE BODY COUNTING PROJECT}

Several improvements were completed at the IVRRF during 1994 that affected counting equipment, procedures, and facilities upgrades. These improvements are described in the following sections.

\subsubsection{New Stainless Steel Room Counting System}

Four new, large-area $\left(3800 \mathrm{~mm}^{2}\right.$ vs. $2000 \mathrm{~mm}^{2}$ ) detectors of the "bucket" style dewar design were installed in the Stainless Steel Room with a new detector positioning system. The new detectors were part of a total capital purchase of nine detectors. The second set of four will be installed in the Iron Room. The new detectors facilitated an improved lung counting system, due to their larger surface area. Calibrations were completed and the array placed in routine service in September 1994. The system demonstrates high reliability, and has had no equipment failure since operations began. The new mounting system for the detectors has a limited range of motion (only one plane of positioning is usually used instead of the previous three), which allows for a greater reproducibility when performing lung measurements. Figure 4.5 shows the new counting system in the Stainless Steel Room.

The lung counting system previously residing in the Stainless Steel Room and employing six organpipetype planar detectors was moved to the Lead Cell. Since the Lead Cell is smaller and because only

(a) Internal manual, PNL-MA-574, Pacific Northwest Laboratory, Richland, Washington. 
some of the detectors are considered reliable for routine operations the counting system was reduced from six detectors to four. This room is currently used as a backup lung counter and for specialpurpose counts.

\subsubsection{New IVRRF Lobby}

The IVRRF lobby was extensively remodelled in 1994 with a lowered ceiling, new carpet, furniture, and improved lighting. Cultured marble reception shelf and trim together with new doors to the restrooms greatly enhanced the appearance and utility of the waiting room for the customers.

\subsubsection{New NaI Detector in Preview Counter}

The Preview Counter uses four $4 \times 9$ inch detectors and one $4 \times 11$ inch detector, for detection of highenergy fission and activation products. The detectors were very old, and have degraded in their 20year lifespan, suffering severe loss of resolution. Two of the $4 \times 9$ detectors were replaced and overall resolution is improved, resulting in greater detection efficiency.

\subsubsection{Iron Room Detector Support}

A very robust baseplate and stanchions for the detector monitoring system were designed and installed in the Iron Room. This same design was duplicated for the new Stainless Steel Room lung counter. Although these supports are strong enough to support the detectors standing free, they are also anchored by pressing against the ceiling to eliminate any tendency to vibrate.

\subsection{SUPPORTING PROGRAMS AND STUDIES AT THE IVRRF}

The following programs and studies were conducted by the IVRRF staff in 1994.

\subsubsection{DOE Phantom Library}

The official operation of the DOE Phantom Library by staff at the IVRRF continued in 1994. This program, supported by DOE-HQ loans state-of-the-art in vivo calibration phantoms to U.S. bioassay laboratories for calibration of measurement systems. The loans are made to DOE laboratories and other government agencies at no cost other than the shipping costs. The program also maintains records and calibration information on phantoms, and provides technical assistance to others in the field of direct radiobioassay.

The development and fabrication of new and improved calibration phantom designs is also performed as part of this program. In 1994, a new child (4-year-old) Bottle Maniken Absorption phantom was developed and fabricated using PNL tissue substitute materials as part of an international intercomparison of laboratories. This work was supported by DOE and the Canadian Bureau of Radiation and Medical Devices. The 4-year-old calibration phantom has travelled to four continents and 22 countries since completion. 
There were 27 phantom loans to other in vivo measurement facilities in 1994, an increase of 6 from the previous year.

\subsubsection{Female Radiation Worker Survey}

A survey of other DOE Laboratories began in 1994 to provide current information on the vital statistics of the female radiation worker population. This was initiated as part of the development of calibration phantoms that support the DOELAP testing program at RESL. No adequate female calibration phantom has been available for use in measurement systems which are used for direct bioassay of female workers, and the percentage of female radiation workers is increasing rapidly. The preliminary study performed at Hanford in 1993 indicated that the International Commission on Radiological Protection (ICRP) Publication 23 (ICRP 1984) Reference Female was not appropriate for the current female radiation worker population, and any new calibration phantom should not use this 30-year-old information. The results of the DOE survey have not been tabulated, due to the Hanford Work Force Restructuring effort.

\subsubsection{U.S. Transuranium Registry Support}

Both post-mortem measurements of U.S. Transuranium Registry (USTR) Whole Body donors, and measurements of workers with past depositions were performed in 1994. Two important cases in the registry files were studied in detail, a Pu deposition case and a Thorotrast case, both deceased.

\section{Pu Deposition Case}

Post-mortem measurements were made in support of the USTR donor program on an individual recently deceased of natural causes. The individual had been involved in a serious plutonium nitrate exposure more than 30 years previous to his death, and had received multiple chelation therapy administrations. Measurements were performed for two days on the individual, both pre- and postautopsy. The data will be part of a future report by USTR on this important case.

\section{Thorotrast Patient}

Post-mortem external photon measurements were performed to obtain estimates of the ${ }^{232} \mathrm{Th}$ and decay progeny activity in a female patient injected with Thorotrast in 1947. Measurements were also performed to determine the macro-distribution of the activity in the body.

Measurement Results

Figure 4.6 displays a spectral plot from a coaxial germanium scanning measurement of the Thorotrast subject. The prominent peaks in the spectrum are associated with ${ }^{228} \mathrm{Ac},{ }^{212} \mathrm{~Pb}$, and ${ }^{208} \mathrm{Tl}$ activities. The results from the two coaxial germanium scans of the cadaver were used to quantify the ${ }^{228} \mathrm{Ac}$, ${ }^{212} \mathrm{~Pb}$, and ${ }^{208} \mathrm{Tl}$ activities. The calibration factor for each nuclide was derived from measurements of an anthropomorphic torso phantom containing a simulated liver with $63.9 \mathrm{nCi}$ of aged ${ }^{232} \mathrm{Th}$ that is assumed to be in equilibrium with the other decay products in the thorium series. The thorium used in the phantom was separated in 1906 . The activity results were calculated from measurements of the 


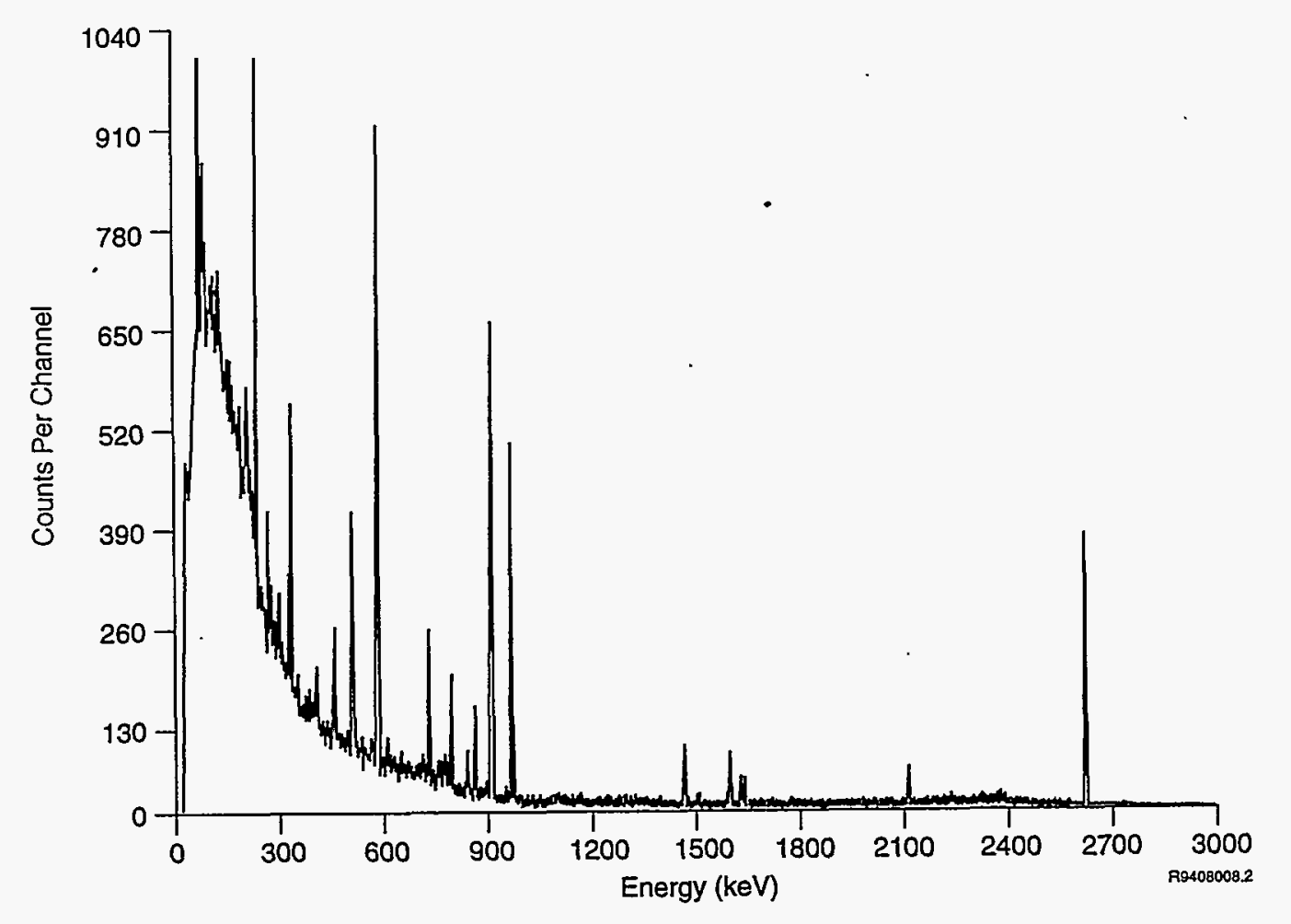

Figure 4.6. Spectral Plot From a Coaxial Germanium Scanning Measurement of the Thorostrast Subject

239-keV photon from ${ }^{212} \mathrm{~Pb}$, the $583-\mathrm{keV}$ photon from ${ }^{208} \mathrm{Tl}$, and from the $911-\mathrm{keV}$ photon from ${ }^{228} \mathrm{Ac}$. Table 4.5 summarizes the measurement results.

The activity values shown in Table 4.5 have been rounded to two significant figures. When the branching ratio of $36 \%$ is applied to the ${ }^{208} \mathrm{Tl}$ result, the ${ }^{232} \mathrm{Th}$ activity estimate is about $20 \mathrm{kBq}$, assuming equilibrium exists between ${ }^{232} \mathrm{Th}$ and ${ }^{208} \mathrm{Tl}$. The total uncertainty in the activity estimates were calculated by propagating the uncertainties in the calibration phantom activity, and the counting errors and positioning errors associated with the phantom and cadaver counts. The uncertainty values represent one standard deviation.

Table 4.5. Activity Estimates from Measurements with Coaxial Germanium Detection System

\begin{tabular}{lccccc}
\hline Nuclide & $\begin{array}{c}\text { Energy } \\
(\mathrm{keV})\end{array}$ & $\begin{array}{c}\text { Net Count Rate } \\
(\mathrm{cpm})\end{array}$ & $\begin{array}{c}\text { Cal. Factor } \\
(\mathrm{cpm} / \mathrm{Bq})\end{array}$ & $\begin{array}{c}\text { Activity } \\
(\mathrm{kBq})\end{array}$ & $\begin{array}{c}\mathrm{L}_{\mathrm{o}} \\
(\mathrm{kBq})\end{array}$ \\
\hline${ }^{212} \mathrm{~Pb}$ & 239 & 140 & 0.006 & $23 \pm 4$ & 0.34 \\
${ }^{203} \mathrm{Ac}$ & 911 & 70 & 0.004 & $17 \pm 2$ & 0.04 \\
${ }^{208} \mathrm{Tl}$ & 583 & 77 & 0.011 & $7 \pm 1$ & 0.09 \\
\hline
\end{tabular}


The information obtained from the multi-channel scale (MCS) measurements is shown in Figure 4.7. The discriminator settings bracketed the $911-\mathrm{keV}$ and the $969-\mathrm{keV}$ peaks. The sodium iodide crystal is collimated with $5 \mathrm{~cm}$ of lead and the collimator width is $1.25 \mathrm{~cm}$. The figure actually depicts the macro-distribution of ${ }^{228} \mathrm{Ac}$ which is in secular equilibrium with its parent ${ }^{28} \mathrm{Ra}$ in the body. The anatomical landmarks such as the head, shoulders, elbows, pelvis, knee, and foot were identified using a microswitch-activated pulsar to add a fixed number of counts to the spectrum at the particular location.

Figure 4.7 illustrates the distribution of ${ }^{228} \mathrm{Ac}$ in the subject. It shows that the activity is concentrated in the torso of the body. Approximately 50 to $60 \%$ of the counts originated from activity in the torso between the superior aspect of the shoulders and the inferior aspect of the pelvis. Approximately 70 to $80 \%$ of the total counts were accumulated during the scan distance between the top of the head to the knees. This distribution pattern is expected, given that the red bone marrow usually contains one of the highest levels of thorotrast activity in the body. The liver and spleen, which typically contain the highest activity values, had been removed previous to the measurements.

\subsection{4 ${ }^{241}$ Am Deposition Case}

A series of in vivo measurements were performed on an individual from the Paul Scherrer Institute in Switzerland who inhaled plutonium aerosol in a 1983 glovebox explosion. The purpose of the study was to obtain estimates of the total ${ }^{241} \mathrm{Am}$ activity in the body and amounts in specific tissues and organs. In particular, estimates were obtained for the activity in the lungs, tracheobronchial lymph nodes (TBLN), liver, and skeleton. Results from the measurements were compared with in vivo measurement results obtained at the Karlsruhe facility in Germany. A comparison of the results is shown in Table 4.6.

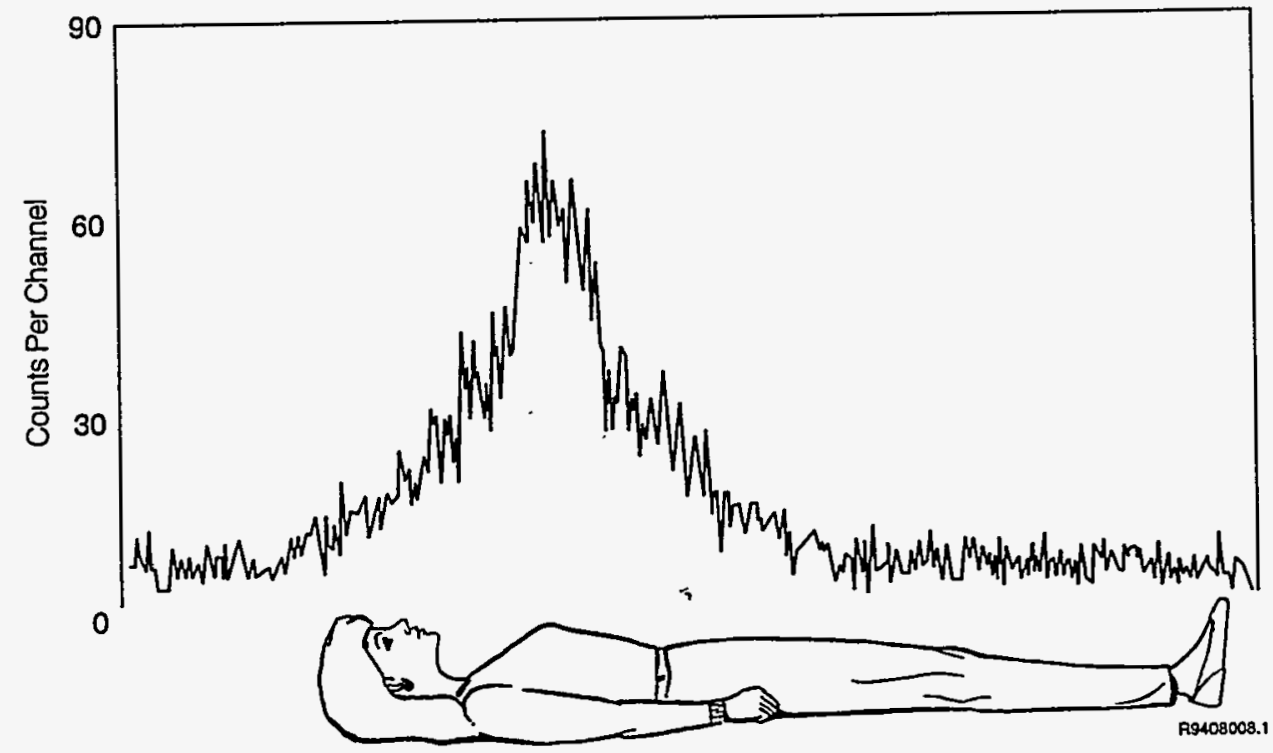

Figure 4.7. MCS Measurement Results Showing Areas of Concentrated Activity in the Thorostrast Subject 
Table 4.6. Comparison of Organ ${ }^{241}$ Am Activity Estimates

\begin{tabular}{lcccc}
\hline \multirow{2}{*}{ Organ } & \multicolumn{2}{c}{ Activity $(\mathrm{Bq})$} & \multicolumn{2}{c}{$\%$ Total Activity } \\
\hline \multirow{3}{*}{ Lung } & IVRRF & Karlsrube & IVRRF & Karlsruhe \\
\cline { 2 - 5 } Liver & $120 \pm 17^{(\text {a) }}$ & $61 \pm 42$ & 44 & 19 \\
TBLN $^{(b)}$ & $57 \pm 9$ & $14 \pm 6$ & 21 & 4 \\
Skeleton & $69 \pm 8$ & $61 \pm 9$ & 25 & 19 \\
\hline Total & $272 \pm 21$ & $315 \pm 57$ & 100 & 100 \\
\hline
\end{tabular}

(a) One sigma total propagated error.

(b) Tracheobronchial lymph nodes.

Although the estimates of total activity and the skeletal activity from the measurements performed at the two facilities are comparable, there are distinct differences in the estimates of the amounts in the liver, lung, and TBLN. The IVRRF estimates of the lung and liver activities are 2 to 3 times the Karlsruhe estimates. The Karlsruhe TBLN activity estimate is 5 times the IVRRF estimate. These differences, presumably caused by differences in calibration methods and measurement methods, are indicative of the variability that can be expected when estimating relatively low activity levels in multiple organs for material such as ${ }^{241} \mathrm{Am}$ that emit low-energy photons.

The liver and skeletal activity estimates determined from the in vivo measurements performed at the two facilities can be expressed as a percentage of the combined activity in the liver and skeleton. The liver and skeletal percentages were within the range of values found for the liver (3-52\%) and skeleton (48-97\%) from the post-mortem analyses of 25 donors to the USTR (Kathren et al. 1988). The Karlsruhe data (14\% liver, $61 \%$ skeleton) is in better agreement with the average percentage of activity found in the liver (24\%) and the skeleton ( $76 \%$ ) of the 25 USTR cases compared to the IVRRF data (liver $46 \%$, skeleton $54 \%$ ).

The percentage represented by the combined lung and TBLN activity (55\%), liver activity (21\%), and skeletal activity (24\%) from the IVRRF measurement data shown in Table 4.6 is in better agreement than the Karlsruhe data with the americium distribution found from post-mortem analyses of 4 totalbody donors to the USTR. These individuals' depositions were via the inhalation pathway. The average percentages determined from the 4 USTR cases were $45 \%$ in the respiratory tract, $17 \%$ in the liver, and $33 \%$ in the skeleton. 


\subsection{PROJECT-RELATED PROFESSIONAL ACTIVITIES}

Staff presentations and professional memberships during 1994 are listed in this section.

\subsubsection{Presentations}

Lynch, T. P., G. A. Rieksts, and D. G. Gross. Large Area Germanium Detectors for In Vivo Counting of Low Energy Photons. PNL-SA-24104 A. Presented at the DOE Lung Intercalibration Committee Meeting, April 20, 1994, Oak Ridge, Tennessee.

Olsen, P. C., and L. K. Davey. The PNL Phantom Library and Phantom Development Capabilities. Presented to the Cascade Chapter of the Health Physics Society at the annual meeting, October 14, 1994, Olympia, Washington.

Rieksts, G. A., P. C. Olsen, and T. P. Lynch. Early Operating Experience with Large Area Germanium Detectors for Detecting Low-Energy Photons. PNL-SA-25192. Presented at the 40th Conference on Bioassay, Analytical, and Environmental Radiochemistry. Cincinnati, OH. November 14, 1994.

\subsubsection{Professional Memberships}

Lynch, T. P. Chairman of ANSI N13.35 Working Group which is writing the ANSI Standard ANSI Standard for the Bottle Manikin Absorption Phantom.

Lynch, T. P. Member of ASTM Task Group E-10.04.27 which is writing the ASTM standard Estimation of Low Energy Photon Emitters in a Wound.

Olsen, P. C. Member of ANSI N13.35 Working Group writing the ANSI Standard ANSI Standard for the Bottle Manikin Absorption Phantom. 


\subsection{HANFORD RADIOLOGICAL RECORDS PROJECT}

The Hanford Radiological Records Project (HRRP) supports RL and Hanford contractor radiation protection programs. The HRRP administers and preserves radiological exposure records for all Hanford workers and visitors, past and present, and provides specified and requested reports using these records. The program is also responsible for maintaining the Hanford Radiation Protection Historical Files. Program personnel operate the computer systems and library equipment necessary to input, store, verify, and retrieve the records and produce the required reports and downloads.

The HRRP uses the REX system, which includes a database containing the personnel radiological exposure data. These data are readily retrievable via a system of personal computers and terminals operated by the HRRP and Hanford contractor dosimetry staffs. The REX system also includes all of the supporting exposure documentation on microfilm and laser optical disk which are indexed into computer-assisted retrieval (CAR) systems. The CAR systems allow for rapid retrieval of the documents for any individual using identifiers, including payroll numbers, social security numbers, names and/or REX IDs (REX IDs are unique numbers generated by the computer for each individual to tie all of their records together). The project also uses a laser optical disk subsystem (called LaserREX). All hardcopy exposure records starting with January 1, 1992, are preserved on LaserREX. LaserREX also stores the electronic records created by the REX transaction log. Hardcopy records generated prior to 1992 are maintained on microfilm.

The Hanford Radiation Protection Historical File records include documents such as policies, procedures, reports, and important communications that define the Hanford radiological dosimetry and radiation protection programs during their history. The historical records are microfilmed and indexed into an additional CAR system. These records are retrievable by author, date or range of dates, document number (if applicable), document title, and up to three keywords.

The program is operated under the applicable sections of Title 10, Code of Federal Regulations, Part 835 (DOE 1993); the Hanford Site Radiological Control Manual (HSRCM-1) (RL 1994), ANSI N13.6, American National Standard Practice for Occupational Radiation Exposure Records Systems (ANSI 1972); the "Hanford Site Services Handbook" (RL 1993) (through 1994); as well as the following DOE Orders: 1300.1, "Micrographic Management" (DOE 1980); 1324.2A, "Records Disposition" (DOE 1988); 5480.11, "Radiation Protection for Occupational Workers" (DOE 1990a); and 5484.1 Chg 3 "Environmental Protection, Safety, and Health Protection Information Reporting Requirements" (DOE 1987). The program also complies with the applicable sections of the Privacy Act (1974) and the Freedom of Information Act (1966).

\subsection{THE ROUTINE PROJECT}

The HRRP is organized into four major functional areas: data administration, data handling, report issuance, and the library. Both data handling and report issuing are performed by the Radiological Records Data Processing Center. 
The database administration function performs system evaluations, troubleshooting, resolution of system and user problems, training of users, oversight of system security, liaison with the BCSR computer analysts, and initiation and testing of modifications to the databases.

Data-handling includes entering data into the REX database and validating all data entry. Validation is accomplished by reviewing field data entry, establishing audits to be matched to entries of results, resolving unmatched results, and interacting directly with contractor personnel. Data-handling also includes dealing directly with contractor personnel and data suppliers to assist them and solve data problems.

The report issuance function provides for generation and issuance of routine exposure status reports to the contractors, quarterly person rem and annual statistical reports to DOE, annual reports to employees, and special reports requested by former employees, as well as those requested by the contractors, RL, the Uranium and Transuranium Registries, and Privacy Act and Freedom of Information Act petitions. This function requires close contact with RL, the contractors, and other personnel dosimetry functions.

The Records Library maintains individual exposure records that are not reducible to database elements and backup documentation as well as the Hanford Radiation Protection Historical Files. The library staff file and retrieve hard-copy documents, prepare documents for long-term storage, and track and account for the documents through the imaging and indexing process. The library contains the individual exposure records of all Hanford personnel since its inception (almost five-million microforms), except those individuals who transferred from Hanford when DuPont left in 1946. These and the Historical File microforms are retrievable through index systems that are maintained by the library staff.

Although the results from the dosimeter and excreta processing, as well as the in vivo counts, are received by electronic transmission, a large amount of data are entered manually by the field dosimetry organizations and the HRRP Data Processing Center staff. The hard copies are then sent to the library for preservation on the imaging systems. Table 5.1 presents CY 1994 statistical information on many of the documents that are entered into the database and indexed into LaserREX. Some documents, such as the Employee and Dosimetry Change Form may contain several pieces of information that require data entry.

The REX database ${ }^{(a)}$ performed very well all year. The majority of the Software Change Requests issued during the year were for changes and enhancements to make the operations more efficient and data entry less cumbersome. The REX User's Group, initiated late in 1993 was instrumental in proposing and defining many of the enhancements and changes. Some of the significant changes included

(a) A description of the REX database can be found in Lyon et al. 1994. 
Table 5.1. Records Activity for Calendar Year 1994

\begin{tabular}{lc}
\hline \multicolumn{1}{c}{ Document Type } & Number \\
\hline $\begin{array}{l}\text { Personal Radiation Exposure History Form (used to document exposure history } \\
\text { prior to Hanford and to initiate a record for a new or rehired employee) }\end{array}$ & 6,440 \\
$\begin{array}{l}\text { Employee and Dosimetry Change Forms (used to document personnel data or } \\
\text { dosimetry changes) }\end{array}$ & 13,094 \\
$\begin{array}{l}\text { Employee and Dosimetry Change Forms (used to document employee } \\
\text { terminations) }\end{array}$ & $\mathbf{5 , 0 7 2}$ \\
$\begin{array}{l}\text { Temporary Dosimeter Assignment Forms (used for issuing temporary } \\
\text { dosimeters to employees due to new hires, changes to dosimetry }\end{array}$ & 10,305 \\
requirements,and employees who forgot their dosimeters) \\
$\begin{array}{l}\text { Visitor and Subcontractor Dosimeter Issue Forms (used to issue dosimetry to } \\
\text { visitors and subcontractors not completing radiological worker training) }\end{array}$ & 11,870 \\
$\begin{array}{l}\text { Investigation of Dosimeter Result Forms and Change Letters (used to estimate } \\
\text { exposure for lost, damaged, or otherwise suspect dosimeter results) }\end{array}$ & $\mathbf{3 , 1 3 0}$ \\
$\begin{array}{l}\text { Special Process Forms (used to document data for specially processed } \\
\text { dosimeters) }\end{array}$ & $\mathbf{5 , 3 5 0}$ \\
$\begin{array}{l}\text { Requests for Exposure Summaries (summaries requested for current and prior } \\
\text { Hanford employees) }\end{array}$ & $\mathbf{8 3 4}$ \\
$\begin{array}{l}\text { Letters Sent to Request Prior Exposure (to request summaries for new } \\
\text { employees with prior exposure or existing employees receiving exposure at off- } \\
\text { site facilities) }\end{array}$ & $\mathbf{2 , 0 1 4}$ \\
\begin{tabular}{l} 
Total number of hardcopy records scanned and indexed into LaserREX(a) \\
\hline
\end{tabular} & $\mathbf{7 6 , 5 5 5}$ \\
\hline
\end{tabular}

(a) This total is for all of the hardcopy records scanned and indexed into LaserREX, some of which are not listed in this table.

- A modification to the security rules for Platinum Report Facility (PRF) ad hoc queries was initiated. The rules were creating some very complex Standard Query Language statements which were preventing joining some tables and slowed down many queries. Security was removed from some tables, where it was not really necessary for privacy, and simplified on others. This made more queries possible and speeded up many others. This change did not affect the security on the system screens.

- Screens were developed for multiple in vivo and excreta bioassay displays. This significantly reduced the time required for Internal Dosimetry àd field dosimetry personnel to review an individual's bioassay records.

- When initially developed, the employee identification data entry for new employees required four screens. This capability was reduced to one screen to reduce the time needed to enter and review the data. 
- Due to the mass movements of personnel between contractors, a screen was developed to make all the necessary changes for an individual with one data entry process, instead of numerous processes.

- A new report was developed that lists all external dosimetry, in vivo, and excreta bioassay frequencies with individual identifiers issued in organization code order. This can be used by managers and dosimetry personnel to determine if the frequencies are still correct. A screen was also developed so the contractors could request the report on demand.

- A number of screen modifications were made to increase efficiency and clarity.

In addition, the BCSR analyst reviewed REX programs with the intention of reducing processing time. One of the significant changes reduced the processing time from 16 central processing unit (CPU) minutes to 3.5 CPU seconds. Another reduced the processing time from $20 \mathrm{CPU}$ minutes to $2 \mathrm{CPU}$ minutes. At $\$ 10.00$ per CPU minute, this will significantly reduce costs over time.

A major reprogramming effort was required to REX and the interface with the External Dosimetry computer to accommodate the new external dosimetry system initiated on January 1, 1995. The data transfer files were modified and downloads revised. Because the new dosimeter identifiers were changed, some of the site-wide forms had to be redesigned and reprinted. Several electronic conversions were made in REX which saved considerable data entry effort.

There has been a significant reduction in rejects of data from external dosimetry, the WBCP, and the excreta bioassay analytical laboratory over the old ORE system. Typically, the year-end number has been reduced from 2000 to 3000 to approximately 200 . This has been accomplished principally by the design of REX and the interfaces.

Several upgrades to LaserREX were accomplished during the year. These upgrades included

- the ability to copy full optical disks - This was required to make copies for offsite storage to satisfy data security requirements.

- the ability to retrieve all records from both work stations - Previously the transaction log records could only be retrieved from the scanning station.

- the ability to print from both work stations without having to reprogram the printer when changing work stations.

A considerable amount of extra paperwork and effort was required during the year due to all the personnel and dosimetry changes. There were several mass personnel changes between contractors, terminations due to enhanced retirement programs initiated by the Hanford Work Force Restructuring Program, the removal of a significant number of dosimeters from personnel not requiring them, and the initiation of the new external dosimetry system. Most of these changes required some paperwork. 
The Hanford personnel dosimetry projects are all upgrading their QA programs. The HRRP is heavily involved in this upgrade. The first element to be completed for the upgrade was a revision of the REX Software Configuration Management Plan (PNL 1994).' At year end a number of draft operational (called desk procedures) and administrative procedures had been prepared and were under review.

\subsection{SUPPORTING STUDIES}

Because of the high cost of processing on the existing Hanford Large Scale Information System mainframe computer a study was initiated by PNL's Information Systems and Services (IS\&S) department to determine if REX could be transferred to a minicomputer. The study was limited to direct migration to a mini-computer to minimize the cost of the transfer. The study revealed that "Migrating REX to a mini-computer is not feasible because the GENER/OL and Platinum Report Facility (PRF) software are not available or planned for mini-computers and the constraint of the study preclude us from considering re-engineering."(a)

The project was reviewed against the 10 CFR 835 (DOE 1993) records requirements. Only one area was in non-compliance. The new regulation requires that considerably more information be included on the termination letters and annual employee exposure report cards. Planning is in progress to meet the requirements before the required date.

\subsection{PROJECT-RELATED PROFESSIONAL ACTIVITIES}

Staff presentations and professional memberships during 1994 are listed in this section.

\subsubsection{Presentations}

Berndt, V. L. 1993. Lessons Learned in Procuring a Laser Optical Disk System. Presented to the Region X Conference of the Association of Records Managers and Administrators, Spokane, Washington, April 27, 1994 and to the Columbia Basin Chapter of the Association of Records Managers and Administrators, Richland, Washington, April 21, 1994.

Berndt, V. L. 1994. Lessons Learned in Procuring a Laser Optical Disk System. Presented to the 39th Annual Conference of the Association of Records Managers and Administrators International, Toronto, Canada, September 25-29, 1994. Published in the conference proceedings.

(a) Internal report by G. R. Danielson, 1994. "REX Hardware Alternatives Study," available in the Hanford Radiation Protection Historical Files. 


\subsubsection{Professional Memberships}

Lyon, M. Chairman of the Health Physics Society Standards Committee Working Group to review ANSI N13.6, American Standard Practice for Occupational Radiation Exposure Records Systems. 


\subsection{RADIATION STANDARDS AND CALIBRATIONS PROJECT}

The primary function of the Radiation Standards and Calibrations Project (RS\&C) is to maintain radiological standards necessary to facilitate appropriate characterizations and calibrations within the Hanford Instrument Calibration and Evaluation Program and External Dosimetry Project. In support of this task, special instrument and dosimeter response-characterizing equipment and supplemental radiological reference fields are maintained, as necessary. This activity provides the means to characterize response to various radiation fields encountered at Hanford and ensures that calibration fields are described in accordance with recommended standards and guides. Typical project activities include

- providing traceability of the calibration sources to the NIST

- maintaining basic radioactive sources and instruments that serve as radiological standards

- reviewing calibration standards, regulations, and handbooks

- ensuring that calibration procedures are in agreement with technically accepted methods.

Project activities conducted during CY 1994 are discussed in the following sections.

\subsection{ROUTINE TASKS}

Routine activities conducted by project personnel included maintaining 1) radiological standards and capabilities and 2) radiological reference fields traceable to national standards.

\subsubsection{Standards and Capabilities}

The radiological standards and capabilities maintained for the various entities of Hanford Radiological Protection Support Services include gamma, beta, and neutron isotopic sources and $\mathrm{x}$-ray generating devices. These standards and capabilities are configured to deliver well-known and easily reproduced quantities of radiation dose or exposure to environmental or personnel dosimeters and radiological survey instruments for providing NIST-traceable calibration and/or response characterization.

\section{Gamma Ray Sources}

Available photon sources include various activities of ${ }^{137} \mathrm{Cs}$ and ${ }^{60} \mathrm{Co}$ configured in either collimatedbeam, well, or open-field geometries, and an ${ }^{241} \mathrm{Am}$ source configured for irradiation in a $2 \pi$ geometry, as listed in Table 6.1.

The "open" sources listed in Table 6.1 are placed in the center of a circular, aluminum table via a pneumatic air-transfer system. Exposure rates at two discrete distances to the source are typically 
Table 6.1. Available Gamma-Ray Sources

\begin{tabular}{|c|c|c|c|c|c|}
\hline Source & Geometry & $\begin{array}{c}\text { Nominal Rate/Range } \\
{[\mathrm{R}(\mathrm{rem}) / \mathrm{hr}]}\end{array}$ & $\begin{array}{l}\text { Location in } \\
\text { Bldg. } 318\end{array}$ & $\begin{array}{l}\text { Reference } \\
\text { No. }\end{array}$ & $\begin{array}{l}\text { Primary Photon } \\
\text { Energy (MeV) }\end{array}$ \\
\hline \multirow{4}{*}{${ }^{60} \mathrm{Co}$} & Well & $0.006-2.000$ & Rm. 121 & $318-027$ & $1.17 / 1.33$ \\
\hline & Open & $2 / 7$ & Rm. 106 & $318-164$ & $1.17 / 1.33$ \\
\hline & Beam & $10-300$ & Rm. 8 & $318-037$ & $1.17 / 1.33$ \\
\hline & Beam & $90-3000$ & Rm. 8 & $318-036$ & $1.17 / 1.33$ \\
\hline \multirow{7}{*}{${ }^{137} \mathrm{Cs}$} & Well & $0.002-0.100$ & Rm. 121 & $318-031$ & 0.662 \\
\hline & Well & $0.040-10.000$ & Rm. 121 & $318-030$ & 0.662 \\
\hline & Beam & $0.100-30.000$ & Rm. 8 & $318-040$ & 0.662 \\
\hline & Open & $0.400 / 2.000$ & Rm. 106 & $318-001$ & 0.662 \\
\hline & Beam & $1-300$ & Rm. 8 & $318-044$ & 0.662 \\
\hline & Open & $1 / 8$ & Rm. 106 & $318-029$ & 0.662 \\
\hline & Beam & $3 / 30$ & Rm. 6 & $318-131$ & 0.662 \\
\hline${ }^{241} \mathrm{Am}$ & Open $(2 \pi)$ & 0.125 & Rm. 6 & $318-184$ & 0.060 \\
\hline
\end{tabular}

characterized. "Beam" sources, with the exception of 318-131, provide a continuum of exposure rates via use of a target positioning stand located on a sliding-rail system. Source 318-131 also includes a moveable target stand, but is typically characterized and used only at the one- and three-meter distances. Device (instrument and/or dosimeter) placement for the most commonly used positions within these beam irradiation facilities is enhanced by laser alignment capabilities. "Well" sources also provide a continuum of exposure rates and facilitate instrument adjustments during irradiation without undue exposure to personnel. Source to target distance is controlled by moving the sources on a trolley system up and down within the well via computer interface.

\section{X-ray Photon Sources}

Two identical Philips Model-324 x-ray machines are currently in use in support of the RS\&C Project. One machine produces Bremstrahlung (broad) photon spectra (e.g., NIST techniques M30, S60, M150, $\mathrm{H} 150$ ) while the second is configured to facilitate production of $\mathrm{K}$-fluorescence technique (narrow) secondary photon spectra (e.g., 17 and $59 \mathrm{keV}$ ) within a shielded enclosure. Figure 6.1 shows an example spectrum of each type of $\mathrm{x}$-ray configuration and Table 6.2 provides a complete listing. of available techniques and their characteristics. Both of these systems use a laser alignment system to aid in target (instrument/dosimeter) positioning. 


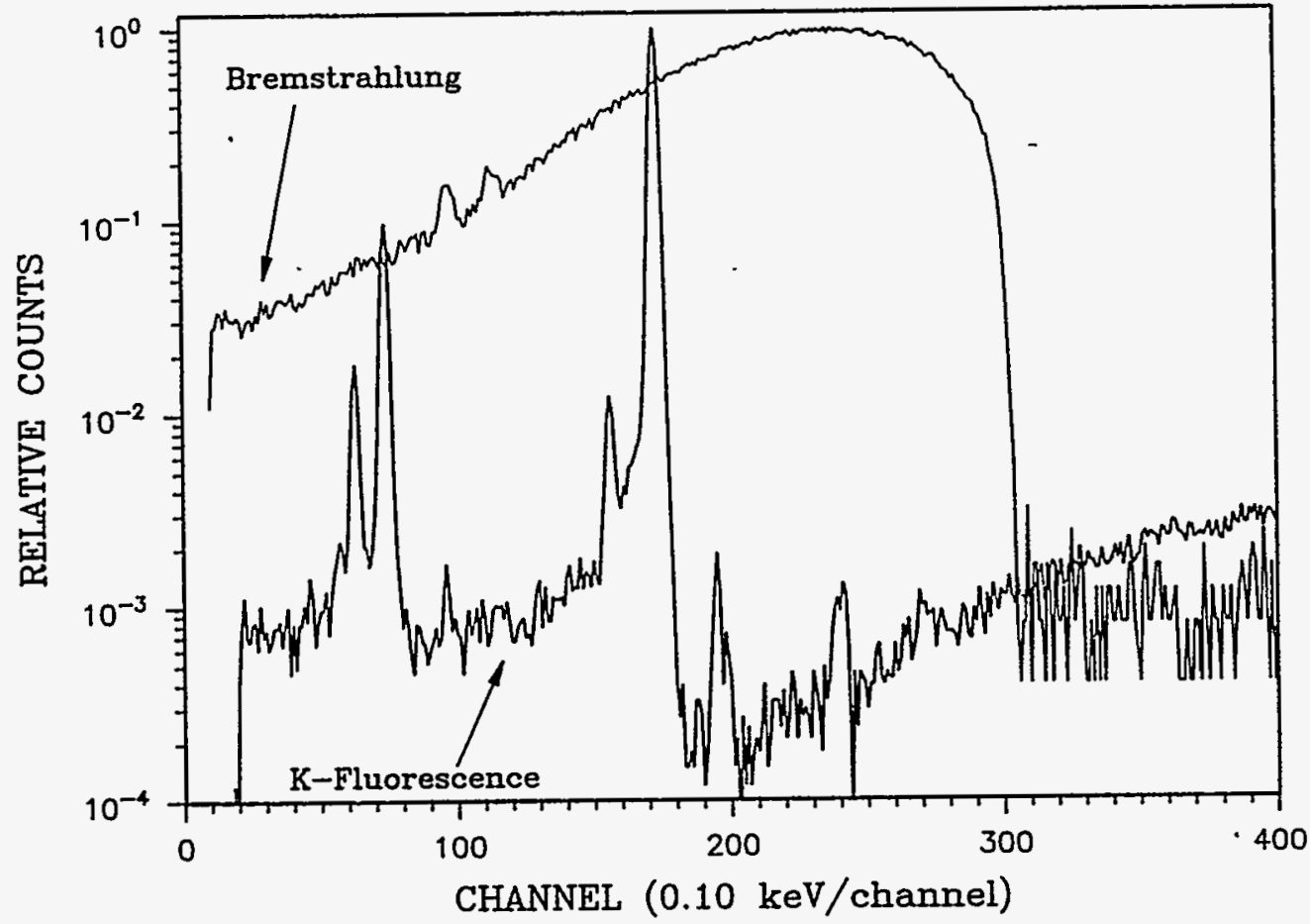

Figure 6.1. K-Fluorescence and Bremstrahlung X-ray Spectra of Similar Peak Energy

\section{Neutron Sources}

Two configurations of ${ }^{252} \mathrm{Cf}$ neutron sources are available. The first configuration allows the use of $1.47-\mathrm{mg}$ and $82-\mu$ g sources $^{(a)}$ within the pneumatic transfer system in Room 106 . During use, these sources are placed approximately at the geometric center of a room 10 meters wide, 14 meters long and 8.8 meters high, such that a low-scatter environment is established. Both sources may be used bare or moderated by a sphere of deuterated water $\left(\mathrm{D}_{2} \mathrm{O}\right) 15$ centimeters in radius, enclosed within a thin stainless steel shell and covered by 0.051 centimeters of cadmium. These provide neutron fields useful for instrument calibrations as well as for dosimeter characterization in accordance with specifications of DOE/EH-0027, the Department of Energy Standard for the Performance Testing of Personnel Dosimetry Systems (DOE 1986b), and ANSI N13.11, American National Standard for DosimetryPersonnel Dosimetry Performance-Criteria for Testing (ANSI 1983).

The second configuration involves a ${ }^{252} \mathrm{Cf}$ source placed in a well to facilitate easy access for instrument calibration. This source provides a fission spectra partially degraded by the significant scattering from the sides of the well.

(a) At original assay. 
Table 6.2. Available X-ray Photon Techniques ${ }^{(a)}$

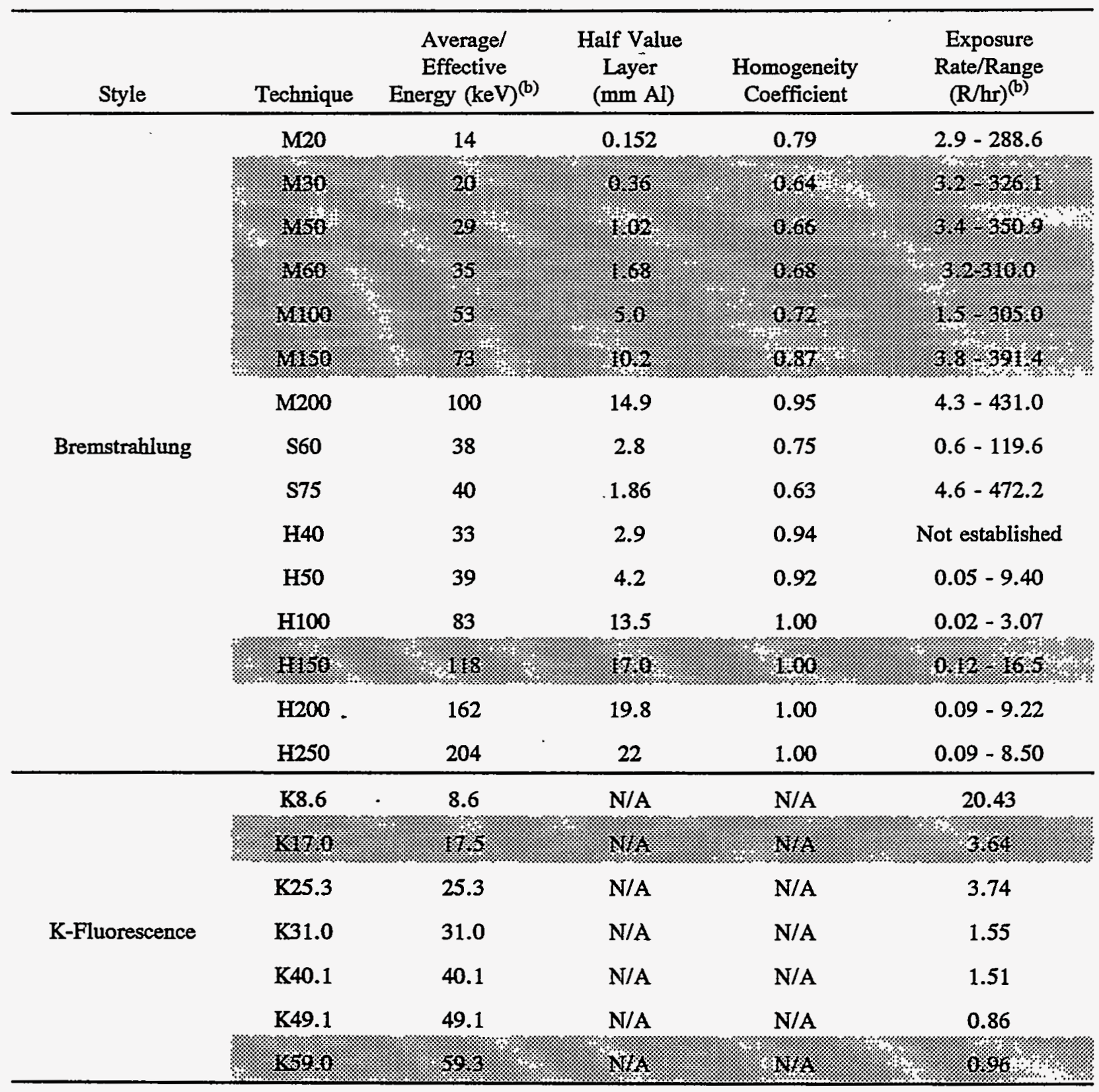

(a) Routine calibration maintained only for shaded techniques.

(b) Nominal.

\section{Beta Particle Sources}

Beta particle sources $\left({ }^{147} \mathrm{Pm},{ }^{204} \mathrm{Tl}\right.$, and $\left.{ }^{90} \mathrm{Sr} /{ }^{90} \mathrm{Y}\right)$ are maintained primarily for dosimetry characterization. Available sources include those manufactured by Amersham-Buchler and calibrated directly by the Physikalisch-Technische Bundesanstalt (PTB), Germany's national physical standards 
organization, and those manufactured in the United States by Amersham and Isotope Products Laboratory. The absorbed dose rate for the ${ }^{147} \mathrm{Pm}$ source has decayed to a value which makes the reference field unusable for most purposes, including periodic constancy verifications. A higher activity replacement has been procured; however, during initial acceptance testing, its energy characteristics were found to be inconsistent with procurement specifications and it was returned to the manufacturer for analysis. Measurements have been made of all Amersham-Buchler sources and the Amersham-U.S. ${ }^{90} \mathrm{Sr} /{ }^{90} \mathrm{Y}$ sources to verify satisfactory compliance with ANSI N13.11, American National Standard for Personnel Dosimetry Performance - Criteria for Testing (ANSI 1983); DOE/EH0027, Department of Energy Standard for the Performance Testing of Personnel Dosimetry Systems (DOE 1986); and International Standards Organization (ISO) 6980, Reference Beta Radiations for Calibrating Dosimeters and Doseratemeters and for Determining Their Response as a Function of Beta Radiation Energy (ISO 1984).

\subsubsection{Traceability to National Standards}

As stated, maintaining radiological reference fields traceable to national standards is one of the primary goals of this project. The traceability pathway has been established over the history of this effort and was initially discussed in the 1993 annual report (Lyon et al. 1994). Since the method of traceability is often unclear and can vary periodically, the current pathway for PNL radiological reference fields is provided here.

Traceability infers an assurance that calibration fields are established and used in a manner consistent with national standards. There are two accepted types of consistency measurements which are commonly used to infer traceability: 1) implied consistency, which is established through the use of a laboratory standard submitted to NIST for calibration within radiation fields applicable to the laboratory, and 2) demonstrated consistency, which can be established through a measurement quality assurance (MQA) interaction with NIST. This latter method is akin to a performance test administrated by NIST and is instrumental in verifying measurement traceability, as opposed to simply obtaining or maintaining a traceable source or reference instrument (i.e., artifact traceability). A disadvantage with traceability based only upon implied consistency is the lack of demonstration which indicates that measurements made of traceable sources or using reference instruments are consistent with those made of or using national standards. Traceability based upon demonstrated consistency provides the assurance that traceable instruments and/or sources are being used properly - whether it be to calibrate additional sources (or reference fields) or laboratory instrument standards - such that traceability is appropriately extended as desired.

NIST supports the use of both techniques in maintaining traceability, but favors the practice of performing MQA interactions on a routine basis coupled with providing infrequent instrument or source calibrations. This project mirrors the NIST philosophy where possible; however, there are some limitations of the NIST capability which require a variance in the normal process. The following descriptions provide the traceability pathway for each of the radiation types applicable within this project. 
Photon sources (i.e., gamma sources and x-ray techniques) are maintained traceable via both implied and demonstrated consistency verifications. Periodically, one or more selected "reference class instruments" are submitted to NIST for calibration to specific radiation fields. Prior to 1994, three air ionization chambers had been submitted for calibration to ${ }^{137} \mathrm{Cs},{ }^{60} \mathrm{Co}$, and many of the available NIST X-ray techniques, including M30, M50, M100, M150, M200, H50, H100, H150, H200, H250, S60, and S75. During 1994, two additional chambers were submitted for calibration. The first was a large volume $\left(1800 \mathrm{cc}\right.$ ) Capintec PR-18 ion chamber (s/n CII1.8.5889) which was calibrated to ${ }^{137} \mathrm{Cs}$ to provide the laboratory with a reliable standard for measuring exposure rates in the region of a few milli-Roentgen and below. Prior to this, low exposure rate calibrations had been performed by calibrating a larger volume working standard, in-house, via a direct replacement method within a radiation field strength that both instruments were capable of measuring with a relatively low uncertainty. The second chamber calibration by NIST was a small volume (30cc) Capintec PM-30 ion chamber (s/n CII30.7502) submitted for traceability to M60 and H40 x-ray techniques. In calibrating these instruments directly to NIST "primary standard" reference fields, they are deemed "secondary standards" and are used within the process of calibrating other radiological reference fields and/or reference instruments for use as tertiary or working standards. The most common traceability pathway currently in use is depicted in Figure 6.2. However, in some cases, secondary standard instruments have been used to calibrate or verify the constancy of working level radiation fields, such as the fields associated with the Well sources.

To achieve demonstrated consistency, NIST has conducted MQA assessments of PNL photon reference fields since 1984, in most cases selecting a subset of the available sources and/or $\mathrm{x}$-ray techniques. The most recent of these occurred in late 1992 during which time M30, M100, and M150 x-ray and ${ }^{137} \mathrm{Cs}$ reference fields were verified.

Currently, NIST does not maintain capabilities for K-fluorescence $\mathrm{x}$-ray or ${ }^{241} \mathrm{Am}$ reference fields. Although traceability for these fields has been established using a similar pathway as that identified in Figure 6.2, the primary reference field is maintained by the National Radiation Protection Board of the United Kingdom. Traceability for irradiations and calibrations made using these reference fields are implied.

Neutron traceability for all irradiations and measurements performed using PNL sources is implied only. The primary pathway to NIST is through direct calibration of PNL ${ }^{252} \mathrm{Cf}$ sources, in terms of neutron emission rate, within the NIST Manganous Sulfate Bath Facility. Dose equivalent rates are calculated for these sources in their bare and moderated configuration based on NIST recommendations provided in National Bureau of Standards (NBS) Special Publication 633, Procedures for Calibrating Neutron Personnel Dosimeters (NBS 1982). A Nuclear Research Corporation Model NP-2 portable neutron monitor (SNOOPY) is maintained as a tertiary standard which is used to convey the dose equivalent rate in a low scatter environment to a calibiration well equipped with a bare ${ }^{252} \mathrm{Cf}$ source. The calibration well is currently established as a working standard specifically for use with SNOOPY survey instruments. Use of the well for calibrating any other neutron survey instrument would not necessarily preserve any implied traceability. The traceability pathway for neutrons is shown in Figure 6.3. 


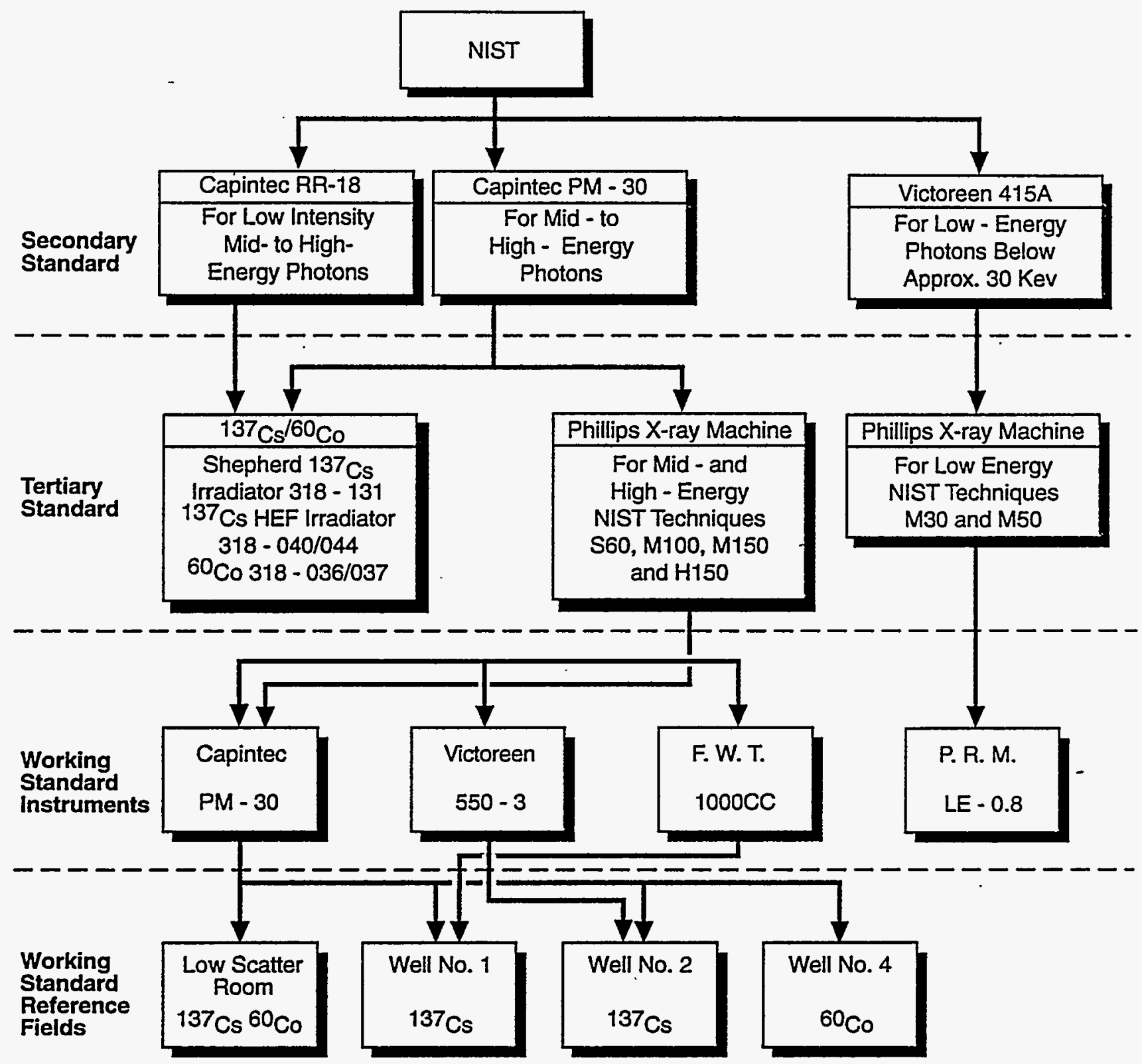

S9504057.1

Figure 6.2. Typical Traceability Pathway for PNL Photon Reference Fields

During the past several years, numerous joint efforts have been made between the NIST and PNL to establish a suitable method for neutron MQA intercomparisons in order to demonstrate traceability. These have involved various measurement devices and outcomes and, although nominal agreement has been somewhat poorer than is typically observed for beta and photon fields, the results are encouraging. 


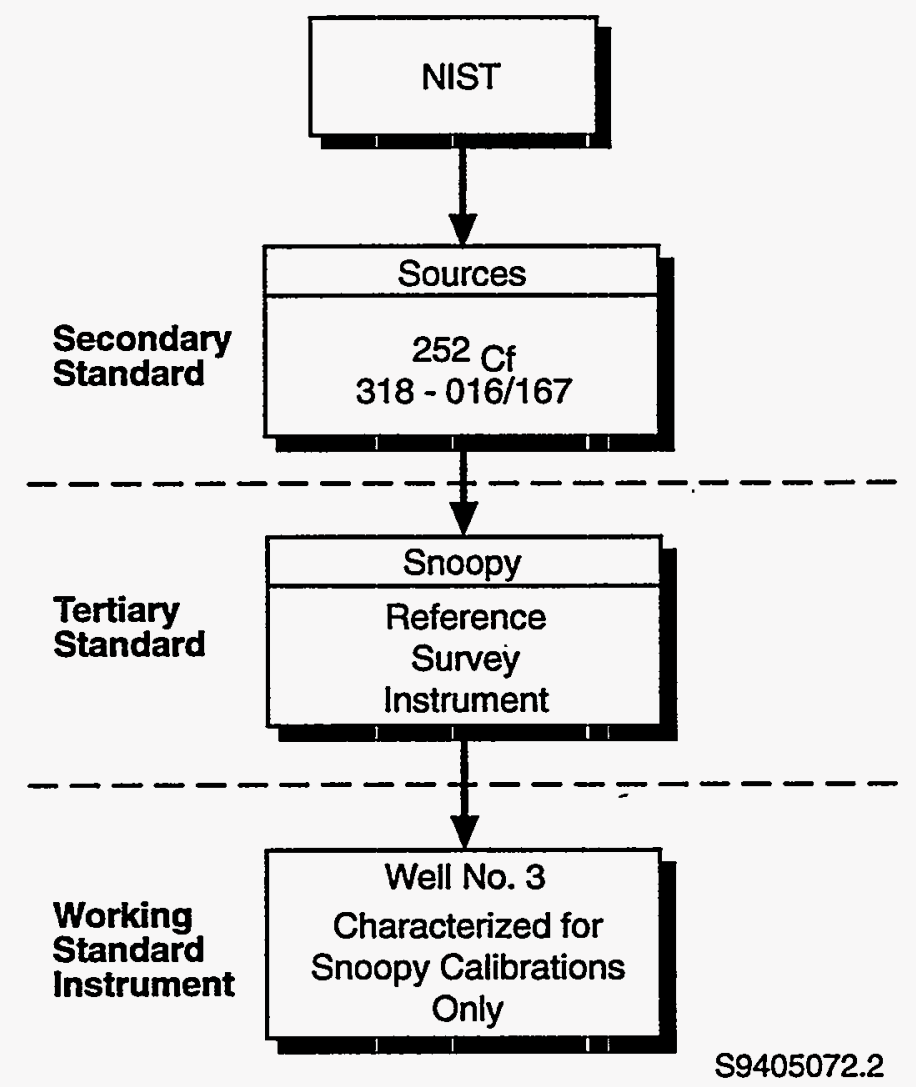

Figure 6.3. Typical Traceability Pathway for PNL Neutron Reference Fields

The NIST-traceability of beta reference fields is based upon both implied and demonstrated consistency. Of highest order in the reference field hierarchy are the Amersham-Buchler ${ }^{90} \mathrm{Sr} /{ }^{90} \mathrm{Y}$ (74 $\mathrm{MBq}$ and $1.85 \mathrm{GBq})$ and ${ }^{204} \mathrm{Tl}(18.5 \mathrm{MBq})$ beta point sources. NIST maintains a similar set of sources at its facility which it has characterized/verified both quantitatively and qualitatively. PNL predominantly uses the alternate (i.e., Amersham-U.S. and Isotope Products Laboratory) set of point sources of similar isotopic distribution, but with subtle differences in construction material and, in the case of the ${ }^{204} \mathrm{Tl}$, a significantly larger activity (i.e., $1.85 \mathrm{GBq}$ ). The ${ }^{90} \mathrm{Sr} /{ }^{90} \mathrm{Y}$ sources of this alternate set, commonly referred to as the ANSI N13.11 sources, were calibrated directly by NIST, the $74 \mathrm{MBq}$ source in 1986 at the NIST and the $1.85 \mathrm{GBq}$ source at PNL by a NIST scientist using a PNL-owned extrapolation chamber. The NIST calibration places these sources as secondary standards in the calibration hierarchy. The PNL-owned extrapolation chamber, used by the NIST scientist, is generally considered to be an absolute standard and is difficult to place in the laboratory traceability hierarchy. It is currently being used as a tertiary standard, since instead of being calibrated by NIST using primary standards, it is compared to the Amersham-Buchler sources which, through periodic MQA intercomparisons with NIST, are considered to be internal secondary standards. The traceability pathway for beta reference fields and the extrapolation chamber is shown in Figure 6.4. 


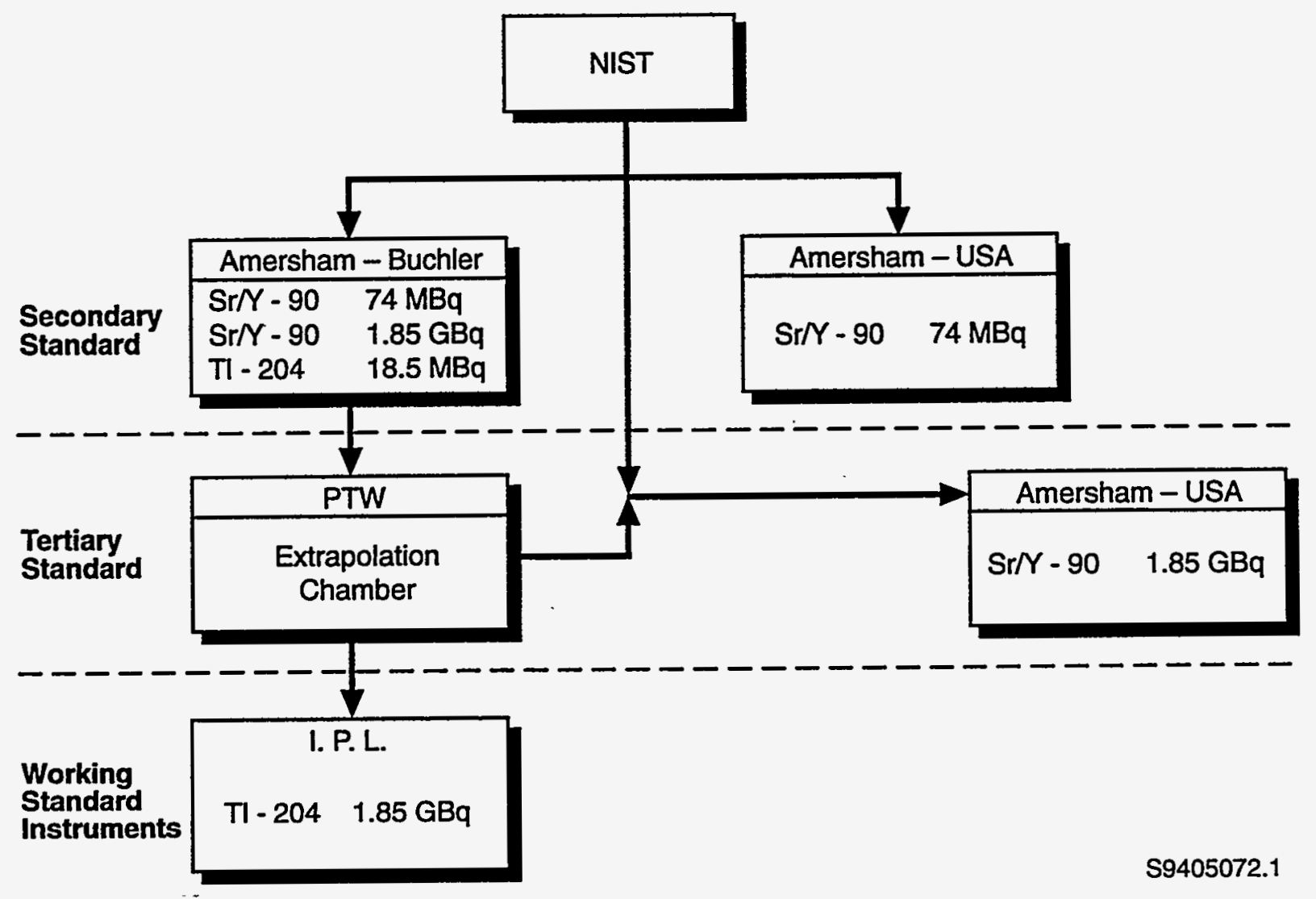

Figure 6.4. Typical Traceability Pathway for PNL Beta Reference Fields

The periodic MQA intercomparison NIST conducts with the PNL calibrations laboratory involves the use of a NIST transfer standard. Intercomparisons were made in 1984-85 and again in 1991-92 between the NIST and PNL Amersham-Buchler sources. These sources were selected to preserve similar geometry, encapsulation, and activity since it is suspected the transfer standard used for these measurements is sensitive to differences in these parameters.

\subsubsection{Calibrations and Constancy Checks}

Following the initial calibration, and between MQA interactions with NIST, verification measurements are performed to assure constancy of characteristics and magnitude for most radiation reference fields maintained by the RS\&C Task. For beam and open geometry photon fields, this includes abbreviated quarterly checks and generally more rigorous annual verifications. $\mathrm{X}$-ray reference fields are verified at the beginning of each calendar quarter. Low scatter room neutron sources are verified on a quarterly basis as a byproduct of the quarterly verification of the SNOOPY tertiary standard. Well sources (photon and neutron) are calibrated annually to provide additional data for modifying the computerized exposure rate calculational program which determines programmatic instrument calibration points. Beta source absorbed dose rates are verified annually using an extrapolation chamber at fixed distances to assure constancy with original calibration data. Instrument standards are 
intercompared annually, including verifying the calibration factors for photon ionization chambers, assuring the proper function of the Physikalisch-Technische Werkstäten (PTW) extrapolation chamber and assuring accuracy and proper functioning of the reference SNOOPY detector (tertiary standard).

Annual calibration verifications of photon reference fields were completed as scheduled in 1994 with quarterly constancy verifications performed at approximately three-month intervals. Fixed-position gamma sources, including the ${ }^{241} \mathrm{Am}$ source (318-184), Shepherd ${ }^{137} \mathrm{Cs}$ irradiator (318-131) and sources within the low scatter room (318-001, -029, and -164), were compared to the previously established baseline dose rates (corrected for decay) and were found to be within $\pm 2 \%$ of those established values (see Table 6.3). Annual calibrations of the well and the high exposure facility gamma sources (318-027, -030,-031, -036, -037, -040 and -044) were used to formulate updated positioning equations used by the computer codes which control source/instrument placement.

As can be seen from Table 6.3, all quarterly constancy verifications indicated calibration reference fields were maintained well within $\pm 5 \%$ of calibrated exposure rates determined during baseline or annual calibrations. For well and high-exposure facility sources, these values represent an average of all positions examined during each quarterly measurement. The Well $\# 4{ }^{60} \mathrm{Co}$ source $(318-027)$ appears to generally have a high bias in comparison to the constancy of other sources; however, this is probably due to uncertainties with the use of the PM- 30 reference ion chamber at the lower end of its measurement capability. No apparent defects were found with the calibration or the function of Well \#4.

During the fourth quarter constancy verification of the Well $\# 2{ }^{137} \mathrm{Cs}$ source (318-030), the measured exposure rates were found to deviate significantly from the calculated values near the upper portion of the well (i.e., relatively small distances from source to detector). These deviations tended to decrease as the source to detector distances were increased and were negligible with the source placed within the lower regions of the well. This trend indicated that an unplanned shift in source position had occurred. Based on the amount of error noted at each measured distance, the position discrepancy was estimated to be 2-3 cm, with the source placed further from the detector than reported. This information was reported to the Instrument Calibration \& Evaluation Project and was subsequently confirmed using physical measurements of the source position.

Annual verifications of the PTW extrapolation chamber were performed using each of the three Amersham-Buchler PTB standards. Strontium/Yttrium-90 sources from Set 31 (318-012 and -013) were used to verify the high energy capability of the instrument and the ${ }^{204} \mathrm{Tl}$ source from Set 4.2 was used to verify the mid-range energy capability. This latter source was chosen due to its young relative age since it is desirable to have as much activity as possible to maintain a low uncertainty level. The instrument responded less than or equal to $2.1 \%$ from the decayed baseline dose rates provided on the source certificates. Annual verifications of ${ }^{90} \mathrm{Sr} /{ }^{90} \mathrm{Y}$ ànd ${ }^{204} \mathrm{Tl}$ sources used for most dosimeter irradiations and instrument evaluations (318-102, -103 and -192) were subsequently performed using the extrapolation chamber. Measured results were within $2.5 \%$ of decayed baseline dose rates. 
Table 6.3. Photon Reference Fields - Calibration Performance Summary (Annual calibrations are shaded)

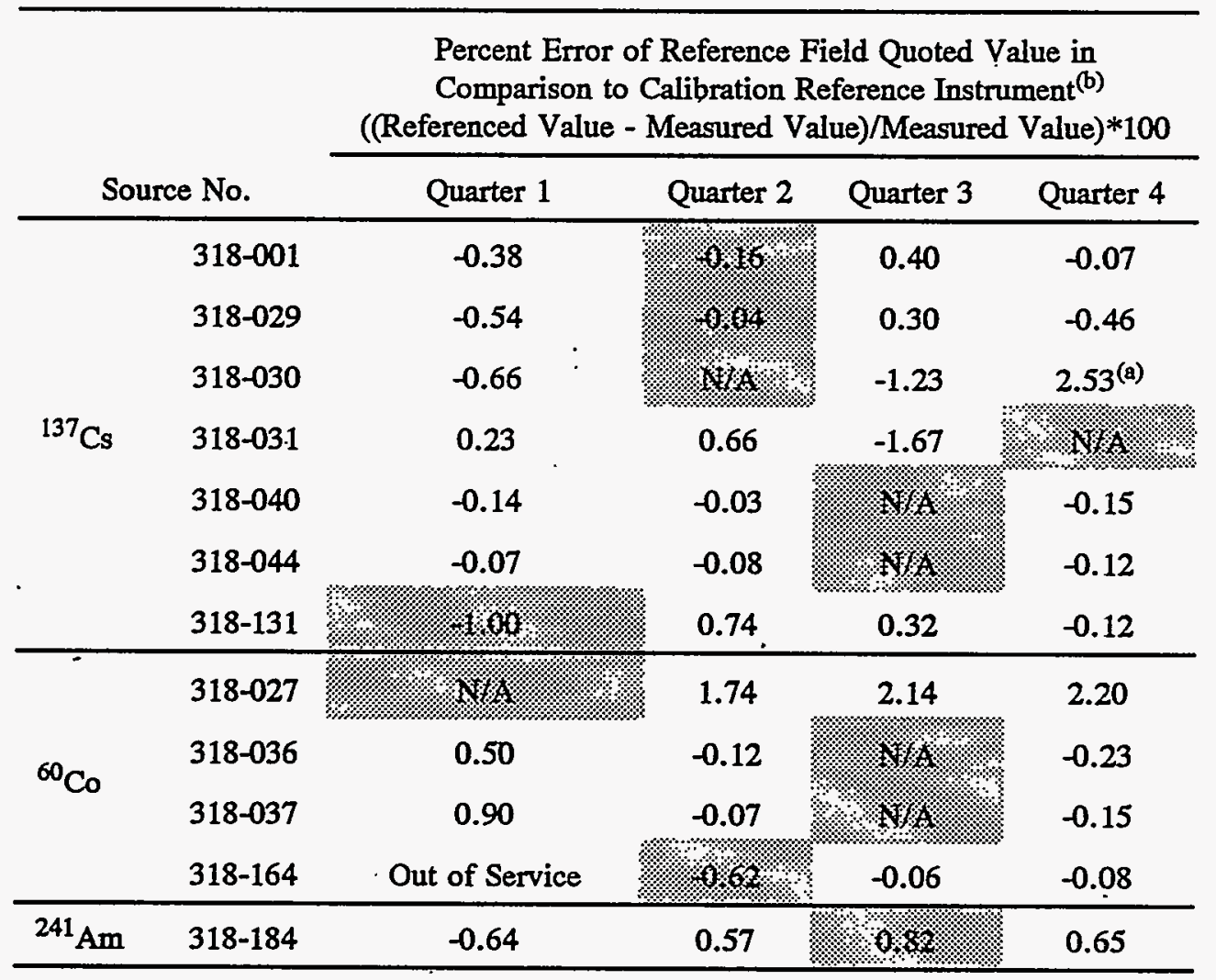

(a) Source position discrepancy identified (see text).

(b) For annual calibration results listed "NA," exposure rates are completely reestablished and comparison to previous rates is unnecessary.

Quarterly measurements for beta sources were made using LiF TL dosimeters. Dosimeters were placed at five positions on a lucite phantom $30 \mathrm{~cm}$ in height and width and $5 \mathrm{~cm}$ thick. This phantom is typically used for dosimeter irradiations to provide anthropomorphic conditions. This method of QC is currently in a "pilot" status while the irradiation parameters and the dosimeter holder characteristics are evaluated.

Well \#3 containing ${ }^{252} \mathrm{Cf}$ source $318-038$ was calibrated during the second quarter and a new calibration curve was generated and installed within the controlling computer. The SNOOPY in-house reference instrument was calibrated prior to the fourth quarter Well \#3 constancy verification. This calibration was performed using only the newest ${ }^{252}$ Cf source $(318-167)$ as a reference based on earlier measurements and information from the NIST which suggest the dose equivalent rate from the older source (318-016) may now be questionable (see Section 6.2.1). Based on these measurements and evidence which suggests that a substantial warm-up period is necessary for the SNOOPY response to 
stabilize, a new room return correction factor was identified which resulted in a final determined efficiency $5.6 \%$ higher than the values established in 1993.

Quarterly constancy measurements of Well \#3 were performed during Quarters 1, 3, and 4. The mean bias of the measured dose equivalent rates versus the calculated rates for quarters 1 and 3 were within $\pm 2 \%$. For Quarter 4 measurements, the mean bias was $4.6 \%$, which was due to the higher efficiency determined in the immediately preceding recalibration of the SNOOPY. It is anticipated this same outcome will be noted in the first quarter measurements of 1995, after which the well will be recalibrated based on the new detector efficiency.

\subsection{SUPPORTING STUDIES}

Four supporting studies were conducted in 1994. These are described below.

\subsubsection{Discontinued Use of Low-Level ${ }^{252}$ Cf Source from Calibration of SNOOPY Reference Instrument}

During the past two calibrations of the in-house reference SNOOPY configured with the counter/scaler, a distinct difference was noted between the calculated efficiencies determined using the two available ${ }^{252} \mathrm{Cf}$ sources within the 318 Building Low-Scatter Room (LSR) (see Figure 6.5). While both sources were calibrated by NIST prior to installation at PNL, one of these sources is much older and of lower initial activity than the other. Source 318-016 was obtained in May 1981 and was initially calibrated to have a neutron emission rate of $3.47 \times 10^{8} \mathrm{n} / \mathrm{sec}$, while the other was obtained in late 1989 and had an initial assessed emission rate of $3.43 \times 10^{9} \mathrm{n} / \mathrm{sec}$. Based on recent information from NIST, it is likely that minor impurities within ${ }^{252} \mathrm{Cf}$ sources such as ${ }^{250} \mathrm{Cf}\left(\mathrm{T}_{1 / 2}=13.2\right.$ years) and ${ }^{254} \mathrm{Cf}$. $\left(\mathrm{T}_{1 / 2}=61.9\right.$ days) create a deviation from the true ${ }^{252} \mathrm{Cf}$ half life $\left(\mathrm{T}_{1 / 2}=2.65\right.$ years) and, consequently, the sources may indicate an emission rate which deviates from the calibrated value. Although the appropriate half life could be determined from the original source production, there is an inherent uncertainty to the isotopic composition of each source which further complicates its determination. NIST now recommends that neutron sources undergo recalibration at a frequency of between 2 and 3 half lives ( 5 to 8 years). Since source $318-016$ has been used at PNL in excess of 5 half lives, it is suspected that the observed difference in SNOOPY efficiency may be evidence of this problem.

As a result of these suspicions, a procedure deviation was implemented during 1994 which omits the use of the older 318-016 source for aiding in the transfer of free-field neutron calibration to the Well \#3 source. As a result, the SNOOPY reference detector cannot be verified within low scatter conditions below a dose equivalent rate of approximately $150 \mathrm{mrem} / \mathrm{h}$. This restriction is expected to remain in effect until the emission rate of the older source can be either verified or revised through inhouse measurement methods or recalibrated at NIST. The latter option is probably not reasonable at this time since the source is within a few years of becoming obsolete due to its low emission rate. 


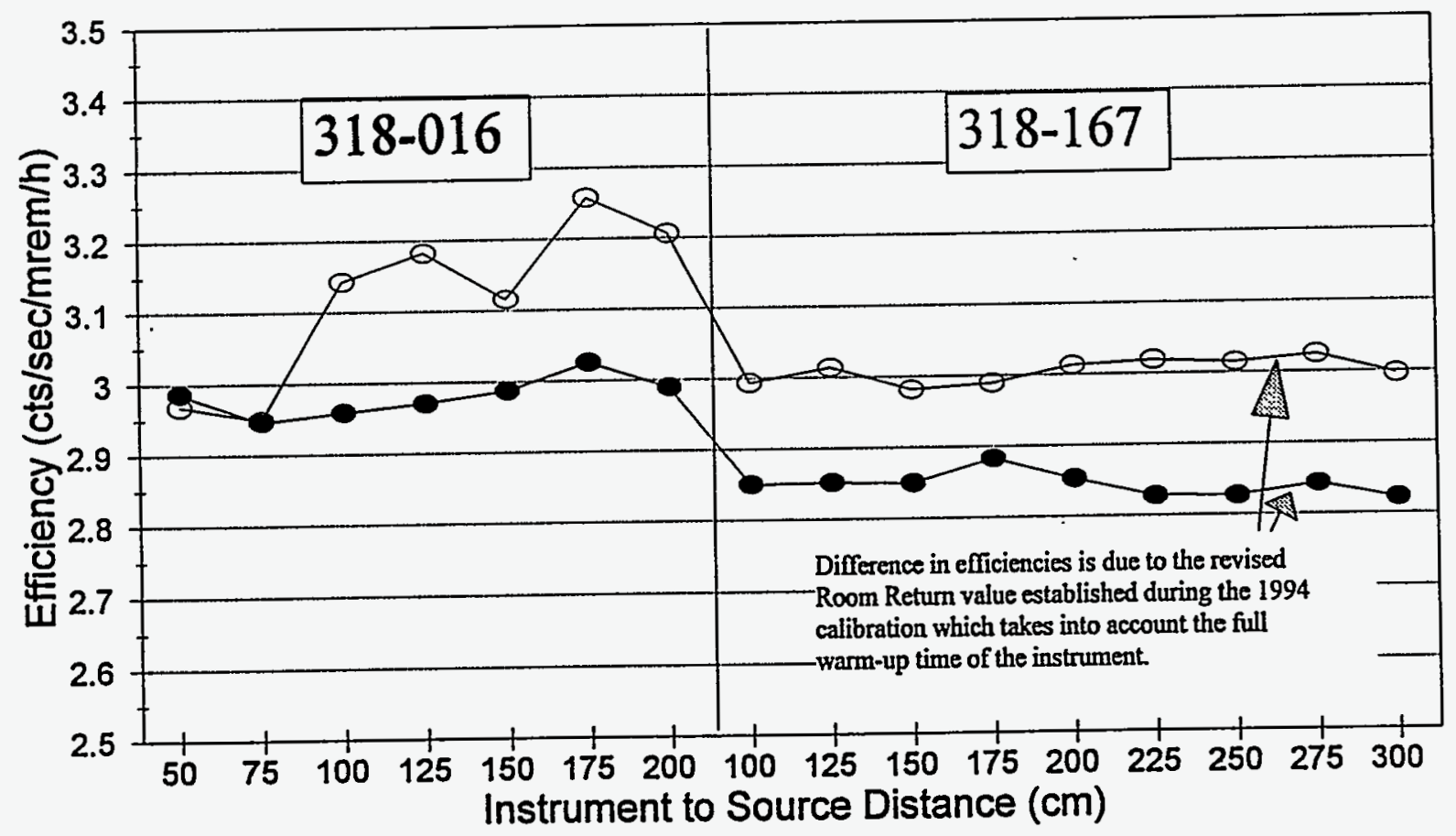

\section{$1993-1994$}

Figure 6.5. Reference SNOOPY Efficiency Using ${ }^{252} \mathrm{Cf}$

Sources 318-016 and 318-167

\subsubsection{Investigation of Precision Long Counter Methodology for Neutron Constancy Verification}

As part of the potential solution to the neutron source calibration problem identified above, preliminary work was performed to restore the 318 Building, Precision Long Counter (PLC) to active use. Several measurements were performed during the year to refamiliarize operators with its configuration and methodology and to identify which of the many $\mathrm{BF}_{3}$ tubes are in satisfactory condition for use. One of the historical problems using this system with 318 Building sources is obtaining $\mathrm{BF}_{3}$ tubes of low enough efficiency to measure the relatively high emission rates. Many of the currently available tubes were calibrated using a NIST-traceable PuBe source which, unfortunately, has been transferred out of the facility. To evaluate whether tubes had changed significantly over the years, several were verified using one of the LSR ${ }^{252} \mathrm{Cf}$ sources to identify if response ratios (between tubes) were constant from earlier determinations. Although this intercomparison was not completed in 1994, it will be the immediate focus in 1995 to complete these investigations to determine the most suitable tubes for use. Supplementary plans include the use of the PLC to reverify or recalibrate current in-house ${ }^{252} \mathrm{Cf}$ sources by intercomparisons to a new manufactured and NIST-calibrated source which is anticipated for procurement during 1995. 


\subsubsection{Damaged Encapsulation Window of $50 \mathrm{mCi}^{204} \mathrm{Tl}$ Source}

Early in 1994, a routine inspection of the Isotope Products $1.85 \mathrm{GBq}(50 \mathrm{mCi}){ }^{204} \mathrm{Tl}$ source indicated that a leak had developed in the encapsulation. The suspected breach was in the thin glass window. Prior to this discovery, it was observed that a Capton covering, installed to provide an additional margin of protection, had become brittle and was breaking apart. Although no contamination of the work area occurred, the window had to be replaced. The source was returned to Isotope Products and a new glass window and Capton covering were installed. When the source was returned to PNL, it was recalibrated in terms of its shallow absorbed dose rate using the PTW extrapolation chamber and found to be very consistent with its earlier value, corrected for decay. In addition, a complete residual maximum energy $\left(E_{\text {real }}\right.$ ) evaluation was performed in accordance with ISO 6980 (ISO 1984). Measurements of the residual maximum beta particle range $\left(\boldsymbol{R}_{\text {reas }}\right)$ were performed using the PTW extrapolation chamber with a fixed electrode spacing of $4 \mathrm{~mm}$ (see Figure 6.6). This standard recommends that ${ }^{204} \mathrm{Tl}$ sources, suitable for calibration purposes, have an $\mathrm{E}_{\mathrm{res}}$ value greater than $0.530 \mathrm{MeV}$, to assure that the beta component is not being overly attenuated by the window, and less than $0.763 \mathrm{MeV}$ to verify a high radiochemical purity. The resulting $\mathrm{E}_{\mathrm{res}}$ for this source was found to be $0.609 \mathrm{MeV}$. Based on these results, the source was placed back into routine service.

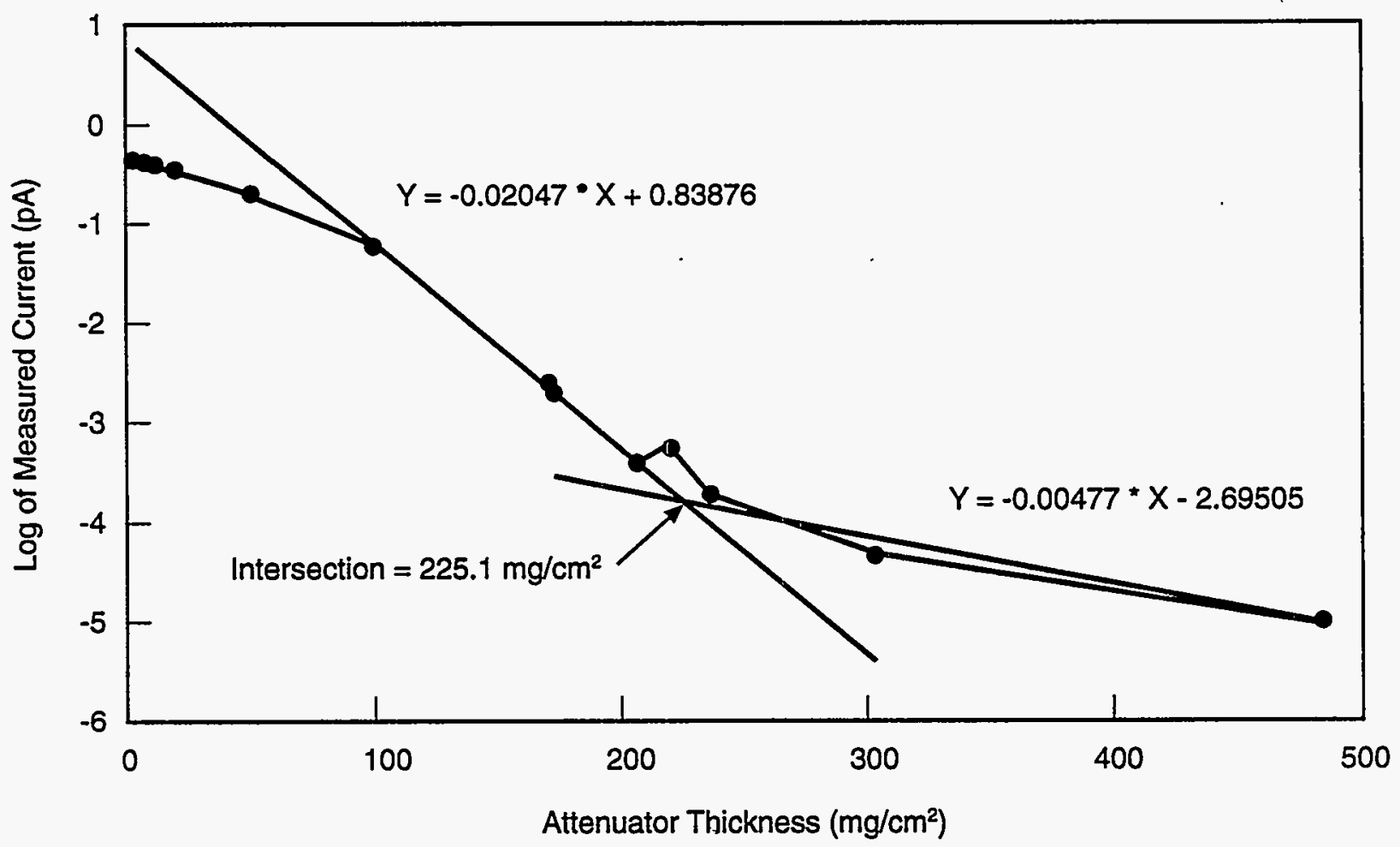

S9504057.5

Figure 6.6. Evaluation of Energy Characteristics for ${ }^{204}$ Ti Source (No. 318-192) with Repaired Window 


\subsubsection{Low-Level Exposure Rate Calibrations of Gamma Sources}

The task of calibrating gamma sources at lower levels has become increasingly prevalent and requires measurements to be performed using NIST-traceable ion chambers which yield electrical currents barely perceptible above electronic noise and drift. These signals range as low as $10 \mathrm{fA}$ and are assessed using electrometers which are capable of registering these currents. However, one of the long-term issues with this process is that the electrometers cannot physically be calibrated, traceable to NIST, below $2 \mathrm{pA}$ due to the limitations of the Westinghouse Standards Laboratory and other calibration laboratories consulted thus far. While there currently is no evidence nor dire concern that the electrometers perform non-linearly below their lowest calibration point, it is difficult to accurately estimate the uncertainty of such measurements. Alternatives are being considered for this methodology. One possibility is the use of large volume pressurized ionization chambers, including models currently on the market or one constructed specifically for the needs of this project. A second method is one which was used for the 1994 calibration of Well \#1 at the lowest seven positions ranging in exposure rates from about 0.080 to $0.420 \mathrm{mR} / \mathrm{h}$. This involved the use of an Eberline HP-270 compensated Geiger-Mueller (GM) detector which was cross-calibrated to an ion chamber response at an exposure rate of 1-2 $\mathrm{mR} / \mathrm{h}$. This cross-calibration point was chosen such that the effects of dead time of the GM detector would be negligible and because the ion chamber measured was still relatively significant at about $0.2 \mathrm{pA}$. While this method preserves the required degree of NIST traceability, there are refinements in technique which will be needed if it is to be used on a common basis. Other options will continue to be investigated.

\subsection{PROJECT-RELATED PROFESSIONAL ACTIVITIES}

One professional presentation was made by project staff during 1994:

McDonald, J. C. 1994. Conversion from Reference Quantities to Dose Equivalent Quantities. Presented at the third Annual Meeting of the Council on Ionizing Radiation Measurements and Standards, November 16-18, 1994, Gaithersburg, Maryland. 


\subsection{INSTRUMENT CALIBRATION AND EVALUATION PROGRAM}

The Instrument Calibration and Evaluation (IC\&E) Program provides complete and reliable radiation protection instrument services for Hanford Site contractors to ensure personnel safety in the Hanford workplace. Specific tasks performed under this program during 1994 included the conduct of the routine instrument pool, the Hanford Test and Evaluation Project, direct support for the HP-9000 Database with includes all instrument calibration records, technical reviews of instrument calibration procedures for Site contractors, maintenance of the Site radiation protection instrument manual, and evaluation of commercially available ion-chamber dose rate survey instruments to replace the Site cutie-pie (CP) survey instrument.

The operation of a complete radiation protection instrument calibration and maintenance program is an integral part of the Hanford Site radiological control program. The IC\&E Program provides complete instrument services, thereby providing the Hanford contractors with a quality, reliable, and accurate instrumentation pool capable of performing at the level necessary to ensure personnel safety as required by 10 CFR 835 (DOE 1993), DOE 5480.11 (DOE 1990a), and HSRCM-1 (RL 1994). Calibrations are performed using the guidance in ANSI N323 (ANSI 1978).

\subsection{ROUTINE TASKS}

The routine program activities fall under the base tasks that comprise the 1994 program: 1) Routine Portable Instrument Pool, 2) Hanford Test and Evaluation Project, 3) Calibration and service of WHC, PNL, and Bechtel Hanford Incorporated non-pool radiation protection instruments, 4) maintenance of a calibrations records database, 6) maintenance of all the necessary radiological, electronic, and mechanical standards traceable to NIST, and 6) the continuing update and revision of the Radiation Protection Instrument Manual. (a) These basic tasks and other important supporting tasks performed in CY 1994 are described in this chapter.

The routine tasks also include the following:

- maintaining traceability of radiological and electronic calibration systems to NIST

- operating a task to service radiation protection emergency kits

- modifying and updating written calibration procedures as new instruments are introduced and calibration techniques are improved

- procuring, acceptance testing, calibrating, and distributing pencil dosimeters

(a) Internal Manual, PNL-MA-563, Pacific Northwest Laboratory, Richland, Washington. 
- performing specification development and acceptance testing on all instruments purchased for pool use and as required by Hanford contractors

- fabricating and certifying instrument performance check sources for Hanford contractors.

The Routine Portable Instrument Pool and the Hanford Instrument Test and Evaluation Project are discussed in the sections below.

\subsubsection{Routine Portable Instrument Pool}

The routine program provides for a complete radiological control portable instrument program. A pool of portable and semi-portable radiation protection instrumentation is maintained for contractor use. Maintaining this instrumentation pool involves

- procuring new and replacement instruments

- overseeing an instrument pickup and delivery service

- maintaining calibration records

- surveying, maintaining and calibrating instruments.

The use of portable instruments by Contractors on the Hanford Site during CY 1994 is shown in Table 7.1. The instrument types are described in detail in the Radiation Protection Instrument Manual. (a)

During the year, a number of new instruments were procured to replace instruments from the pool that had been damaged or disposed of as a result of contamination. In addition, the Site mission of restoration and remediation has required more contamination monitoring instruments and low-level gamma field instruments. The following items were purchased in 1994:

- $2030 \mathrm{GM}$ tubes for probe repairs and replacement parts

- 750 photomultiplier tubes for portable alpha meter (PAM) probe manufacture and repairs.

As part of a complete portable instrument program, procurement continued for multirange, checksource devices to verify the performance of instruments in the field as required in ANSI standards and DOE orders. To complement these devices and the existing Site instrument check sources, the program to annually verify and recertify designated check-sources continued. The program's source calibration capabilities allow for the recertification of sources. Four counting systems provide this source certification service:

(a) Internal manual, PNL-MA-563, Pacific Northwest Laboratory, Richland, Washington. 
Table 7.1. Portable Instrument Usage for CY 1994

\begin{tabular}{|c|c|c|c|c|c|c|c|}
\hline \multirow[b]{2}{*}{ Instrument Type } & \multicolumn{2}{|c|}{ Bechtel $^{(a)}$} & \multicolumn{2}{|c|}{ Westinghouse } & \multicolumn{2}{|c|}{ Battelle } & \multirow[b]{2}{*}{ Total } \\
\hline & $\begin{array}{l}\text { Number of } \\
\text { Instruments }\end{array}$ & $\begin{array}{l}\text { Percent of } \\
\text { BHI Total }\end{array}$ & $\begin{array}{l}\text { Number of } \\
\text { Instruments }\end{array}$ & $\begin{array}{l}\text { Percent of } \\
\text { WHC Total }\end{array}$ & $\begin{array}{l}\text { Number of } \\
\text { Instruments }\end{array}$ & $\begin{array}{l}\text { Percent of } \\
\text { PNL Total }\end{array}$ & \\
\hline EBM & 1 & $<1 \%$ & 33 & $<1 \%$ & 11 & $<1 \%$ & 45 \\
\hline $\mathrm{CP}$ & 131 & $13 \%$ & $1443^{\circ}$ & $15 \%$ & 472 & $12 \%$ & 2046 \\
\hline DAD/GAD/FDPD & 51 & $5 \%$ & 21 & $<1 \%$ & 88 & $2 \%$ & 160 \\
\hline EGM & 306 & $30 \%$ & 2566 & $27 \%$ & 1303 & $33 \%$ & 4175 \\
\hline TPC & 4 & $<1 \%$ & 53 & $<1 \%$ & 26 & $<1 \%$ & 83 \\
\hline LPC & & & 3 & $<1 \%$ & & & 3 \\
\hline HPC & 6 & $<1 \%$ & 58 & $<1 \%$ & 6 & $<1 \%$ & 70 \\
\hline $\mathrm{XCP}$ & $\cdot$ & & 32 & $<1 \%$ & & & 32 \\
\hline SNOOPY & 7 & $<1 \%$ & 105 & $1 \%$ & 41 & $1 \%$ & 153 \\
\hline PAM & 236 & $23 \%$ & 2505 & $26 \%$ & 805 & $20 \%$ & 3546 \\
\hline LUD $^{(b)}$ & 8 & $<1 \%$ & 296 & $3 \%$ & 139 & $4 \%$ & 443 \\
\hline PANCAKE & 214 & $20 \%$ & 1855 & $19 \%$ & 827 & $21 \%$ & 2896 \\
\hline LLM & 8 & $<1 \%$ & 72 & $<1 \%$ & 17 & $<1 \%$ & 97 \\
\hline BBCP & 9 & $<1 \%$ & 69 & $<1 \%$ & 67 & $2 \%$ & 145 \\
\hline PAC-6 & 4 & $<1 \%$ & 4 & $<1 \%$ & 2 & $<1 \%$ & .10 \\
\hline BWCP & 1 & $<1 \%$ & 29 & $<1 \%$ & 40 & $1 \%$ & 70 \\
\hline $\mathrm{SNM}_{8}{ }^{(\mathrm{c})}$ & 3 & $<1 \%$ & 100 & $1 \%$ & & & 103 \\
\hline HP210 & 15 & $2 \%$ & 124 & $1 \%$ & 48 & $1 \%$ & 187 \\
\hline RO2 & 19 & $2 \%$ & 95 & $1 \%$ & 5 & $<1 \%$ & 119 \\
\hline EXT & 3 & $<1 \%$ & 41 & $<1 \%$ & 24 & $<1 \%$ & 68 \\
\hline RO7 & 6 & $<1 \%$ & . 47 & $<1 \%$ & 30 & $<1 \%$ & 83 \\
\hline $\begin{array}{l}\text { TOTAL BY } \\
\text { CONTRACTOR }\end{array}$ & 1,032 & & 9,551 & & 3,951 & & 14,534 \\
\hline$\%$ OF TOTAL & $7 \%$ & & $66 \%$ & & $27 \%$ & & \\
\hline
\end{tabular}

(a) Service initiated July 1, 1994.

(b) Includes Ludlum models 21, 28, 177-8, 177, 177-36, 177-56, 177-52.

(c) Includes HHD440, HHD470P, Ludlum Model 3, Ludlum Model 316. 
- a Nuclear Measurements Corporation windowless proportional detector

- an Eberline proportional portal monitor detector

- a Berthold large area (8-inch diameter) flow through proportional counting system

- a gamma spectroscopy Germanium-Lithium drifted system.

WHC has discontinued certifying all sources except their own instrument calibration sources, which require traceability to NIST.

\subsubsection{Hanford Instrument Test and Evaluation Project}

The Hanford Instrument Evaluation Committee was established to provide a Hanford intercontractor information exchange mechanism to assure that the highest quality portable and semi-portable radiological protection instrumentation program is maintained at Hanford. Responsibilities of the committee include the following:

- discuss and propose solutions to ongoing or potential radiological instrumentation problems and needs on site

- identify new radiological instrumentation available from manufacturers that may be useful to the Hanford Site operations

- oversee the procurement of the instruments, and review the evaluations of the performance by contractor organizations

- establish or review minimum acceptable operational criteria for portable and semi-portable radiological instrumentation used for safety on the Hanford Site

- promote information exchange between contractors on radiological protection instrumentation usage and problems/resolutions.

Representatives from all of the Hanford contractors and a representative of $\mathrm{RL}$ are on this committee. During 1994, the committee continued to perform evaluations on instruments identified as needing further evaluations before approval and placement on the "approved instrument list." The approved instrument list was developed to meet HSRCM-1 (RL 1994.) requirements that only approved instruments may be used on site. In addition to evaluating existing instruments, the committee evaluated several new instruments. Instruments on which tests were performed included Victoreen High-Range CP (HRCP), Eberline RO3-B (CP), Eberline RO-7, Bicron Surveyor X with a scaler option and a modified battery board enabling four vs. two batteries to be used, Science Applications International Corporation AP-2 Alpha Detector, Johnston Triton III tritium monitor, and the Eberline PCM-2 Personnel Automatic Contamination Monitor. Testing was provided to determine the MDA of plant contamination survey instruments with higher scanning speeds than are currently being used at Hanford. 
Late in the year, the Site contractors determined that compliance with 10 CFR 835 (DOE 1993) required that full environmental type-testing was necessary for each instrument used in radiological control monitoring. The committee determined the schedules, priorities, methods, and costs of contractors' compliance by January 1, 1996.

\subsection{SUPPORTING STUDIES}

A study was conducted to determine the maximum survey speed required to detect three times the total contamination values given in Table 2-2 of the Hanford Site Radiological Control Manual (RL 1994). This information was developed to support implementation of the statistical survey methodology which requires a fast scan of the material's surface at a speed that can detect 3 times the total contamination value. Scan speeds are interpolated from empirically derived minimum detectable count rates (MDCRs) for beta/gamma and alpha contamination survey instruments. The MDCRs were measured using distributed contamination sources. The instruments tested were a $15.5-\mathrm{cm}^{2}$ pancake GM detector, a $100-\mathrm{cm}^{2}$ gas proportional detector, and a 50- $\mathrm{cm}^{2}$ Hanford PAM. In support of the same survey method, the MDA of a 5-second static count was determined for both $95 \%$ and $67 \%$ confidence levels.

\subsection{PUBLICATIONS AND PRESENTATIONS}

Staff publications, presentations, and external professional activities are listed in this section.

\subsubsection{Publications}

Durham, J. S., M. L. Johnson, and D. L. Gardner. 1994. Contamination Surveys for Release of Material. PNL-9789, Pacific Northwest Laboratory, Richland, Washington.

\subsubsection{Presentations}

Johnson, M. L. 1994. Scan Speeds to Detect One Times and Three Times DOE Radiological Control Manual Table 2-2 Total Contamination Limits. Presented at the Fourth Conference on Radiation Protection and Dosimetry, October 23-27, 1994, Orlando, Florida.

Johnson, M. L. 1994. Minimum Detectable Activity of Hanford Survey Instruments. Presented at the Radiological Control Managers Workshop, March 3-5, 1994, Oakland, California.

\subsubsection{External Professional Activities}

Johnson, M. L. Chairperson of Working Group for ANSI N323B, "Radiation Protection Instrumentation Test and Calibration - Air Monitoring Instruments.”

Johnson, M. L. Member of Working Group for ANSI N323A, "Radiation Protection Instrumentation and Calibration - General Requirements and Portable Instruments." 
Johnson, M. L. Member of Working Group for ANSI N323C, "Radiation Protection Instrumentation and Calibration - Fixed Instruments." 


\subsection{REFERENCES}

American National Standards Institute (ANSI). 1993. Performance Criteria for Radiobioassay. ANSI N13-30, New York.

American National Standards Institute (ANSI). 1983. American National Standard for Dosimetry Personnel Dosimetry Performance - Criteria for Testing. ANSI N13.11, New York.

American National Standards Institute (ANSI). 1978. Radiation Protection Instrumentation Test and Calibration. ANSI N323, New York.

American National Standards Institute (ANSI). 1972. American Standard Practice for Occupational Radiation Exposure Records Systems. ANSI N13.6, New York.

Baumgartner, W. V., A. W. Endres, and S. R. Reese. 1992. Quality Control Program for the Hanford External Dosimetry Thermoluminescent Processing System. PNL-8299, Pacific Northwest Laboratory, Richland, Washington.

Dirkes, R. L., R. W. Hanf, and R. K. Woodruff, eds. 1994. Hanford Site Environmental Report for Calendar Year 1993. PNL-9823, Pacific Northwest Laboratory, Richland, Washington.

Durham, J. S. 1992. VARSKIN MOD2 AND and SADDE MOD2: Computer Codes for Assessing Skin Dose from Skin Contamination. NUREG/CR-5873, PNL-7913, Pacific Northwest Laboratory, Richland, Washington.

Endres, A. W., L. W. Brackenbush, W. V. Baumgartner, and J. J. Fix. 1995. Response of Hanford Combination Neutron Dosimeter Exposed to Plutonium Sources. PNL-10516, Pacific Northwest Laboratory, Richland, Washington.

Freedom of Information Act. Public Law 89-487, July 4, 1966.

International Commission on Radiological Protection (ICRP). 1984. Reference Man: Anatomical Physiological and Metabolic Characterstics. ICRP Publication 23, Pergamon Press, New York.

International Standards Organization (ISO). 1984. Reference Beta Radiations for Calibrating Dosemeters and Doseratemeters and for Determining Their Response as a Function of Beta Radiation Energy. ISO 6980, Geneva.

Kathren, R. L., J. F. McInroy, M. M. Reichert, and M. J. Swint. 1988. "Partitioning of Pu-238, Pu239, and Am-241 in Skeleton and Liver of U.S. Transuranium Registry Autopsy Cases." Health Physics 54(2):181-188. 
Lyon, M., D. E. Bihl, J. J. Fix, R. K. Piper, T. J. Froelich, J. A. Leonowich, and T. P. Lynch. 1991. Hanford Radiological Protection Support Services Annual Report for 1990. PNL-7752, Pacific Northwest Laboratory, Richland, Washington.

Lyon, M., D. E. Bihl, J. J. Fix, R. K. Piper, T. J. Froelich, J. A. Leonowich, and T. P. Lynch. 1992. Hanford Radiological Protection Support Services Annual Report for 1991. PNL-8236, Pacific Northwest Laboratory, Richland, Washington.

Lyon, M., D. E. Bihl, J. J. Fix, R. K. Piper, T. J. Froelich, and T. P. Lynch. 1993. Hanford Radiological Protection Support Services Annual Report for 1992. PNL-8764, Pacific Northwest Laboratory, Richland, Washington.

Lyon, M., D. E. Bihl, J. J. Fix, T. J. Froelich, R. K. Piper, and P. C. Ölsen. 1994. Hanford Radiological Protection Support Services Annual Report for 1993. PNL-10047, Pacific Northwest Laboratory, Richland, Washington.

National Council on Radiation Protection and Measurements (NCRP). 1989. Limit for Exposure to "Hot Particles" on the Skin. NCRP Report No. 106, Bethesda, Maryland.

Pacific Northwest Laboratory (PNL). 1994. REX Software Configuration Management Plan. REX-001, Pacific Northwest Laboratory, Richland, Washington.

Privacy Act, 44 Federal Regulations 510772 (1974).

Sula, M. J., E. H. Carbaugh, and D. E. Bihl. 1991. Technical Basis for Internal Dosimetry at Hanford. PNL-6866.R1, Pacific Northwest Laboratory, Richland, Washington.

U.S. Department of Commerce/National Bureau of Standards. 1982. Procedures for Calibrating Neutron Personnel Dosimeters. NBS Special Publication 633, Washington, D.C.

U.S. Department of Energy (DOE). 1980. Micrographics Management. DOE Order 1300.1, Washington, D.C.

U.S. Department of Energy (DOE). 1986a. Handbook for the Department of Energy Laboratory Accreditation Program for Personnel Dosimetry Systems. DOE/EH-0026, Washington, D.C.

U.S. Department of Energy (DOE). 1986b. Department of Energy Standard for the Performance Testing of Personnel Dosimetry Systems. DOE/EH-0,027, Washington, D.C.

U.S. Department of Energy (DOE). 1987. Environmental Protection, Safety, and Health Protection Information Reporting Requirements. DOE Order 5484.1, Washington, D.C. 
U.S. Department of Energy (DOE). 1988. Records Disposition. DOE Order 1324.2A, Washington, D.C.

U.S. Department of Energy (DOE). 1989. Department of Energy Laboratory Accreditation Program (DOELAP) for Personnel Dosimetry. DOE 5480.15, Washington, D.C.

U.S. Department of Energy (DOE). 1990a. Radiation Protection for Occupational Workers. DOE Order 5480.11, Washington, D.C.

U.S. Department of Energy (DOE). 1990b. Radiation Protection of the Public and the Environment. DOE Order 5400.5, Washington, D.C.

U.S. Department of Energy (DOE). 1991. Quality Assurance. DOE Order 5700.6C, Washington, D.C.

U.S. Department of Energy (DOE). 1993. Occupational Radiation Protection. 10 CFR 835, Department of Energy, Washington, D.C.

U.S. Department of Energy (DOE). 1994. U.S. Department of Energy Radiological Control Manual. DOE/EH-0256T, Revision 1, Washington, D.C.

U.S. Department of Energy Richland Field Office (RL). 1993. Hanford Site Services Handbook. RL 1400-1A, Richland, Washington. Available on HANINFO.

U.S. Department of Energy Richland Field Office (RL). 1994. Hanford Site Radiological Control Manual. HSRCM-1, Revision 2, Richland, Washington. 


\section{DISTRIBUTION}

No. of

Copies

\section{OFFSITE}

12 DOE/Office of Scientific and

Technical Information

DOE Albuquerque Field Office

R. Enge

Battelle Pantex

Pantex Plant

P.O. Box 30020

Amarillo, TX 79120

L. M. Coco

Mound Laboratory

EG\&G

Mound Applied Technologies

P.O. Box 3000

Miamisburg, OH 45342

J. M. Graf

Los Alamos National Laboratory

P.O. Box 1663

Los Alamos, NM 87545

R. M. Rogers

EG\&G Rocky Flats

Rocky Flats Plant

P.O. Box 464

Golden, CO 80402-0464

DOE Chicago Field Office

A. E. Keuhner

Technical Support Section

Brookhaven National Laboratory

Upton, NY 11973
No. of

Copies

R. E. Toohey

Argonne National Laboratory

9700 South Cass Avenue

Argonne, IL 60439

DOE Idaho Field Office

H. D. Christiansen

Westinghouse Idaho Nuclear

Company, Inc.

P.O. Box 4000

Idaho Falls, ID 83404

DOE Nevada Field Office

B. P. Smith

Reynolds Electrical and

Engineering Co., Inc.

P.O. Box 98521

Las Vegas, NV 89193

DOE Oak Ridge Field Office

J. S. Bogard

Oak Ridge National Laboratory

Martin Marietta Energy

Systems, Inc.

P.O. Box 2008

Oak Ridge, TN 37831

J. B. Hunt

Y-12 Plant

Martin Marietta Energy

Systems, Inc.

P.O. Box 2008

Oak Ridge, TN 37831

Distr.1 
No. of

Copies

DOE San Francisco Field Office

C. T. Prevo

Lawrence Livermore National

Laboratory

P.O. Box 808

Livermore, CA 94550

DOE Savannah River Field Office

D. A. Stevenson

Westinghouse Savannah River Company

Savannah River Plant

P.O. Box 616

Aiken, SC 29802

\section{ONSITE}

4 DOE Richland Operations Office

T. L. Aldridge

D. L. Clark

D. L. Rice

W. B. Scott

$4 \quad$ Environmental Restoration

Contractor

T. M. Brun (TMA)

D. E. Gergely (BHI)

J. D. Moroney, III (TMA)

J. E. Tarpinian (BHI)

2 Hanford Environmental Health

Foundation

R. H. Ronish

M. J. Swint

3 Westinghouse Hanford Company

W. A. Decker, Jr.
No. of

Copies

T. D. Merkling

T. J. Kelly

Washington State University (Tri-Cities)

R. L. Kathren

$42 \quad$ Pacific Northwest Laboratory

D. E. Bihl (2)

D. M. Brehm

R. A. Buchanan

J. J. Fix (2)

T. J. Froelich (2)

D. P. Higby

G. R. Hoenes

J. R. Houston (2)

J. R. Johnson

M. Lyon (10)

T. P. Lynch

J. C. McDonald

L. H. Munson

I. C. Nelson

P. C. Olsen (2)

R. K. Piper (2)

K. H. Pryor

B. A. Rathbone

K. L. Soldat

R. A. Walters

Technical Report Files (5)

Radiation Protection

Historical Files

(c/o V. L. Berndt) (2) 